RODRIGO AMORIM MOTTA CARVALHO

USO DE FILMES OBTIDOS PELA POLIMERIZAÇÃO POR PLASMA DE TETRAETILORTOSSILICATO NA FABRICAÇÃO DE DISPOSITIVOS MINIATURIZADOS 
RODRIGO AMORIM MOTTA CARVALHO

USO DE FILMES OBTIDOS PELA POLIMERIZAÇÃO POR PLASMA DE TETRAETILORTOSSILICATO NA FABRICAÇÃO DE DISPOSITIVOS MINIATURIZADOS

Tese apresentada à Escola Politécnica da Universidade de São Paulo para obtenção do Título de Doutor em Engenharia. 
FICHA CATALOGRÁFICA

Carvalho, Rodrigo Amorim Motta

Uso de filmes obtidos pela polimerização por plasma de tetraetilortossilicato na fabricação de dispositivos

miniaturizados / R.A.M. Carvalho. -- São Paulo, 2008.

$96 \mathrm{p}$.

Tese (Doutorado) - Escola Politécnica da Universidade de São Paulo. Departamento de Engenharia de Sistemas Eletrônicos.

1.Filmes finos 2.Polimerização 3.Circuitos integrados I.Universidade de São Paulo. Escola Politécnica. Departamento de Engenharia de Sistemas Eletrônicos II.t. 


\section{USO DE FILMES OBTIDOS PELA POLIMERIZAÇÃO POR PLASMA DE TETRAETILORTOSSILICATO NA FABRICAÇÃO DE DISPOSITIVOS MINIATURIZADOS}

Tese apresentada à Escola Politécnica da Universidade de São Paulo para obtenção do Título de Doutor em Engenharia.

Área de Concentração:

Microeletrônica

Orientadora:

Prof. ${ }^{a}$ Doutora

Maria Lúcia Pereira da Silva 


\section{AGRADECIMENTOS}

Agradeço a Prof ${ }^{a}$. Dr ${ }^{a}$. Maria Lúcia Pereira da Silva pela orientação deste trabalho, pela confiança, paciência e principalmente amizade que ao longo deste foram essenciais. Agradeço aos amigos do Grupo de Tecnologias Limpas (CTG) pelo apoio e amizade.

Agradeço à minha família e à minha esposa, Tatiana, pelo apoio e incentivo.

Ao Laboratório de Sistemas Integráveis da EPUSP, pela infra-estrutura.

À Fundação de Amparo à Pesquisa do Estado de São Paulo (FAPESP) pelo apoio financeiro e a todos que, direta ou indiretamente, colaboraram para execução deste. 


\section{RESUMO}

Os antigos e já bem desenvolvidos dispositivos para tratamentos e/ou análise de amostras têm sido grandemente estudados para novas adaptações, devido à importância de se construir sistemas miniaturizados. A obtenção destes sistemas miniaturizados baseia-se não apenas na construção ou metodologia, mas pode depender de modificação superficial para melhoria de desempenho ou diferenciação de aplicações. A modificação de superfície com filmes finos obtidos por plasma é bem conhecida na Microeletrônica. Assim, este trabalho teve como objetivo avaliar a possibilidade do uso da modificação superficial - pela produção de filmes finos a partir da polimerização por plasma de Tetraetilortossilicato, TEOS - para fabricação de estruturas miniaturizadas, principalmente para retenção e/ou pré-concentração, em pré-tratamento de amostras ou mesmo para proteção de sistemas de detecção.

A metodologia utilizada correspondeu a testes destes filmes em canais ou membranas seletivas. Quanto aos canais utilizou-se geometria planar e/ou tridimensional; as membranas foram testadas em geometria planar. Microcanais tridimensionais, usados tanto em fase gasosa como líquida, foram testados para determinação de retenção/pré-concentração de compostos orgânicos voláteis. Para testes de retenção de compostos inorgânicos em fase líquida (água como solvente) utilizaram-se não só microcanais, tridimensionais ou planares, como também membranas. Proteção de sistemas de detecção exigiu o uso de geometria plana. Quanto ao filme a base de TEOS, este foi testado imediatamente após a deposição, após envelhecimento por no mínimo seis meses ou após exposição a condições adversas - como a que levam à hidrólise de radicais orgânicos presentes no filme, ou mesmo após hidrofobização da superfície, por exposição à Hexametildissilazana, HMDS.

A construção de dispositivos, com canal planar ou tridimensional, permitiu o desenvolvimento de diferentes sistemas de tratamento, e respectivos métodos de análise, para separação, retenção e pré-concentração de amostras. Os resultados obtidos demonstraram que um dispositivo com canal tridimensional, tratado pela deposição a base de TEOS e posterior hidrólise do filme, permite a retenção de íons e formação de clusters de cobre, em fase líquida. Do mesmo modo, permite a separação de compostos orgânicos em pequena concentração e retenção de compostos polares, em fase gasosa. Para dispositivo planar foi observada a separação de íons através de estrutura plana, similar às utilizadas em eletrocromatografia. 
Os estudos processados permitiram propor pequenos dispositivos, de baixo custo e fabricação simples, que podem ser facilmente implantados na área de análises. Assim, o canal tridimensional testado tem comportamento semelhante ao de uma pré-coluna. Como é de simples construção e sua entrada e saída possui similaridades com uma pré-coluna comercial, a instalação desta pré-coluna em um cromatógrafo miniaturizado requererá poucas etapas. Essa nova pré-coluna também apresentaria grandes vantagens se fosse adicionada imediatamente antes de detectores não específicos, tais como os usados no nariz eletrônico. Pela diminuição de compostos presentes na mistura, as dificuldades de análise dos resultados igualmente decresce, pela maior facilidade de criação de padrões.

Palavras-chave: MicroTAS, Microestruturas, Micro-Coluna cromatográfica, TEOS, Filme fino, Polimerização por plasma 


\section{Abstract}

The long-established and well-known devices for sample pretreatment and/or analysis have been widely studied to new adaptations due to the miniaturization trend. The production of these miniaturized systems requires not only new approach on manufacturing and methodology but also depends on surface modification for performance improvement or new applications development. Surface modification using plasma-produced thin films is well established in Microelectronics. Therefore, the aim was to evaluate the use of Plasma polymerized Tetraethylorthosilicate surface modification on manufacturing of miniaturized structures. The main use of such a modification is on devices for sample pretreatment retention, pre-concentration, or even for protecting detection system surface.

The methodology carried out tested these thin films in channels and selective membranes. Whereas channels used three-dimensional and planar geometries, membranes were tested only with planar geometries. Three-dimensional microchannels, used in gaseous or liquid phase, were tested for retention/preconcentration of volatile organic compounds (VOC's). Retention of inorganic compounds in aqueous liquid phase was tested using not only three-dimensional and planar microchannels but also membranes. Protection of detection systems required planar geometry. TEOS thin film was tested after: deposition, ageing for several months; exposition to severe environmental conditions that leads to hydrolysis of organic radicals present in the film; surface hydrophobization due to hexamethyldisilazane, HMDS, exposure.

Manufacturing of miniaturized three-dimensional and planar devices leads to some solutions on sample pretreatment and respective analysis methodology. These devices can be used for separation, retention and pre-concentration. The results pointed out that a threedimensional microchannel with plasma deposited TEOS film previously hydrolyzed allows ion retention and clusters formation in a copper aqueous solution. Furthermore, in gaseous phase, VOC's in small concentration can be separated whereas polar compounds can be retained. Planar device allows separation of inorganic ions in a structure similar to the ones used in electrochromatography.

Small and low-cost devices are thus here provided, which can easily be machined and are very useful in the chemical analysis field. The three-dimensional microchannel presented behavior similar to the one of a chromatographic pre-column. This microchannel can also be easily adapted to a miniaturized chromatograph. Other possible use is in sample pretreatment, 
coupled ahead of non-specific detectors, such as electronic noise arrays, since it can decrease the numbers of compounds to be detected and, consequently, reduce drawbacks concerning results analysis.

Keywords: MicroTAS, Microstructures, Micro-Chromatography column, TEOS, Thin film, Plasma polymerization 


\section{LISTA DE TABELAS}

Tabela 2.1 Sumário dos principais substratos utilizados e possíveis estruturas a serem obtidas.

Tabela 3.1. Resumo dos comportamentos obtidos para o filme produzido pela deposição por plasma de TEOS.

Tabela 3.2. Tempo de retenção e Número de Pratos Teóricos obtidos em uma coluna com filme recém depositado e em uma coluna sem filme.....

Tabela 3.3. Injeções seqüenciais $\mathrm{e}$ a os principais tempos de retenção

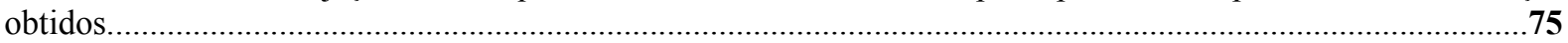

Tabela 3.4. Valor mínimo de potencial elétrico e máximo corrente para diferentes volumes de $\mathrm{CuSO}_{4} \mathrm{e}_{\mathrm{o}}$ mínimo tempo necessário para ocorrer tal condição...

Tabela 3.5. Valor máximo de corrente obtido para a solução aquosa de $\mathrm{CuSO}_{4}$ e o mínimo tempo para obter tal

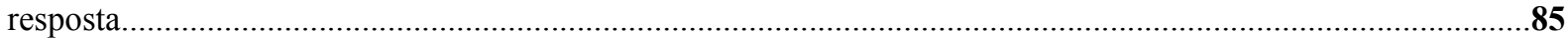

Tabela 3.6. Resumo das possibilidades de uso do filme produzido pela deposição por plasma de TEOS em dispositivos miniaturizados.. 


\section{LISTA DE FIGURAS}

Figura 1.1. Microscopia de força atômica para filmes depositados em reator com: eletrodos internos (a e b) e

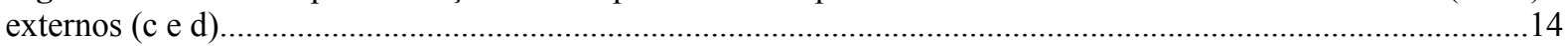

Figura 2.1. Resumo dos testes de otimização do uso do filme em dispositivos..............................................26

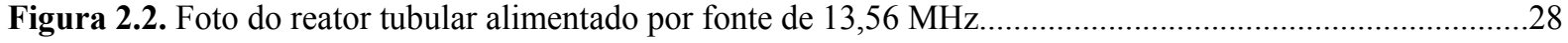

Figura 2.3. Desenho esquemático do reator e do sistema de bombeamento..................................................28

Figura 2.4. Foto do Sistema semi-automatizado para testes de estruturas......................................................30

Figura 2.5. Desenho esquemático do Sistema para Análise de Filmes e/ou Estruturas Miniaturizadas................31

Figura 2.6. Partes e peças do sistema de aquecimento e da cela para acomodação da estrutura.........................32

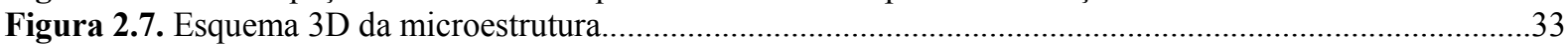

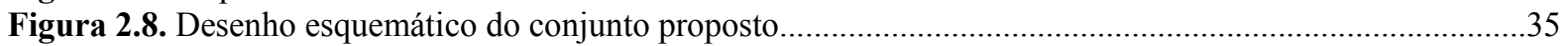

Figura 2.9. Arranjo experimental para testes de Condutividade................................................................37

Figura 2.10. Detalhe do sistema utilizado quanto ao nível de solução aquosa de $\mathrm{KMnO}_{4}$ e de água....................38

Figura 3.1. Superfície do acrílico com (A) e sem (B) reação com a acetona...................................................42

Figura 3.2. Superfície do alumínio após a aplicação de potencial elétrico......................................................43

Figura 3.3. Microscopia óptica do microcanais após mergulho em acetona para estrutura................................45

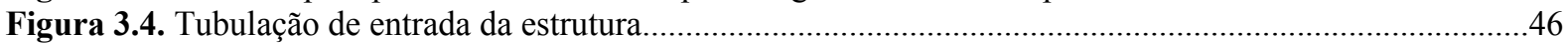

Figura 3.5. Núcleo de alumínio da microestrutura após aplicação de potencial elétrico....................................46

Figura 3.6. Análise por microscopia óptica após deposição do filme nos microcanais usinados.........................47

Figura 3.7. Variação de cor pela passagem da solução de azul de metileno...................................................48

Figura 3.8. Arranjo montado para aplicação de potencial elétrico.................................................................49

Figura 3.9. Fotos da região da membrana e das películas de alumínio após a aplicação do potencial elétrico.....49

Figura 3.10. Espectro típico para imersão em solução aquosa saturada de sulfato de cobre II............................50

Figura 3.11. Clusters de cobre formados através da aplicação de potencial elétrico em solução aquosa saturada

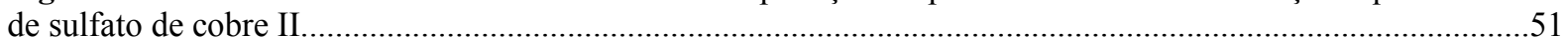

Figura 3.12. Espectro de EDS das principais espécies presentes após aplicação de potencial elétrico................51

Figura 3.13. Espectro de EDS das principais espécies presentes após mergulho na solução aquosa de sulfato de

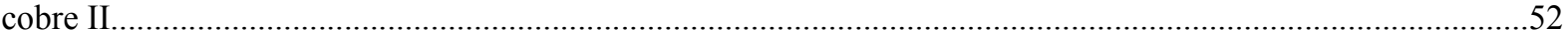

Figura 3.14. Medidas de QCM sem estrutura e nitrogênio como gás de arraste...............................................55

Figura 3.15. Medidas de QCM com estrutura sem filme e nitrogênio como gás de arraste................................55

Figura 3.16. Variação de freqüência em função do tempo para injeção de n-hexano antes da reação com a

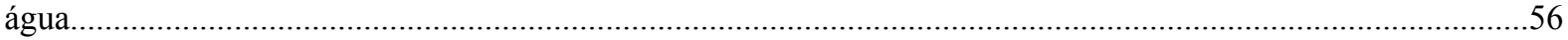

Figura 4.17. Variação de freqüência em função do tempo para injeção de 2-propanol antes da reação com a

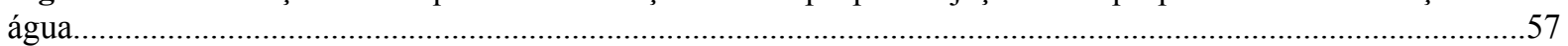

Figura 3.18. Variação de freqüência em função do tempo para injeção de água..............................................58

Figura 3.19. Variação de freqüência em função do tempo para injeção de n-Hexano após a reação com a água.59 Figura 3.20. Variação de freqüência em função do tempo para injeção de 2-Propanol após a reação com a

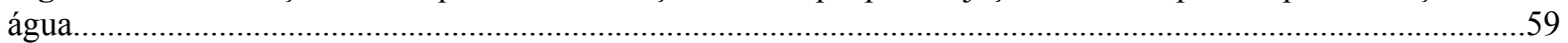

Figura 3.21. Variação de freqüência em função do tempo para injeção de água após a reação com a água.........60

Figura 3.22. Variação de freqüência em função do tempo para injeção de água após a reação com a água.........61

Figura 3.23. Variação de freqüência em função do tempo para injeção de água após a reação com a água.........62

Figura 3.24. Seqüência de injeções de $10 \mu \mathrm{L}$ de n-Hexano, 2-Propanol e água em coluna com filme recém

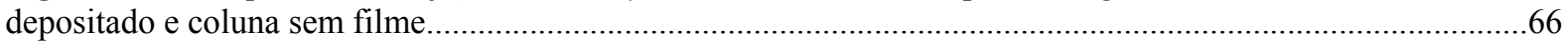

Figura 3.25. Variação da freqüência em função do tempo para solução aquosa, saturada de n-Hexano e de 10

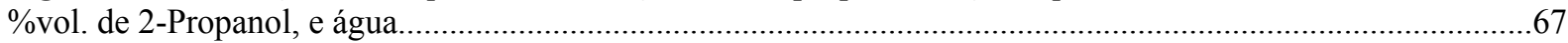
Figura 3.26. Variação da freqüência em função do tempo para diversas seqüências de injeções de $10 \mu \mathrm{L}$ de água

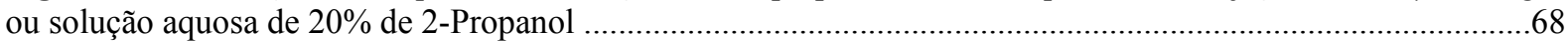

Figura 3.27. Inserção de $10 \mu \mathrm{L}$ e $100^{\circ} \mathrm{C}$ de: n-Dodecano; n-Hexano; 2-Propanol e água..................................70 Figura 3.28. Eluição de n-Hexano usando $10 \mu \mathrm{L}$ de 2-propanol a temperatura ambiente: filme recém depositado

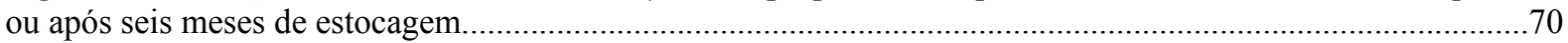

Figura 3.29. Variação da freqüência em função do tempo para n-Hexano e 2-Propanol após condicionamento da

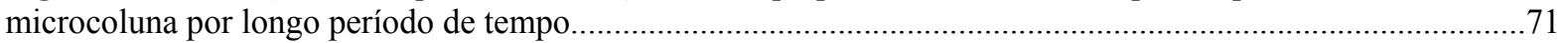
Figura 3.30. Medida de QCM gasoso com $10 \mu \mathrm{L}$ de injeção de n-Dodecano n-Hexano, 2-propanol e água.....72 Figura 3.31. Injeções seqüenciais de $4 \mu \mathrm{g}$ de n-Dodecano......................................................................73

Figura 3.32. Medida de QCM gasoso e injeção de n-Dodecano, n-Hexano, 2-Propanol e água...........................74

Figura 3.33. Variação da freqüência em função do tempo para injeção de $10 \mu \mathrm{L}$ de solução de $50 \%$ de n-Hexano

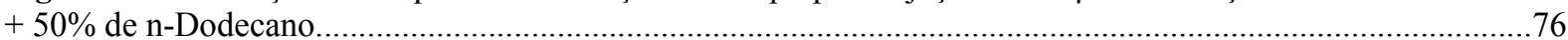

Figura 3.34. Medida de QCM gasoso para solução 50 \% em vol. de n-Dodecano + n-Hexano...........................76 
Figura 3.35. Medida de QCM gasoso: n-Dodecano, n-Hexano, 2-Propanol e água.

Figura 3.36. Medida de QCM gasoso para mistura $50 \%$ em vol. de n-Dodecano + n-Hexano. 79

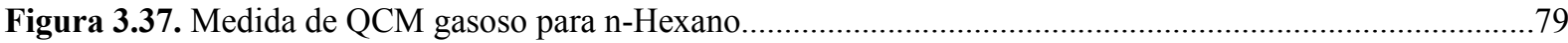

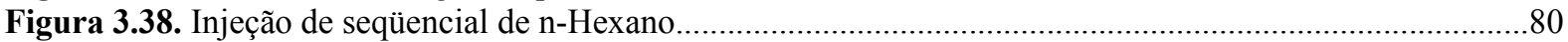

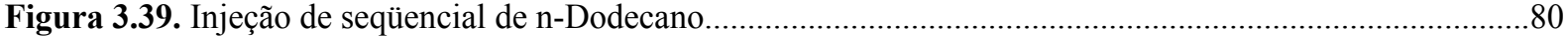

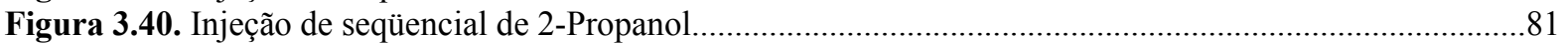

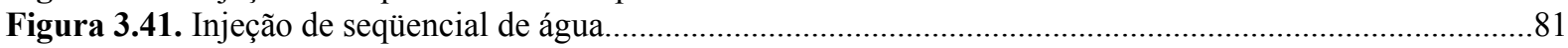

Figura 3.42. Formação de cobre metálico dentro do filme ......................................................................84

Figura 3.43. Coluna com aplicação de potencial elétrico distribuído ao longo do canal...................................85

Figura 3.44. Esquema e fotos do arranjo utilizado para testes do filme para separação de íons em fase líquida..86

Figura 3.45. Corrosão do alumínio usado como contato na celulose e na celulose tratada com deposição do filme à base de TEOS . .87

Figura 3.46. Esquema da construção de uma cavidade selada utilizando celulose modificada pela deposição de

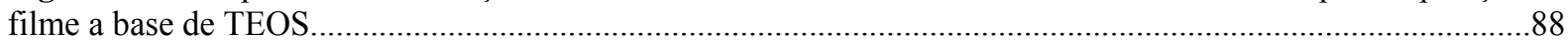

Figura 3.47. Resultado da corrente e condutividade pela aplicação de potencial elétrico em função do tempo para celulose e celulose modificada. 


\section{SUMÁRIO}

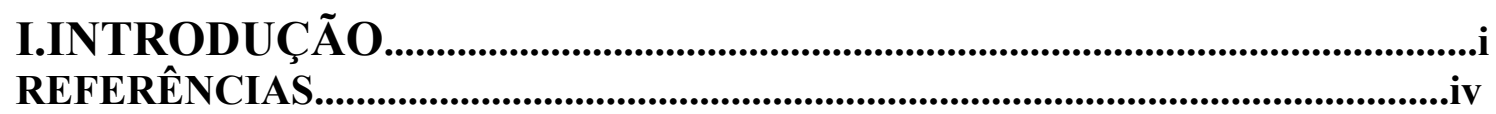

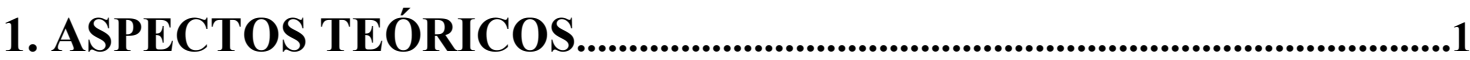

1.1. MEMS: Introdução.......................................................................................................1

1.2. Pré-tratamento de amostras: pré-concentração e retenção.....................................2

1.2.1. Separação de componentes: Cromatógrafos e/ou dispositivos miniaturizado.4

1.2.2. Microcolunas..............................................................................................................

1.2.3. Fase estacionária................................................................................................................

1.3. Membranas......................................................................................................................6

1.3.1. Principais membranas..................................................................................................6

1.3.1.1. A celulose como membrana.....................................................................................6

1.4. Deteç̧ão.....................................................................................................................................

1.5. Materiais para fabricação..............................................................................10

1.5.1. Substratos...................................................................................................................10

1.5.2. Materiais para adsorção e deteç̧ão.....................................................................11

1.6. Conceitos envolvidos...................................................................................................14

1.6.1. Cromatografia........................................................................................................14

1.6.2. Microbalança de quartzo..........................................................................................15

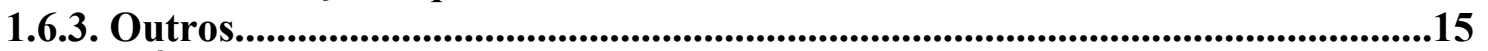

REFERÊNCIAS.....................................................................................................................16

2. METODOLOGIA, MATERIAIS E MÉTODOS......................................24

2.1. Metodologia...................................................................................................................24

2.2. Equipamentos................................................................................................................27

2.2.1. Equipamentos para obtenção do filme..............................................................27

2.2.2. Equipamentos para análise das estruturas........................................................29

2.3. Dispositivos..............................................................................................................33

2.3.1. Estrutura tridimensional................................................................................33

2.3.2. Estrutura planar...............................................................................................................34

2.4. Métodos...............................................................................................................35

2.5. Reagentes e Materiais........................................................................................................39

REFERÊNCIAS...................................................................................................................40

3. RESULTADOS E DISCUSSÕES.................................................................41

3.1. Propriedades relevantes para filmes à base de TEOS...............................................41

3.1.1. Filmes com baixa concentração de radicais carbônicos........................................41

3.1.2. Filmes com alta concentração de radicais carbônicos..........................................43

3.1.2.1. Deposição em topografia não planar...................................................................44

3.1.2.2. Deposição em substrato flexível e poroso.............................................................47

3.1.2.3. Deposição em substrato rígido e não poroso......................................................50

3.2. Modelamento do comportamento do filme à base de TEOS..................................53

3.2.1. Filme fino depositado em microcanais tridimensionais.......................................54

3.2.2.1. Testes em fase gasosa.............................................................................................54

3.3. Dispositivos propostos utilizando filme fino à base de TEOS...............................63 
3.3.1. Microcanais tridimensionais......................................................................65

3.3.1.1. Filme recém depositado.........................................................................................65

3.3.1.2. Filme recém depositado e canal empacotado.............................................69

3.3.1.3. Filme após a reação com água....................................................................71

3.3.1.4. Filme após a reação com água e exposição a vapor de HMDS......................77

3. 3. 1.5 Microcanais tridimensionais e medidas em fase líquida.................................82

3.3.2 Com canal planar................................................................................................................85

3.3.3. Membranas (substrato flexível).....................................................................88

3.3.4. Modificação pelo recobrimento de eletrodos........................................................89

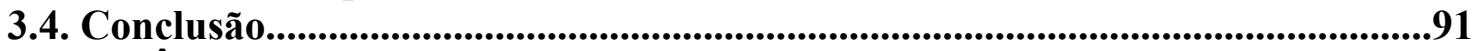

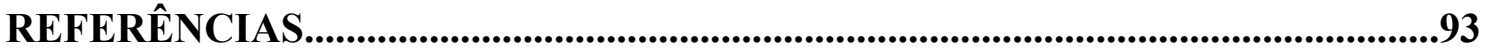

4. CONCLUSÕES E TRABALHOS FUTUROS..........................................94

Apêndice 1 - Fundamentos teóricos da cromatografia....................................1

1. Tipos de Cromatografia...........................................................................................................1

2. Classificação dos Métodos Cromatográficos...................................................................3

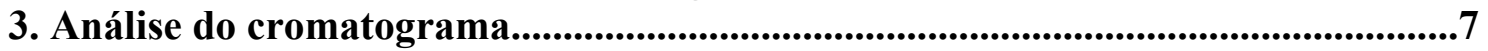

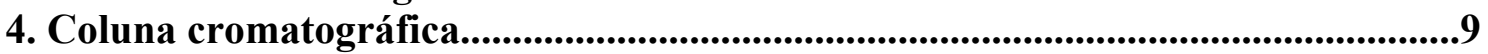

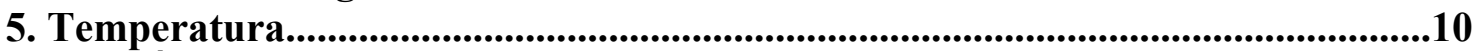

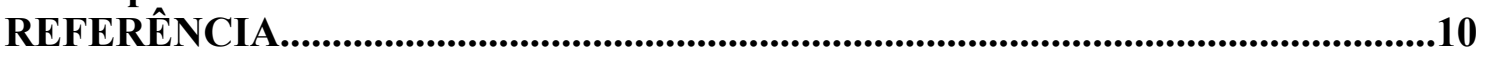




\section{INTRODUÇÃO}

Atualmente, MEMS (MicroElectroMechanical Systems) são comuns nas mais variadas áreas do conhecimento [1], e entre elas encontra-se a área de análises químicas [2, 3, 4]. Quanto a esta última, praticamente todas as etapas podem ser miniaturizadas e atualmente a tendência é que o sejam, o que o torna o $\mu$ TAS (miniaturized total chemical analysis system) um dos grandes objetivos a serem alcançados. Por etapas compreendem-se a extração/obtenção de pequeno volume de amostra, pré-tratamento desta amostra (manipulação da matriz), além de provável reação do analito para obtenção da informação a ser registrada pela detecção. Em todas estas etapas é provável que os dispositivos miniaturizados que as compõem possuam microcanais, pois microcanais são comumente utilizados para transporte, mistura e reação de fluídos. Assim, microcanais podem ser utilizados tanto em dispositivos para análise [5] como em processos químicos, simples [6] ou bastante complexos [7].

Estas várias operações com fluídos/amostras, que geralmente ocorrem em microcanais, também são altamente dependentes da condição das superfícies em que tais fluídos estão sendo manipulados. Por exemplo, o transporte de material, e/ou sua mistura, podem depender do carácter hidrófobo da superfície [8]. Não apenas para soluções, mas também emulsões ou partículas, o espalhamento ou recolhimento destas também depende da condição da superfície, e esta modificação pode ocorrer pela aplicação de tensão elétrica na superfície [9].

As superfícies apresentam uma série de fenômenos importantes para a fabricação de dispositivos miniaturizados, e a adsorção é uma destas valiosas propriedades, pois pode ser usada para a separação, pré-concentração ou retenção de componentes de um mistura [10].

A separação de componentes é obtida quando estes, apesar de fracamente adsorvidos na superfície, apresentem diferentes graus de adsorção. É o caso do desenvolvimento de colunas cromatográficas, por exemplo [11]. A pré-concentração [7] requer que um componente da mistura, apesar de fracamente adsorvido, seja preferencialmente removido da matriz. A adição de um reagente com maior afinidade pela superfície irá retirá-lo posteriormente. A retenção de compostos depende de interações fortes, ou mesmo reação com a superfície, para remoção de interferentes da matriz [12]. A adsorção é igualmente importante na detecção, por exemplo, muitos detetores têm seus limites de detecção diminuídos pelo uso de filmes adsorventes em sua superfície [13, 14]. Assim, tanto o formato 
dos dispositivos miniaturizados quanto as propriedades de suas superfícies são importantes na área de análises.

Portanto, a produção de dispositivos miniaturizados para separação, retenção e/ou préconcentração de componentes de uma mistura é de grande utilidade no desenvolvimento de sistemas de análise química, e, como demonstrado por Nascimento [15] e revisto por Silva [11], a retenção, em sistemas miniaturizados pode ser baseada principalmente em adsorção e ter uma série de outras vantagens, como por exemplo, a remoção de alto volume de VOC's (volatile organic compounds) [16]. Do mesmo modo, a retenção em emulsões, ou mesmo de partículas tais como microorganismos [11], pode ocorrer em sistemas miniaturizados, neste caso utilizando oclusão em materiais nanoporosos ou estruturas desenhadas especificamente para promover retenção por colisão [17, 18], respectivamente. Observe-se que algumas dessas utilizações são em fase gasosa, mas outras em fase líquida.

A separação de componentes geralmente ocorre por técnica cromatográfica e essa técnica tem atualmente gerado amplos estudos visando sua miniaturização [11]. A cromatografia é uma técnica que depende da adsorção em superfície e apresenta ampla gama de configurações, podendo ocorrer em fase gasosa ou líquida. Em fase gasosa, apresenta alto desempenho com o uso de colunas capilares, ou seja, de canais estreitos e longos. $\mathrm{Na}$ cromatografia também é comum o uso de sistemas para retenção de possíveis interferentes ou contaminantes de coluna imediatamente antes desta. Estes dispositivos são semelhantes às próprias colunas, são normalmente denominados pré-colunas e podem evitar não só entrada de compostos altamente adsorventes na coluna como também de partículas. Também para estes dispositivos a miniaturização é uma necessidade premente. A superfície da fase estacionária, responsável pela adsorção, é bem variada, mas se apresentar nanocanais cria-se a possibilidade de cromatografia por exclusão de tamanho, ou seja, separação de compostos distintos de acordo com seu tamanho molecular [19]. Portanto, um sistema microcanal+filme adsorvente é de grande valia tanto para a miniaturização da técnica de cromatografia quanto para produção de dispositivos de retenção e/ou pré-concentração.

Dentre as utilizações em fase líquida de superfícies porosas, além da remoção de partículas e/ou nanopartículas, a adsorção de íons metálicos e posterior redução destes para utilização na fabricação de nanoclusters, úteis no desenvolvimento de células de combustível ou microbaterias [20], apresenta uma série de desafios e grandes vantagens. Portanto, a obtenção de sistemas porosos nanoestruturados é uma demanda atual, que, contudo, depende de muitas etapas de fabricação e leva à utilização de materiais caros e, muitas vezes, 
incompatíveis com a tecnologia de microeletrônica, responsável pelo baixo custo e alta miniaturização dos dispositivos atualmente disponíveis. Do mesmo modo, em fase líquida, a adsorção de íons metálicos, com a possível separação destes dentro do filme, é objeto de estudo da eletrocromatografia [21].

Filmes porosos possuem muitas outras aplicações, especialmente no desenvolvimento de sensores [22, 23]. Muitos materiais porosos são à base de silicone [24, 25, 26], mas apenas um pequeno número deles é fabricado com a deposição por plasma [27].

Polimerização por plasma de Tetraetilortossilicato (TEOS) é um possível material poroso, mas comumente utilizado apenas para obtenção de óxido de silício, utilizando oxigênio e altas temperaturas $\left(400{ }^{\circ} \mathrm{C}\right)$ [28]. Polimerização por plasma de TEOS, apesar de não comum, permite, à temperatura ambiente, a formação de uma estrutura semelhante ao silicone $\left[\mathrm{Si}(\mathrm{OEt})_{2} \mathrm{OSi}(\mathrm{OEt})_{2}\right]$ que, através da reação dos radicais OEt com a água, forma um filme hidrofílico e poroso [29]. Ou seja, é possível controlar o caráter hidrofóbico bem como sua porosidade.

Portanto, este trabalho teve como objetivo avaliar a possibilidade do uso da modificação superficial - pela produção de filmes finos a partir da polimerização por plasma de TEOS - para fabricação de estruturas miniaturizadas, principalmente para retenção e/ou pré-concentração, em pré-tratamento de amostras ou mesmo para proteção de sistemas de detecção.

Este trabalho encontra-se dividido nos seguintes itens: o capítulo 1 apresenta os principais aspectos teóricos, o capítulo 2 apresenta a metodologia e os materiais e métodos utilizados, o capítulo 3 apresenta os principais resultados obtidos. O capitulo 4 apresenta as conclusões. 


\section{REFERÊNCIAS}

[1] MICROFLUIDICS in commercial applications, an industry perspective Lab Chip, 2006, 6v, 1118-1121p, DOI: 10.1039/b610250f.

[2] Grayson, R. A. C. et al. A BioMEMS Review: MEMS Technology for Physiologically Integrated Devices. Proceedings of the IEEE. 92 (1). 6-21p. 2004.

[3] Weigl, B. H.; Bardell, R. L.; Cabrera, C. R.; Lab-on-a-chip for drug development. Advanced Drug delivery reviews. 2003. 55. 349-377p.

[4] Verpoorte, E.; Rooij, N. F.; Microfluidics meets MEMS. Proceedings of the IEEE. 91v. June 6. 930-953p. 2003.

[5] Daridon, A. et al. Multi-layer microfluidic glass chips for microanalytical applications. J Anal Chem. 371. 261-269p. 2001.

[6] Lobbecke, S. et al. Concepts for modularization and automation of microreaction technology. Chem. Eng. Technol. 2005. 28. 484-493p.

[7] Marko, T. L. G.; Miniaturization is mandatory unraveling the human proteome. Varga Proteomics. 2002. 2. 345-351p.

[8] Schumacher, J. T. et al. Hydrophobic coating of microfluidic chipsstructured by SU-8 polymer for segmented flow operation. J. Micromech. Microeng. 18. 1-6p. 2008.

[9] Zhao, Y.; Cho, S. K. Microparticle sampling by electrowetting, actuated droplet sweeping. 2006. 6. 137-144p.

[10] Silva M. L. P.; Gameiro, J. G. Pre-concentrators: trends and future needs. Revista Brasileira de Aplicações de Vácuo. 25. 123-130p. 2006.

[11] Yashiin, Y. A.; Yashin, A. Y. Miniaturization Of Gas-Chromatographic Instruments.

Journal of Analytical Chem. 56 (9). 794p. 2001.

[12] Squires, T. M.; Quake, S. R. Microfluidics: Fluid physics at the nanoliter scale. Reviews Of Modern Physics. 2005. 77v.

[13] Ho, C. K. et al. Review of chemical sensors for in-situ monitoring of volatile contaminants. Sandia National Laboratories. SAND2001-0643. Albuquerque. 2001.

[14] Capone, S. et al. Solid state gas sensors: state of the art and future activities. Journal of Optoelectronics and Advanced Materials. 5v. 1335-1348p. 2003.

[15] Nascimento, A. P. Fabricação de sistemas para retenção de compostos orgânicos presentes em fase gasosa ou líquida. 2005. Tese (Doutorado) - Escola Politécnica, Universidade de São Paulo, São Paulo, 2005.

[16] Silva, M. L. P. et al. Study of preconcentration of non-polar compounds in microchannels with constrictions. Sensors and Actuators B-Chemical. 232-239p. 2006.

[17] Santos, L. C. et al. Miniaturized structures for removal or selection of particles from liquid flow. Sensors and Actuators B-Chemical. 2007.

[18] Beraldo, F. P. et al. Design of new miniaturized structures for removal of particles from gaseous fluids. XI IMCS. Italy. July. 2006.

[19] Ciola, R. Fundamentos da cromatografia a líquido de alto desempenho. São Paulo. Ed. Edgard Blücher Ltda. 2003. 179p.

[20] Dewan, C.; Teeters, D. Vanadia xerogel nanocathodes used in lithium microbatteries. Journal of power sources. 119-121p 310-315p. 2003.

[21] Faria, A. M. et al. Monolithic stationary phases for chromatographic separations. Química Nova, São Paulo, 29v. 2006.

[22] Gerhard, R. - Multhaupt, Less can be - More holes in polymers lead to a new paradigm of piezoelectric materials for electret transducers. IEEE. 9 (5). 850-859p. 2002.

[23] Bjorkqvist, M. et al. Characterization of thermally carbonized porous silicon humidity sensor. Sensor Actuat A-Phys. 112 (2-3). 244-247p. 2004. 
[24] Kurihara, L. A. et al. Hybrid inorganic-organic mesoporous silicates - Nanoscopic reactors coming of age. ADV MATER. 2000. 12 (19). 1403-1419p.

[25] Wu, A. T.; Brett, M. J. Sensing humidity using nanostructured SiO posts: Mechanism and optimization. SENSOR MATER. 13 (7). 399-431p. 2001.

[26] Nocun, M.; Bugajski, W. Humidity sensor based on porous glass-ceramic, OPT APPL. 2000. 30 (4). 613-618p.

[27] Kraus, F.; Cruz, S.; Muller, J. Plasma polymerized silicon organic thin films from HMDSN for capacitive humidity sensors. Sensors and Actuators B-Chemical. 88 (3). 300311 p. 2003.

[28] Prasad, V. et al. VACUUM. 2002. 65 (3-4). 443-455p.

[29] Carvalho, R.A.M. et al. Plasma Polymerized TEOS Films For Nanochannels Formation And Sensor Development. Sensors And Actuators B-Chemical. 108. 955p. 2005. 


\section{ASPECTOS TEÓRICOS}

Este capítulo faz uma breve revisão dos conceitos fundamentais de MEMS e suas aplicações, úteis para a compreensão deste trabalho.

\subsection{MEMS: Introdução}

MEMS (Microelectromechanical Systems) promoveram um desenvolvimento enorme em diversas áreas tecnológicas, com ênfase especial na análise química $[1,2,3,4,5]$, e uniram diferentes campos de pesquisa. MEMS [6] permitiram a existência de menores equipamentos de controle, que, aliados ao desenvolvimento computacional das últimas décadas, levaram a obtenção de reatores mais eficientes.

Devido à miniaturização conseguida com estes dispositivos, em Química Analítica é possível observar uma notável evolução, pois a miniaturização permite obter e manipular pequenos volumes de amostras. O uso de pequenos volumes não apenas diminuiu o tempo de análise, mas também corresponde ao desenvolvimento de tecnologias limpas, uma vez que estes sistemas necessitam de pequena quantidade de materiais para serem fabricados. Nesta última área a idéia do microssistema de análise total ( $\mu$ TAS - miniaturized total chemical analysis system) é perseguida por muitos autores [3].

Sistemas miniaturizados ( $\mu \mathrm{TAS}$ ) permitem, ou irão permitir em futuro próximo, uma análise em tempo curto e utilizando poucos recursos. Assim, o desenvolvimento de sistemas que permitem a análise utilizando volume da ordem de microlitros colabora para o desenvolvimento de tecnologias mais limpas de muitos modos: permite menor uso de reagentes e menor descarte de produtos; utiliza dispositivos que, via de regra, exigiram pouca matéria-prima para sua produção e que não apresentam grandes dificuldades para descarte, etc. A obtenção de tais dispositivos, por outro lado, irá exigir a abordagem de muitas etapas.

Como abordado anteriormente, essas etapas correspondem à seleção da amostra e provável pré-tratamento, muitas vezes para diminuir sua complexidade ou para melhorar o limite de detecção. Por fim, a amostra resultante do tratamento é separada em seus componentes ou um analito interage com reagentes, etc. para sofrer detecção. 
A obtenção da amostra corresponde à escolha de pequena, porém significativa, parte de um sistema que pode ser muito complexo. A coleta pode ser feita de muitos modos e depende fundamentalmente do tipo de amostra a ser manipulada: biológica, ambiental, em ambiente corrosivo, em fluxo contínuo, etc [7]. Este trabalho não atuou no desenvolvimento de dispositivos de coleta e, portanto, não dará ênfase a esta etapa.

Após a coleta da amostra, esta é manipulada de vários modos, mas é de fundamental importância o pré-tratamento da amostra. As amostras para análise química, em especial na área ambiental ou biológica, apresentam uma complexidade que em geral impede sua total determinação de modo rápido e eficiente com uma ou poucas etapas de trabalho. Este trabalho genericamente abordará, quanto ao pré-tratamento, apenas a pré-concentração e a retenção. Ênfase é dada a produtos orgânicos voláteis em fase gasosa e íons de metais pesados em fase líquida, pois ambos tratam-se de problemas ambientais sérios.

A separação das amostras em seus componentes é importante na cromatografia e será abordada quanto à possibilidade de miniaturização. Outra vertente importante na cromatografia é o uso de membranas, que é igualmente importante no pré-tratamento de amostras. Detetores normalmente exigem superfícies adsorventes para melhorar seu limite de detecção. Contudo, tais superfícies apresentam outras necessidades, entre elas precisam ser protegidas de ambientes agressivos, daí a necessidade de passivação, ou seja, há necessidade de um compromisso entre duas propriedades em geral díspares, o que normalmente corresponde a uma grande dificuldade. Por fim, superfícies adsorventes podem ser obtidas por plasma, o que será brevemente descrito posteriormente.

\subsection{Pré-tratamento de amostras: pré-concentração e retenção}

Este capítulo irá considerar como pré-concentradores quaisquer dispositivos usados para aumentar a concentração do analito através da sua pré-concentração anteriormente à análise, e posterior liberação rápida, para garantir um melhor limite de detecção.

Vários autores revisaram a pré-concentração recentemente [8, 4]. Porém, como Lichtenberg [4] alerta, a pré-concentração ainda não está bem desenvolvida mesmo para sistemas mais simples, como avaliação de emissão gasosa. O primeiro caso de préconcentração em sistema miniaturizado e para análise em cromatografia gasosa foi apresentado pela Sandia National Labs em 2000 [9, 10]. O equipamento possui quatro etapas distintas para a análise, a primeira correspondendo ao pré-concentrador. A coleta do analito é 
feita através de um filme depositado sobre uma membrana de nitreto de silício e este filme trata-se de um silicone. Há uma coluna cromatográfica para separação e a detecção em fase gasosa [11], efetuada usando-se um sensor SAW (surface acoustic wave), e para fase líquida, eletroforese para separação e fluorescência para detecção [12].

O pré-concentrador, cuja maior vantagem é a diminuição de uma série de fenômenos e interferentes $[13,14,15,16]$, exige, por outro lado, que o detector esteja próximo a sua saída, para obtenção de bom limite de detecção [17]. Contudo, Outra vantagem da pré-concentração em dispositivo miniaturizado são questões de segurança, que permitem seu uso virtualmente em qualquer lugar, além de trabalhar ininterruptamente [18], sendo obtidos produtos portáteis, rápidos, sensíveis, de fácil manuseio, de baixo custo e com pouco erro de medida [19]. O interesse de acoplamento de cromatógrafos a sistemas de pré-concentração é a obtenção de equipamentos portáteis, com baixo limite de detecção e possibilidade de análise de matrizes complexas.

A construção desses dispositivos é normalmente planar. Nakamoto [20,21], afirma que para o desenvolvimento de pré-concentradores o tempo de dessorção é um fator crítico assim como o uso da variação de temperatura e propôs uma distribuição planar do adsorvente ao dispositivo. Esse formato planar também é usado em microcolunas, como descrito posteriormente.

Uma questão relevante quanto ao uso de MEMS é a retenção, não só de compostos, mas também de emulsão e partículas, como comentado na introdução. Há uma preocupação constante quanto à emissão de partículas, de origem industrial e natural, principalmente para a atmosfera, pois isto é responsável pela formação de aerossóis e fumaça. O tamanho, em diâmetro, das partículas vai desde centenas de angstroms a mícrons e podem causar graves problemas à saúde e ao meio ambiente. Por essa razão, a poluição do ar é uma das maiores preocupações da vida moderna e, a coleta e análise de amostras de ar é muito importante, especialmente para partículas muito pequenas, como aerossóis, que podem ficar suspensas no ar por um período de tempo muito longo [22, 23, 24, 25]. É importante observar que quanto à poluição do ar, é dada atenção especial aos compostos orgânicos, voláteis e semi-voláteis, que podem vir de origem industrial e são deletérios ao meio-ambiente. [26, 27]. Metais pesados são outro tipo de material tóxico que deve ser analisado e são normalmente coletados utilizando impactadores [28, 29]. Muitas das análises de meio-ambiente para metais presentes em partículas consideram pré-concentração, eventualmente por retenção, devido à pequena concentração na amostra [30]. A coleta destas partículas, via de regra, considera a possibilidade de haver microorganismos aderidos à superfície, o que exige, após coleta, 
análise específica. Microorganismos habitualmente são coletados utilizando-se alguns aparatos que fazem uso de processos úmidos ao invés de paredes coletoras [31]. Algumas melhorias podem ser conseguidas pelo uso de barreiras eletrostáticas ou ultravioletas [32], mas esses métodos também culminam na eliminação de microorganismos.

\subsubsection{Separação de componentes: Cromatógrafos e/ou dispositivos miniaturizados}

Entre os equipamentos para química analítica apropriados para miniaturização, os cromatógrafos são uma das técnicas mais relevantes, pois a separação dos componentes em uma matriz complexa apresenta diversas vantagens. Um artigo recente sobre cromatógrafos para gases conclui que há duas tendências para a cromatografia: análise rápida e miniaturização [33].

A utilização de sistemas cromatográficos, aliados a pré-concentradores, permite baixo limite de detecção, confiança na determinação do material e analisam tanto amostras líquidas quanto gasosas [34]. Portanto, um dos maiores interesses na obtenção de pré-concentradores é o acoplamento a sistemas cromatográficos, para a fabricação de equipamentos portáteis [35].

Cromatógrafos miniaturizados apresentam alta velocidade de análise e uma nova abordagem de fabricação foi apresentada nos últimos anos [36, 37, 38]. A aplicação mais importante para este equipamento miniaturizado está na solução de problemas ambientais tais como análise de pesticidas, PCB's (policloro-bifenilas), freons, VOC's, odores, poluentes em locais fechados, etc. - ou aplicação em sistemas de segurança, para detecção de explosivos.

Análise de VOC's (volatile organic compounds) tem recebido muita atenção pelos problemas ambientais que estes compostos acarretam. VOC's são normalmente analisados por cromatografia gasosa e podem fazer uso de pré-concentradores [39]. Sistemas pequenos de adsorção já foram reportados [40,41] e atualmente estão sendo miniaturizados [42]. Zellers et al [43] propôs a construção de um micro cromatógrafo $(\mu \mathrm{CG})$ para a determinação de 30-50 tipos distintos de vapores, misturados em ppb (partes por bilhão) [44], e adsorção em esferas de grafite [45, 46, 47,]. Uma variação possível é a análise de compostos orgânicos semivoláteis em solução aquosa pela a extração por membrana [48].

Existe uma série de dispositivos miniaturizados sendo utilizados para pesquisa em genoma e proteoma e para análise de drogas $[49,50]$. No processo de extração em fase sólida a adsorção é fundamental e é utilizada principalmente para tratamento de amostras em fase 
líquida [3]. A adsorção é útil na avaliação de íons em soluções aquosas [51] e equipamento miniaturizado para determinação de traços foi desenvolvido [52]. Um pré-concentrador que utiliza apenas o aumento de área superficial do silício [53] foi testado e permitiu a préconcentração de íon de cobre em soluções aquosas. A superfície do silício pode ser modificada com organo-silanos para permitir a adsorção de outros compostos como proteínas [54]. Estas técnicas dependem da formação de microcanais, que podem ocorrer por um processo barato, como uso de uma impressora a laser e filme de poliéster [55, 56], ou mesmo torno mecânico, no formato tridimensional [57] ou não.

\subsubsection{Microcolunas}

Microcanais podem ser fabricados em estrutura planar e funcionam como coluna cromatográfica. Devido ao uso de tecnologia microeletrônica para a produção de dispositivos MEMS, os microcanais são normalmente obtidos em uma configuração planar. Novas abordagens para a fabricação de cromatógrafos miniaturizado e/ou colunas foram apresentadas nos últimos anos $[36,37,38]$, mas a maior parte delas é construída em lâminas de silício para análises com gás ou líquidos [58, 59, 60, 61].

Por muitos anos a miniaturização de um cromatógrafo em silício foi um alvo importante de pesquisa, especialmente quanto às colunas, tanto para cromatografia gasosa quanto líquida $[62,63,64,65]$. Por exemplo, Potkay produziu uma coluna apolar com aproximadamente 4900 pratos teóricos e capaz de separar 16 componentes gasosos em 75 segundos, entretanto, números maiores de pratos teóricos podem ser conseguidos. Para eletrocromatografia, Verpoorte relatou a separação de metanol e benzaldeído em uma coluna empacotada em um microchip com até 290.000 pratos teóricos/m [3] e Ho [66] 777.000 pratos teóricos/m, para rodamina, em uma coluna microfabricada.

\subsubsection{Fase estacionária}

Uma etapa importante na fabricação de colunas é a produção da fase estacionária que apresenta algumas dificuldades. As fases estacionárias são apresentadas normalmente em uma larga escala de polaridade e são produzidas principalmente com compostos orgânicos e organosilanos. Entretanto, sua produção usa normalmente a injeção de um líquido reagente no 
canal já formado, o que pode levar à não homogeneidade de deposição da fase estacionária $[67,68]$, o que levou a tentativa de depositar a fase estacionária anteriormente à selagem do canal.

Uma nova tendência é usar membranas como fase estacionária [69] em lugar de coluna empacotada. As membranas são muito úteis para trocas de íons, entre outras interações. Novamente, o caráter hidrofóbico da membrana pode ser muito útil na separação.

\subsection{Membranas}

O termo membrana será usado aqui de modo estrito, significando um material poroso e que permite a passagem de alguns produtos em detrimento de outros. Esta definição é muito usada na área de tratamento de águas $[70,71]$. Assim, nos EUA define-se que para produzir água pura, utiliza-se o método de osmose reversa que consiste em fazer escoar a água salgada através de uma membrana semipermeável (que permite que algumas moléculas passem e outras não) e pela qual os sais não passam [72].

\subsubsection{Principais membranas}

Para o objetivo deste trabalho é importante obter membranas capazes de permitir a passagem de íons por seu meio, e, se possível, que esta passagem se dê seletivamente, isto é, privilegiando um íon em relação aos demais $[73,74]$. Membranas deste tipo são comuns em eletrodos íon-seletivos, e, portanto, breve consideração sobre esses eletrodos é feita posteriormente.

Uma membrana pode ser obtida pela modificação superficial de um substrato, por exemplo, celulose, que quando modificada por polimerização por plasma, pode atuar como membrana seletiva para compostos orgânicos $[75,76]$.

\subsubsection{A celulose como membrana}

Atualmente, a modificação superficial da celulose recebe grande atenção pela possibilidade de produção de compósitos ecologicamente corretos, ou seja, obtidos por 
produtos naturais e passíveis de reciclagem ao final do processo. Esses compósitos são leves, de baixo custo e de fácil produção, sem abrasão excessiva das máquinas, contudo o caráter hidrofílico da superfície da celulose dificulta a mistura, logo a necessidade de modificação superficial. De fato, muitas estruturas que existem em planta já correspondem a compósitos naturais, os que as tornam modelos para desenvolvimento de novos materiais que, claro, sejam ambientalmente corretos [77]. Um exemplo, de modificação que leva à produção de material com grande apelo industrial é a fabricação de membranas porosas, mas com propriedades superficiais tais que a filtração não dependa apenas do tamanho do poro, mas também da interação com a superfície [78].

Em geral, para produzir-se o compósito procura-se modificar a superfície de tal modo que a celulose possa ser ligada quimicamente ao outro material. Segundo Belgacem [79], para tal os modos de modificação superficial são:

- Tratamentos físicos, como plasma

- Grafitização com moléculas:

○ hidrofóbicas

○ bifuncionais

○ organo-metálicos

Íons podem percorrer uma membrana de celulose e testes com campos magnéticos estáticos evidenciaram um aumento significativo na velocidade do transporte de $\mathrm{K}$ pela aplicação do campo. A situação é irreversível, ou seja, após o uso de solução aquosa de $\mathrm{KCl}$ e campo magnético de $0.24 \mathrm{~T}$ o transporte comporta-se diferente independente da posterior remoção do campo ou da troca de solução [80].

Outro grande uso da celulose é na fabricação de membranas de separação. Segundo Smitha [81], desde a década de 50 se demonstrou a vantagem do uso de membranas de celulose para a separação de compostos orgânicos e uma década depois a celulose já era modificada para melhorar seu desempenho. Atualmente, a possibilidade de uso de membranas de celulose já envolve até mesmo a separação de isômeros.

Soylak [82] observa que membranas a base de celulose são muito úteis na préconcentração de metais pesados presentes em muitos meios, entre eles amostras hídricas. Por outro lado, a implantação de íons F- em membrana semelhante dificultou a passagem de íons [83]. 


\subsection{Detecção}

Inúmeros detetores distintos podem ser utilizados. Para cromatógrafos miniaturizados, SAW (Surface Acoustic Wave) é adequado pela rapidez de resposta. Testes de dispositivos como cromatógrafos a gás e SAW já foram realizados para compostos orgânicos e explosivos presentes no ar, na água e na terra $[84,85]$ e há alguns anos atrás a Sandia Labs (E.U.A) apresentou um pequeno aparelho que usa estes sensores e uma coluna cromatográfica não apenas para fase gasosa mas também para amostras líquidas [86].

Além dos já citados SAW (surface acoustic wave) [87 e 88], outros detetores bastante utilizados, especialmente com filmes adsorventes depositados em sua superfície, para melhorar o limite de detecção são os quimiresistores [89] e detectores de cristal piezelétrico de quartzo [89 e 90]. Dois destes sensores (Chemiresistor Sensor and SAW sensor) foram testados recentemente para monitoração de VOC's presentes no solo e água subterrânea [65], sendo recomendados para pré-concentração.

Como abordado anteriormente, a detecção usando eletrodos seletivos é bastante comum. Eletrodos íons-seletivos (ISE) são sensores químicos com maior história e provavelmente a aplicação de rotina mais freqüente, pois com os ISEs pode-se determinar um íon na presença de outros íons interferentes. A presença de interferentes, os quais podem inibir ou mascarar a resposta eletroquímica da espécie de interesse, pode ocorrer em geral, devido aos seguintes fenômenos:

- a passivação do eletrodo, ou seja, adsorção do interferente à superfície do eletrodo, que impede o acesso da espécie de interesse;

- competição do interferente com a espécie de interesse pelos sítios ligantes existentes à superfície do eletrodo;

- eletrólise do interferente, pré-concentrado à superfície do eletrodo ou em solução, em valor de potencial próximo ao potencial de eletrólise da espécie de interesse [92].

O recobrimento da superfície do eletrodo com uma membrana polimérica, que possa, com base na carga e/ou tamanho, bloquear o acesso do interferente e ser permeável à espécie de interesse é a principal maneira de diminuir o grau de interferência, por meios físicos, ou seja, nesses eletrodos é comum o uso de membranas seletivas não só para a identificação de íons, mas também para proteção da superfície sensora.

A proteção da superfície pode ser feita com filmes espessos - polímeros, tais como acetato de celulose ou Nafion. Nafion é um polieletrólito aniônico que é capaz de repelir espécies aniônicas, enquanto permite a passagem de cátions. Por sua vez, os filmes de acetato 
de celulose atuam com base no tamanho das espécies envolvidas. As membranas poliméricas para ISEs são as mais versáteis e têm sido descritas para cerca de 60 analitos. A seletividade deste tipo de ISEs é principalmente dada pelo agente complexante lipofílico, usualmente chamado como ionóforo. Os ionóforos altamente seletivos podem também ser usados nos sensores óticos que necessitam de maior equilíbrio. Outra maneira de excluir interferentes com base nas interações eletrostáticas pode ser através do recobrimento da superfície do eletrodo com monocamadas, como no caso dos eletrodos com monocamadas auto-arranjadas. Por exemplo, a incorporação de uma monocamada de fosfolipídio a um eletrodo de mercúrio aumenta permeabilidade devido à presença dos grupos hidrofóbicos na camada fosfolipídica [93].

Portanto, os componentes-chave da membrana são o ionóforo e o íon lipofílico; o primeiro assegura a seletividade para o íon alvo e o segundo se encarrega do funcionamento do ISE. O ionóforo se liga seletivamente ao íon primário, discriminando-o dos íons interferentes. Os eletrodos íon-seletivos para cátions geralmente usam ionóforos neutros e, usualmente, contêm anéis macrocíclicos de heteroátomos ou grupos funcionais que são capazes de complexar o íon primário, onde a cavidade do anel serve para excluir os íons interferentes, baseado nos diferentes raios iônicos. Há vários fatores que determinam a possibilidade de se empregar um composto como ionóforo. Entre os mais importantes estão a força da interação ionóforo-íon e a lipofilicidade. A força da interação do ionóforo-íon talvez seja a mais importante e é determinada pela constante de formação do complexo.

Um pré-requisito para um ISE dar resposta é que nenhuma quantidade de íons com carga oposta ao íon primário seja extraída na membrana. Isto significa que a membrana deve ser permeável somente a íons com a mesma carga que o íon primário. Esta característica da membrana é chamada de permeabilidade seletiva, ou também conhecida como exclusão de Donan, e refere-se à repulsão eletrostática de íons carregados com carga diferente ao íon primário. A presença na membrana de íons lipofílicos garante a exclusão de íons com carga oposta ao íon primário, assim como a operação do ISE, mantendo a concentração do íon primário constante na membrana.

Por fim, a matriz polimérica fornece estabilidade mecânica à membrana. Esta deve ser inerte e não ter interação química com o íon em análise. Dependendo da sua polaridade e lipofilicidade, os plastificantes podem ser usados para influenciar na seletividade e na resposta dos eletrodos íon-seletivos. Os plastificantes são importantes porque reduzem a viscosidade, proporcionam homogeneidade à membrana e asseguram uma relativa mobilidade dos íons na 
membrana, assim também estes devem ser compatíveis com todos os componentes da membrana.

\subsection{Materiais para fabricação}

Este item aborda apenas substratos usados nesse trabalho (silício, acrílico e amido, na forma de partículas) e possíveis materiais para adsorção.

\subsubsection{Substratos}

Em sua revisão sobre dispositivos fluídicos e seus substratos, Mello [94] cita que até os anos 90 praticamente qualquer dispositivo fluídico foi construído em quartzo, vidro ou silício, para utilizar as técnicas de microeletrônica, já bem desenvolvidas. Mas a necessidade de aplicar altas tensões, por exemplo, para eletroforese capilar, tornou o uso do silício difícil em certas áreas, onde prevalece então o vidro, que também apresenta melhores características ópticas, mas a dificuldade de fabricação dos canais é maior e seu uso comercial é mais restrito. Outras características importantes são o custo, que para material plástico é pequeno, a infraestrutura para fabricação, que tem de ser maior para vidro, ou silício, e características obtidas nos perfis dos canais; por exemplo, vidro apresenta corrosão isotrópica e, além disso, a soldagem é mais difícil. Portanto, polímeros em geral, e plásticos em particular, são bastante favoráveis para a produção de dispositivos fluídicos porque tem baixo custo, facilidade de usinagem e/ou replicagem.

Assim, a miniaturização de dispositivos normalmente é realizada com silício e vidro, mas a tendência do uso de substrato polimérico vem se acentuando [95], especialmente para acrílico [96]. Acrílico é transparente o que permite seu uso em dispositivos ópticos [97], contudo Loverich [98] observou que, apesar de polimetildisiloxana (PDMS) e acrílico serem os materiais mais comuns para fabricação de dispositivos, suas propriedades elétricas precisam ser ajustadas quanto à constante dielétrica e modulo de elasticidade para não haver perda de tensão elétrica.

Partículas, com diâmetro variando entre nanômetros a alguns mícrons podem ser utilizadas na fabricação de sensores de maneiras distintas [99]. Por exemplo, partículas ouro desempenham um papel importante sobre a resposta elétrica em sensores de $\mathrm{SnO}_{2}$ [100] e 
nanopartículas são essenciais na melhoria de desempenho de análises biológicas [101, 102]. Além disso, partículas estão presentes em microTAS durante o pré-tratamento de amostras em muitas situações, pois são utilizadas como material de encapsulamento em micropréconcentradores [103], em microcolunas cromatográficas [104], etc.

Partículas podem ser tratadas em ambiente de plasma de modo a alterar as suas propriedades superficiais ou para produzir compósitos [105]. Existem diversas maneiras de se obter partículas e/ou compósitos; a partícula é inserida na região de plasma ou são produzidas durante o processo de plasma. A Inserção de partículas pode ocorrer através de leito fluidizado [106], ocorrendo em câmaras de eletrodos externos, em altas freqüências de RF ou até mesmo em pressão atmosférica [107, 108, 109]. A produção de partículas no plasma normalmente sofre uma reação simultânea de diferentes reagentes, mas, em tais condições, a possibilidade de formação de compósitos é restrita. Entretanto, atualmente novos processos foram propostos, tais como a atomização de uma solução dentro do plasma [110].

Polissacarídeos, como amido e celulose, apresentam uma vasta utilidade, incluindo desenvolvimento de sensores. Amido pode ser plastificado para produzir filmes transparentes com alta condutividade iônica $[111,112,113]$. Esses filmes são potenciais candidatos a sensores biológicos e umidade.

\subsubsection{Materiais para adsorção e detecção}

Tanto a melhora do limite de detecção como a pré-concentração exigem a fabricação de materiais adsorventes e com grande área superficial, por exemplo, filmes de alumínio [114, 115], nanofibras, normalmente, fabricadas por electrospinning [116, 117, 118], ou silício poroso [119, 120], polímeros condutores [121] ou adsorventes [122], materiais porosos, orgânicos ou inorgânicos, $[123,124,125]$ que possuem várias funções químicas $[126,127$, 128]. Outra classe importante são os nanomateriais e/ou nanocompósitos [129 - 135], etc.

A produção de dispositivos MEMS utiliza os processos de microeletrônica, entre eles a deposição por plasma. Dentre os filmes que se podem produzir, os filmes adsorventes [136, 137, 138] apresentam grande interesse, pois podem ser utilizados na produção de sensores ou pré-concentradores. Muitos destes filmes absorventes são os mesmos utilizados em análises cromatográficas [139] e muitos deles são compostos orgânicos [140].

Embora compostos de silício possam ser facilmente polimerizados por plasma [141] para produzir filmes semelhantes aos utilizados como fase estacionária em análises 
cromatográficas, poucos trabalhos deram importância para tal fato. Até mesmo filmes finos adsorventes depositados por plasma são recentes.

Na década de 90, Kamo [142] produziu ftalocianina de cobre através da polimerização por plasma para a detecção de compostos orgânicos com ligações duplas e uma década depois Maggioni [143] propôs a utilização de dessorção por plasma para fins similares. No entanto, polimerização por plasma apresenta diversas vantagens uma vez que espécies ativas únicas são formadas no plasma e que normalmente favorecem a obtenção de novos materiais. Além disso, filmes finos são mais adequados para dispositivos miniaturizados porque minimizam a permeação do analito, o que dificulta o processo de adsorção/dessorção. Portanto, com plasma não apenas filmes muito finos e homogêneos podem ser obtidos, mas também existe a possibilidade de produzir novos materiais com novas propriedades adsorventes [141].

Dentre os filmes adsorventes já produzidos, éteres e ésteres polimerizados por plasma DC apresentaram características interessantes [138]. Estes reagentes possuem uma cadeia carbônica com oxigênio, um átomo polar, que pode produzir filmes finos altamente polares. Éter etílico, acetato de etila e metila foram polimerizados e os filmes finos obtidos foram hidrofílicos [57], mostraram boas propriedades de adsorção para VOC's (compostos orgânicos voláteis), mas não resistência à variação $\mathrm{pH}$ [144]. O uso de filme orgânico em uma estrutura helicoidal também demonstrou a possibilidade da fabricação de equipamentos miniaturizados e de baixo custo [57]. Filmes adsorventes produzidos utilizando hexametildissilazana (HMDS) são moderadamente resistentes aos ácidos e bases, mas altamente hidrofóbicos e oleofólicos [137]. Por outro lado, polímeros que contêm flúor são freqüentemente hidrooleofóbicos [145], com resistência térmica e à corrosão, mas não absorventes. Assim, um dos usos comuns da polimerização por plasma de compostos fluorados é a proteção superficial, em muitas áreas tecnológicas, tais como [146] microeletrônica, biomateriais, têxtil, embalagens, etc. Filmes finos que contêm flúor são também utilizados como [147, 148] material de baixa constante dielétrica, mas várias outras utilidades foram desenvolvidas e alguns exemplos foram retardadores de incêndio [150], membranas seletivas [150, 151] e materiais ópticos com baixo índice de refração [152]. No entanto, devido aos diferentes mecanismos de polimerização, baseados em radicais livres, em plasmas de RF contendo compostos orgânicos fluorados a polimerização é mais rápida do que plasmas com reagentes de hidrocarbonetos [153].

Dentre os filmes com capacidade de adsorção obtidos pela polimerização por plasma de organo-silanos, Tetraetilortossilicato (TEOS) [154] e dos menos estudados, já que TEOS é comumente utilizado para deposição de óxido de silício. 
A polimerização por plasma do Tetraetilortossilicato (TEOS), que leva à formação de um filme fino com estrutura semelhante ao silicone, isto é [ $\left.\mathrm{Si}(\mathrm{OEt})_{2} \mathrm{OSi}(\mathrm{OEt})_{2}\right]$, é portanto uma boa hipótese de fase estacionária. Este fato é especialmente verdadeiro porque os filmes obtidos são hidrofóbicos, mas em contato com água formam nanocanais com $20 \mathrm{~nm}$ de profundidade, os quais aumentam a área superficial do filme, possibilitando a retenção de metais, em fase líquida, e compostos orgânicos voláteis (VOCs), em fase gasosa [155].

Estudo prévio da polimerização por plasma de TEOS [154] apontou uma grande diferença de comportamento para filmes produzidos a mesma freqüência (13,56 MHz), mas com eletrodos internos ou externos. Eletrodos externos implicam em grande perda de potencial entre o eletrodo e a câmara de plasma e, portanto, em geral propiciam menor energia para o plasma. Filmes obtidos com eletrodos externos apresentam maior quantidade relativa de radicais carbônicos, medidos por espectroscopia de infravermelho, o que os torna bastantes porosos por imersão em água, devido à hidrólise dos grupos OEt; assim, a adsorção de compostos orgânicos é favorecida pelo aumento da área. Além disso, a existência destes radicais também favorece e a resistência à radiação ultravioleta. A Figura 1.1 apresenta o resultado de AFM (Microscopia de Força Atômica) dos filmes obtidos nessas duas condições distintas. 


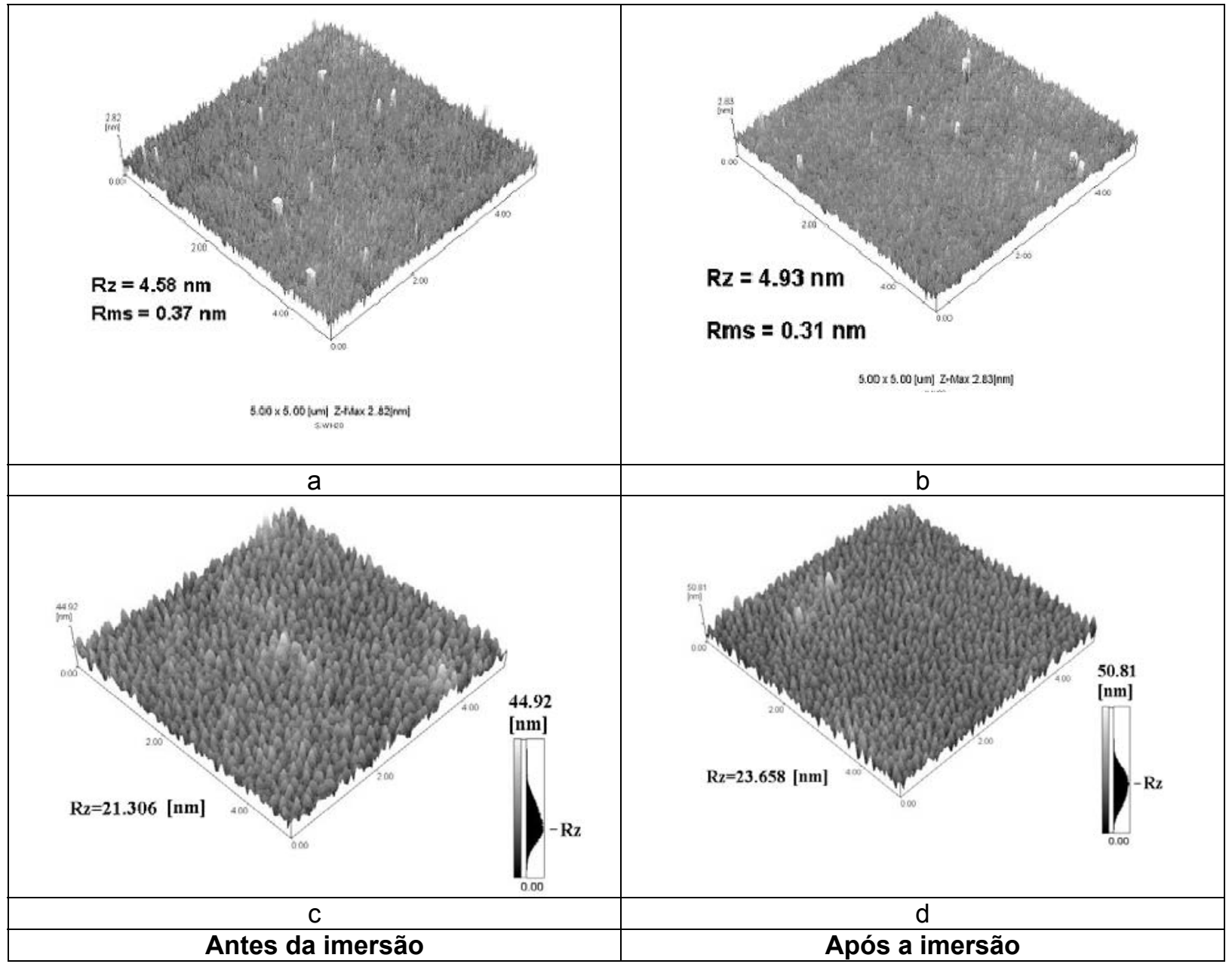

Figura 1.1. Microscopia de força atômica para filmes depositados em reator com: eletrodos internos (a e b) e externos (c e d) [154].

Para o estudo de microorganismos em estruturas miniaturizadas, o filme a base de TEOS apresenta grandes vantagens, pois sua estrutura, semelhante à de óxido de silício, pode ser considerada biocompatível. Além disso, por apresentar nanocanais pode facilitar a retenção destes microrganismos para posterior análise. Deve-se salientar, contudo, que não foi dada ênfase a esta hipótese, por não fazer parte do escopo deste trabalho.

\subsection{Conceitos envolvidos}

\subsubsection{Cromatografia}

O uso de microcanais para pré-concentração, separação ou retenção de compostos faz uso da injeção rápida de pequena quantidade de amostra em um fluxo contínuo. Após a injeção, 
vários processos ocorrem, mas um dos mais importantes, como previamente abordado, é a adsorção. Para avaliar quanto à adsorção está sendo efetiva é possível usar os conceitos de pratos teóricos e de resolução de modo similar ao que é feito em cromatografia. Uma explicação mais detalhada encontra-se no Anexo 1.

\subsubsection{Microbalança de quartzo}

Para avaliação da adsorção e permeação, tanto em fase líquida como gasosa, a técnica de microbalança de quartzo apresenta muitas vantagens. De fato, é igualmente possível, utilizando a técnica verificar a permeação e/ou redução de íons em um material poroso [156].

A técnica faz uso de cristais piezelétricos. Para estes, quando usados em um circuito oscilador, a equação de Sauerbrey indica que a freqüência de oscilação de um cristal varia linearmente com a massa de uma substância em contato com a sua superfície. Portanto, se uma substância é adsorvida na superfície do cristal, é possível calcular tal massa pela variação de freqüência provocada no cristal. Normalmente, devido a suas boas características piezelétricas e mecânicas, utiliza-se Cristian piezelétricos de quartzo. Com tais cristais podese obter detecção da ordem de 1ng. A técnica é conhecida como Microbalança de Quartzo.

\subsubsection{Outros}

No presente caso, utiliza-se a proposta de Silva [157] de observação visual e uso de traçadores, além de outras técnicas, para definição do comportamento do fluido em membranas. Esse tipo de abordagem é mais adequada para compreender estruturas planares ou substratos permeáveis, como a celulose. 


\section{REFERÊNCIAS}

[1] Grayson, C. R. et al. A Biomems Review: Mems Technology For Physiologically Integrated Devices. Proceedings Of The Ieee. 92 (1). 6-21p. 2004.

[2] Weigl, H.; Bardell, R. L.; Cabrera, C. R. Lab-On-A-Chip For Drug Development. Advanced Drug Delivery Reviews. 55. 349-377p. 2003.

[3] Verpoorte, E.; Rooji, N. F. Microfluidics Meets MEMS. Proceedings of the IEEE. 91. 930-953p. 2003.

[4] Lichtenberg, J.; Rooji, N. F.; Verpoorte, E. Sample Pretreatment On Microfabricated Devices. Talanta. 2002. 56. 233-266p.

[5] Rai-Choudhury, P. Handbook Of Micromachining And Microfabrication. Iet. 1997. 702. Isbn: 0852969112.

[6] Petersen, J. MEMS: What lies ahead? Digest of Technical papers, Transducer 95. Eurosensors IX. 1.25p. 1995.

[7] Squires, T. M.; Quake, S. R. Microfluidics: Fluid physics at the nanoliter scale. Reviews of modern physics. 77. 2005.

[8] Silva, M. L. P.; Gameiro, J. G. Pre-concentrators: trends and future needs. Revista Brasileira de Aplicações de Vácuo. 25v. 123-130p. 2006.

[9] Mamginelli, R. P. et al. Finite Element Modeling of a Microhotplate for Microfluidic Applications. Presented at MEMs. 1999. San Juan. Puerto Rico.

[10] Micro Analytical Systems Department Technology $-\mu$ ChemLab ${ }^{\mathrm{TM}}$ Fact Sheet; $\mu$ ChemLab Technology Team, "Autonomous Micro-Chemical Analysis Laboratory ( $\mu$ ChemLab Technologies)," Sandia Report, SAND2001-1997, Sandia National Laboratories, Albuquerque, NM, Printed July 2001.

[11] Lindner, D. The $\mu \mathrm{ChemLab}^{\mathrm{TM}}$ project: micro total analysis system R\&D at Sandia National Laboratories. Lab on a Chip. 1. 15N-19Np. 2001.

[12] Sylwester, A. CPAC Summer Institute 2001 Proceedings and Summary Topics in Process Analysis and Control with special emphasis on: Developing Analytical Tools for High Throughput Experimentation (Discovery, Development, \& Process Optimization). Sandia's ChemLab Program. University of Washington Seattle. WA. 25-27p. 2001.

[13] Ho, C. K.; Lohrstorfer, C. F. In situ monitoring of vapor phase TCE using a chemiresistor microchemical sensor, Ground water monitoring and remediation. 23 (4). 8590p. 2003.

[14] Ho, C. K.; et al. Development of a surface acoustic wave sensor for in-situ monitoring of volatile organic compounds. Sensors. 3 (7). 236-247p. 2003.

[15] Rivera, D. et al. Characterization of the ability of polymeric chemiresistor arrays to quantitate trichloroethylene using partial least squares (PLS): effects of experimental design, humidity, and temperature. Sensors and Actuators B-Chemical. 92 (1-2). 110-120p. 2003.

[16] Ho, C. K.; Hughes, R. C. In-situ chemiresistor sensor package for real-time detection of volatile organic compounds in soil and groundwater. Sensors. 2 (1). 23-34p. 2002.

[17] Hughes, R.; Manginell, R.; Kottenstette. R. Chemical Sensing with an Integrated Preconcentrator/chemiresistor Array. 2001 Joint International Meeting. the 200th Meeting of The Electrochemical Society, Inc. and the 52nd Annual Meeting of the International Society of Electrochemistry. San Francisco, California G1. Chemical and Biological Sensors and Analytical Methods. September. 2-7p. 2001.

[18] examples of this impact on midia can be seen in a)NONDESTRUCTIVE TESTING I NFORMATION ANALYSIS CENTER Newsletter, 24 (4) spt (1999) pag5; b) http://www.howstuffworks.com/ c) http://peace-officers.com http://www.eetimes.com/ c) 
http://www.elecdesign.com e)http://www.sciencedaily.com and f)http://www.sensorsmag.com - all acess in june.

[19] Sylwester, A. Micro Instrumentation for High Throughput Experimentation. "MCL Technologies" CPAC Summer Institute 2002 Final Report. Topics In Process Analysis And Control. University of Washington. July. 17-19p. 2002.

[20] Nakamoto, T.; Sumitimo, E. Study of robust odor sensing system with auto-sensitivity control. Sensors and Actuators B -Chemical. 89 (3). 285-291p. 2003.

[21] Nakamoto, T.; Isaka, Y.; Ishige, T. Odor-sensing system using preconcentrator with variable temperature. Sensors and Actuators B-Chemical. 69 (1-2). 58-62p. 2000.

[22] Lighty, J. S.; Veranth, J. M.; Lighty, A. F. S. Combustion Aerosols: Factors Governing Their Size and Composition and Implications to Human Health, Journal of the Air \& Waste Management Association. 50v. September. 1565-1618p. 2000.

[23] Kanakidou, M. et al. Human-activity-enhanced formation of organic aerosols by biogenic hydrocarbon oxidation. Journal of Geophysical Research. 105. Issue D7. 9243-9254p. 2000.

[24] Grosjean, D. In situ organic aerosol formation during a smog episode: Estimated production and chemical functionality. Atmospheric Environment. 26A. no6. 953-963p. 1992.

[25] Damle, A.S.; Ensor, D.S.; Ranade, M.B. Coal combustion aerosol formation mechanisms: a review. Aerosol Sci. Technol. 1:1. 119-133p 1982.

[26] Rathbun, R. E. Transport, Behavior, and Fate of Volatile Organic Compounds in Streams. Critical Reviews in Environmental Science and Technology. 30. 129-295p. 2000.

[27] Jacek, A.; Pawliszyn, K.; Pawliszyn, J. Air Sampling and Analysis of Volatile Organic Compounds with Solid Phase Microextraction. J. Air \& Waste Manage. Assoc. 51. 173-184p. 2001.

[28] Lynam, M. M.; Keeler, G. J. Comparison of methods for particulate phase mercury analysis: sampling and analysis. Anal Bioanal Chem. 374. 1009-1014p. 2002.

[29] Telgheder, U.; Khvostikov, V. A. Collection and determination of metal contaminants in gases a review. Journal of Analytical Atomic Spectrometry. 12 (1-6). 1997.

[30] Steve J. H. et al. Atomic spectrometry update. Environmental analysis. J. Anal. At. Spectrom. 18. 170-202p. 2003.

[31] Terzieva, S. Comparison Of Methods For Detection And Enumeration Of Airborne Microorganisms Collected By Liquid Impingement. Applied And Environmental Microbiology. 2264-2272p. 1996.

[32] Dottori, M.; Fava, G.; Ruello, M. L. Bacteria Removal and Viability Attenuation by Means of an Electrostatic Barrier. Indoor Built Environ. 13. 309-314p. 2004.

[33] Yashin, Y. A. Miniaturization Of Gas-Chromatographic Instruments. Journal Of Analytical Chem. 56 (9). 794p. 2001.

[34] Vitko, J. Chemical and Toxin Detection, Bioterrorism: Homeland Defense Symposium: The Next Steps. Conference Proceedings Section V. Tech Panel: Homeland Defense Beyond. Santa Monica. California. 8-10p. 2000.

[35] Editorial. Analytical Instrument Report. 19 (18). 2003.

[36] Staples, E. J. ACS National (ACS2000). March 26-30. USA. 219. 236-ANYL Part 1 (2000).

[37] Watson, G.W.; McGuire, D. Proceedings of the American Chemical Society Meeting. (ACS_99). Ontario. CA. 5-7p. 1999.

[38] Watson, G. W.; Staples, E. J.; Viswanathan, S.; Environmental Progress. 22 (3). 215p. 2003.

[39] Compendium of Methods for the Determination of Toxic Organic Compounds in Ambient Air. Second Edition. Compendium Method TO-15. Determination Of Volatile Organic Compounds (VOCs) In Air Collected In Specially-Prepared Canisters And Analyzed By Gas Chromatography/ Mass Spectrometry (GC/MS). EPA/625/R-96/010b. Center for 
Environmental Research Information Office of Research and Development U.S. Environmental Protection Agency. Cincinnati. OH. USA. 1999.

[40] Feng, C. H.; Mitra, S, Two-stage microtrap as an injection device for continuous on-line gas chromatographic monitoring. Journal Of Chromatography A. 805 (1-2). 169-176p. 1998.

[41] Mitra, S. et al. Continuous monitoring of volatile organic compounds in air emissions using an on-line membrane extraction-microtrap-gas chromatographic system. Journal Of Chromatography A. 736 (1-2). 165-173p. 1996.

[42] Kim, M.; Mitra, S. A microfabricated microconcentrator for sensors and gas chromatography. Journal Of Chromatography A. 996 (1-2). 1-11p. 2003.

[43] Zellers, E. T. et al. Determinations of Complex Vapor Mixtures in Ambient Air with a Wireless Microaanlytica System: Vision, Progress, and Homeland Security Applications. University of Michigan. Technical Report. 1-5p. 2003.

[44] Lu, C. J.; Zellers, E. T. Multi-adsorbent preconcentration/focusing module for portable$\mathrm{GC} /$ microsensor-array analysis of complex vapor mixtures. The Analyst 127. 1061-1068p. 2002.

[45] Tian, W. C. et al. Microfabricated preconcentrator/focuser for a microscale gas chromatograph. J. Microelectromechanical Systems. 12(3). 264-23p. 2003.

[46] Tian, W. C.; Pang, S. W. Performance of Preconcentrator/Focuser with Microfabricated Si Heater. University of Michigan. Technical Report. 2002.

[47] Tian, W. C.; Pang, S. W. Thick and Thermally Isolated Microheaters for Preconcentrator/Focuser in Micro Gas Chromatography. University of Michigan, Technical Report. 2002.

[48] Guo, X. M; Mitra, S. On-line membrane extraction liquid chromatography for monitoring semi-volatile organics in aqueous matrices. J. Chromaotography A. 904 (2). 1189 196p. 2000.

[49] Alonso, M. G.; Adams, A. T. Development of a Plastic Microfluidics Chip, IVD Technology. 41-50p. 2003.

[50] Weigl, B. H.; Bardell, R. L.; Cabrera, C. R. Lab-on-a-chip for drug development, Advanced Drug delivery reviews. 55. 349-377p. 2003.

[51] Czae, M. Z.; Wang, J. Pushing the detectability of voltammetry: how low can we go?. Talanta. 50 (5). 921-928p. 1999.

[52] see, for example U.S. Patent No. 05942103.

[53] Silva, J. A. F. et al. Simulations of silicon microstructurre preconcentration of metallic ions. 8th Symposium On Microelectronics Technology And Devices. Brazil. 2003.

[54] Huber, D. L. et al. Programmed adsorptionn and release of proteins in a microfluidic device. Science. 301 (5631). 352-354p. 2003.

[55] Lago, C. L. et al. Analytical Chemistry. 75 (15). 3853p. 2003.

[56] Coltro, W. K. T.; Carrilho, E. Development of preconcentration microchannels in polyester films incorporateed on separation microdevices. Acta Microscopica. 12 (Supplement C). 281-282p. 2003.

[57] Lima, R. R. et al. Production and deposition of adsorbent films by plasma polymerization on low cost micromachined non-planar microchannels for preconcentration of organic compound in air. Sensors and Actuators B-Chemical. 108. 1-2. 435-444p. 2005.

[58] MICROSYSTEM Technology in Chemistry and Life Science, chapter Integrated ChipBased Microcolumn Separation Systems. Springer Berlin / Heidelber. 194. 51-82p. 1997.

[59] Potkay, J. A. et al. A high-performance microfabricated gas chromatography column. IEEE The Sixteenth Annual International Conference on Micro Electro Mechanical Systems. MEMS-03 Kyoto japan. 395- 398p. 2003. 
[60] Potkay, J. A. et al. High-performance temperature-programmed microfabricated gas chromatography columns. Journal of Microelectromechanical Systems. 14. 5. 1039- 1050p. 2005.

[61] Widmer, H. M. et al. Integration Of A Micro Liquid Chromatograph Onto A Silicon Chip. The 8th International Conference on Solid-State Sensors and Actuators and Eurosensors IX Stockholm. Sweden. 756-759p. 1995.

[62] MICRO ANALYTICAL Systems Department Technology- $\mu$ ChemLabTM Fact Sheet. $\mu$ ChemLab Technology Team. "Autonomous Micro-Chemical Analysis Laboratory ( $\mu$ ChemLab Technologies)" Sandia Report. SAND2001-1997. Sandia National Laboratories. Albuquerque. NM. 2001.

[63] Lindner, D. The $\mu$ ChemLabTM project: micro total analysis system R\&D at Sandia National Laboratories. Lab on a Chip. 1. 15N-19N. 2001.

[64] Sylwester, A. "Sandia's ChemLab Program". CPAC Summer Institute 2001 Proceedings and Summary Topics in Process Analysis and Control with special emphasis on: Developing Analytical Tools for High Throughput Experimentation (Discovery, Development, \& Process Optimization). University of Washington Seattle. WA. 2001.

[65] Clifford, K. et al. Field Demonstrations of Chemiresistor and Surface Acoustic Wave Microchemical Sensors at the Nevada Test Site. Sand Report. SAND2003-0799. 2003.

[66] Ho, C. K. et al. Development of a surface acoustic wave sensor for in-situ monitoring of volatile organic compounds. Sensors. 3 (7). 236-247p. 2003.

[67] Mello, A. On-chip chromatography: the last twenty years. Lab Chip. 2. 48N-54N. 2002.

[68] Rivera, D. et al. Characterization of the ability of polymeric chemiresistor arrays to quantitate trichloroethylene using partial least squares (PLS): effects of experimental design, humidity, and temperature. Sensors and Actuators B-Chemical. 92 (1-2). 110-120p. 2003.

[69] Ghosh, R. Separation of proteins using hydrophobic interaction membrane Chromatography. Journal of Chromatography A. 923. 59-64p. 2001.

[70] Seshan, K. Handbook of thin-film deposition processes and techniques: principles, methods, equipment and applications. $2^{\text {nd }}$ Edition. Norwich. N.Y. Noyes Publications/William Andrew Pub. 629p. 2002.

[71] Mulder, M. Basic principles of membrane technology. $2^{\text {nd }}$ Edition. Dordrecht: Kluwer Academic. 564p. 2003.

[72] Thresher, R. Energia Eólica Hoje Questões Globais. Ejournal. USA. 24- 26p. 2005.

[73] Mulder, M. Basic principles of membrane technology. $2^{\text {nd }}$ Edition. Dordrecht: Kluwer Academic. 564p. 2003.

[74] Scott, K.; Hughes, R. Industrial Membrane Separation Technology. $1^{\text {st }}$ Edition. Blackie Academic \& Professional. Univesity of Newcastte e University of Salford. 1996.

[75] Silva, M.L.P.; Demarquette, N. R.; Tan, I. H. Use of HMDS/Hexane double layers for obtaining low cost selective membrane. Cellulose Chemistry and Technology. 10. 171-178p. 2003.

[76] Silva, M.L.P.; Demarquette, N. R.; Tan, I. H. Paper surface modification by plasma deposition of double layers of organic silicon compounds. Journal of Materials Chemistry. Inglaterra. 11. 1019-1025p. 2001.

[77] Tuula, T. T. et al. Biomimetic engineering of cellulose-based materials. TRENDS in Biotechnology. 25. 7. 299-306p.

[78] Klein, E. Affinity membranes: a 10-year review. Journal of Membrane Science. 179. 127p. 2000.

[79] Belgacem, M. N.; Gandini, A. Surface Modification of Cellulose Fibres. Polímeros: Ciência e Tecnologia. 15. 2. 114-121p. 2005.

[80] Ohata, R.; Tomita, N.; Ikada, Y. Effect of a static magnetic field on ion transport in a cellulose membrane. Journal of Colloid and Interface Science. 270. 413-416p. 2004. 
[81] Smitha, B. et al. Separation of organic-organic mixtures by pervaporation - a review. Journal of Membrane Science. 241. 1-21p. 2004.

[82] Soylak, M. et al. Membrane filtration - atomic absorption spectrometry combination for copper, cobalt, cadmium, lead and chromium in environmental samples. Environ Monit Assess. 127. 169-176p. 2007.

[83] Mukherjee, P. et al. Surface modification of nanofiltration membranes by ion implantation. Journal of Membrane Science. 254. 303-310p. 2005.

[84] Mamginelli, R. P. et al. MEMs99. San Juan. Puerto Rico. 1999.

[85] MICRO ANALYTICAL Systems Department Technology - $\mu$ ChemLabTM Fact Sheet. $\mu$ ChemLab Technology Team. "Autonomous Micro-Chemical Analysis Laboratory ( $\mu$ ChemLab Technologies)" Sandia Report. SAND2001-1997. Sandia National Laboratories. Albuquerque. NM. 2001.

[86] Lindner, D. The mChemLab ${ }^{\mathrm{TM}}$ project: micro total analysis system R\&D at Sandia National Laboratories. Lab on a Chip. 1. 15N. 2001.

[87] Arshak, K. et al. A review of gas sensors employed in electronic nose applications. Sensor Review. 24. 2. 181-198p. 2004.

[88] Capone, S. et al. Solid State Gas Sensors: State Of The Art And Future Activities. Journal of Optoelectronics and Advanced Materials. 5. 5. 1335-1348p. 2003.

[89] Ho, C. K. et al. Review of Chemical Sensors for In-Situ Monitoring of Volatile Contaminants. SAND2001-0643. Sandia National Laboratories. Albuquerque. NM. 2001.

[90] Ávila, M. et al. Molecularly imprinted polymers for selective piezoelectric sensing of small molecules. TrAC Trends in Analytical Chemistry. 27. 1. 54-65p. 2008.

[91] Ying, Z. et al. Polymer coated sensor array based on quartz crystal microbalance for chemical agent analysis. European Polymer Journal. 44. 4. 1157-1164p. 2008.

[92] Pereira, A. C.; Santos, A. S.; Kubota, L. T. Tendências em modificações de eletrodos amperométricos para aplicações eletroanalíticas. Quimica Nova. 25. 6. 1012-1021p. 2002.

[93] Torres, K. Y. C.; Marzal, P. C.; Kubota, L. T. Recentes avanços e novas perspectivas dos eletrodos íons-seletivos. Química Nova. 29. 5. 1094-1100p. 2006.

[94] Mello, A. Plastic fantastic?. Lab Chip. 2. 31N-36N. 2002.

[95] Becker, H.; Gartner, C. Polymer Microfabrication Methods for Microfluidic Analytical Applications. Electrophoresis. 21. 12-26p. 2000.

[96] Martynova, L. et al. Fabrication of Plastic Microfluid Channels by Imprinting Methods. Anal. Chem. 69. 4783-4789p. 1997.

[97] Luan, L. et al. Integrated Optical Sensor in a Digital Microfluidic Platform. IEEE Sensors Journal. 8. 5. 628-635p. 2008.

[98] Loverich, J. J.; Kanno, I.; Kotera, H. Concepts for a new class of all-polymer micropumps. Lab Chip. 6. 1147-1154p. 2006.

[99] Yamazoe, N. Toward innovations of gas sensor technology. Sensors and Actuators BChemical. 108. 1-2. 2-14p. 2005.

[100] Montmeat, P. et al. Physico-chemical contribution of gold metallic particles to the action of oxygen on tin dioxide sensors. Sensors and Actuators B-Chemical. 95. 1-3. 83-89p. 2003.

[101] Vaseashta, A.; Malinovska, D. D. Nanostructured and nanoscale devices. Sensors And Detectors Science And Technology Of Advanced Materials. 6. 3-4. 312-318p. 2005.

[102] Wang, Y. et al. Electrochemical Sensors for Clinic Analysis. Sensors. 8. 2043-2081p. 2008.

[103] Kim, M.; Mitra, S. A microfabricated microconcentrator for sensors andgas chromatography. Journal of Chromatography A. 996. (1-2). 1. 2003.

[104] Saito, Y.; Jinno, K. Miniaturized sample preparation combined with liquid phase separations. Journal of Chromatography A. 1000. 1-2. 53-67p. 2003. 
[105] Kersten H., Deutsch H., Stoffels E., Stoffels W.W., Kroesen G.M.W., Hippler R., MicroDisperse Particles in Plasmas: From Disturbing Side Effects to New Applications Contributions to Plasma Physics, Volume 41, Issue 6, Pages 598 - 609, 2001.

[106] T. Hanabusa, S. Uemiya, T. Kojima, Surface modification of particles in a plasma jet fluidized bed reactor, Surf. Coat. Technol. 88 (1996) 226- 231.

[107] Claire Tendero, et.al., "Atmospheric pressure plasmas: A review", Spectrochimica Acta Part B, v. 61, 1, p. 2-30, 2006.

[108] S. Ogawa, A. Takeda, M. Oguchi, K. Tanaka, T. Inomata, M. Kogoma, Zirconia coating on amorphous magnetic powder by atmospheric pressure glow plasma, Thin Solid Films 386 (2001) 213-216.

[109] Y. Sawada, M. Kogoma, Plasma-polymerized tetrafluoroethylene coatings on silica particles by atmospheric pressure glow discharge, Powder Technol. 90 (1997) 245- 250.

[110] D. Ross, Karen K. Gleason, "The CVD of Nanocomposites Fabricated via Ultrasonic Atomization", Chem. Vap. Deposition, v. 12, p. 225-230, 2006

[111] A.M. Regiani, C.E. Tambelli, A. Pawlicka, A.S. Curvelo, A. Gandini, J.F. LeNest and J.P. Donoso, Polym. Int. 49 (2000), p. 960.

[112] D. Dragunski and A. Pawlicka, Mol. Cryst. Liq. Cryst. 374 (2002), p. 561.

[113] L.V.S. Lopes, G.O. Machado, A. Pawlicka and J.P. Donoso, Electrochim. Acta 50 (2005), p. 3978

[114] Perez, GP, Yelton, WG, Cernosek, RW, Simonson, RJ, Crooks, RM, Gas adsorption gates based on ultrathin composite polymer films, ANALYTICAL CHEMISTRY, 75 (14): 3625-3630, JUL 152003.

[115] Yelton, WG, Pfeifer, KB, Staton, AW, Porous A12O3 nanogeometry sensor films Growth and analysis, JOURNAL OF THE ELECTROCHEMICAL SOCIETY, 149 (1): H1H5, JAN 2002.

[116] Zheng-Ming Huang, Y.-Z. Zhang, M. Kotaki, S. Ramakrishna, A review on polymer nano.bers by electrospinning and their applications in nanocomposites, Composites Science and Technology, 63, 2223-2253, (2003).

[117] Larrondo, L., St.John Manley, R., Journal of Polymer Science, Polymer Physics Edition, 19, 909 (1981).

[118] Shin, Y. M., et al., Polymer, 42, 9955, (2000).

[119] Gennissen, PTJ, DeMunter, D, Kuhl, M, Porous silicon as a sacrificial material Bell TE, JOURNAL OF MICROMECHANICS AND MICROENGINEERING, 6 (4): 361-369, DEC 1996.

[120] Galeazzo, E, Peres, H. E. M., Santos, G, et al., Sensor Actuat B-Chem, 93 (1-3), 384 (2003).

[121] Liu J, Lin YH, Liang L, Voigt JA, Huber DL, Tian ZR, Coker E, Mckenzie B, Mcdermott MJ, Templateless assembly of molecularly aligned conductive polymer nanowires: A new approach for oriented nanostructures, CHEMISTRY-A EUROPEAN JOURNAL, 9 (3): 605-611. FEB 32003.

[122] Grate, JW, Nelson DA, sorptive polymeric materials and photopatterned films for gas phase chemical microsensors, Proceedings of the IEEE, 91 (6), 881-889, (2003).

[123] Cansell, F., Aymonier, C., Loppinet-Serani, A., Review on materials science and supercritical fluids, CURRENT OPINION IN SOLID STATE \& MATERIALS SCIENCE, 7 (4-5): 331-340, AUG-OCT, 2003.

[124] Lin, Y. S., Kumakiri, I., Nair, B. N., Alsyouri, H., Microporous inorganic membranes SEPARATION AND PURIFICATION METHODS, 31 (2): 229-379, 2002.

[125] Polarz, S., Smarsly, B., Nanoporous materials, JOURNAL OF NANOSCIENCE AND NANOTECHNOLOGY, 2 (6): 581-612, DEC 2002. 
[126] Hentze, H. P., Antonietti, M., Template synthesis of porous organic polymers, CURRENT OPINION IN SOLID STATE \& MATERIALS SCIENCE, 5 (4): 343-353, AUG 2001.

[127] Elorza, A. Z., Molecularly imprinted polymers: synthesis and characterisation Cormack PAG, JOURNAL OF CHROMATOGRAPHY B-ANALYTICAL TECHNOLOGIES IN THE BIOMEDICAL AND LIFE SCIENCES, 804 (1): 173-182, MAY 52004.

[128] Blanco-Lopez, M. C., Lobo-Castanon, M. J., Miranda-Ordieres, A. J., Tunon-Blanco, P., Electrochemical sensors based on molecularly imprinted polymers, TRAC-TRENDS IN ANALYTICAL CHEMISTRY, 23 (1): 36-48, JAN 2004.

[129] Shi JL, Hua ZL, Zhang LX, Nanocomposites from ordered mesoporous materials, JOURNAL OF MATERIALS CHEMISTRY, 14 (5): 795-806, MAR 72004.

[130] Shchukin, D. G., Sukhorukov, G. B., Nanoparticle synthesis in engineered organic nanoscale reactors ADVANCED MATERIALS ,16 (8): 671-682, APR 192004.

[131] Roy D, Fendler J, Reflection and absorption techniques for optical characterization of chemically assembled nanomaterials, ADVANCED MATERIALS, 16 (6): 479-508, MAR 18 2004.

[132] Gedanken, A., Using sonochemistry for the fabrication of nanomaterials, ULTRASONICS SONOCHEMISTRY, 11 (2): 47-55, APR 2004.

[133] Cui DX, Gao HJ, Advance and prospect of bionanomaterials, BIOTECHNOLOGY PROGRESS, 19 (3): 683-692, MAY-JUN 2003.

[134] Ye, X. G., Wai, C. M., Making nanomaterials in supercritical fluids: A review, JOURNAL OF CHEMICAL EDUCATION, 80 (2): 198-204, FEB 2003.

[135] Moriarty, P., Nanostructured materials, REPORTS ON PROGRESS IN PHYSICS, 64 (3): 297-381, MAR 2001.

[136] MEMS-based multi-inlet/outlet preconcentrator coated by inkjet printing of polymer adsorbents Bassam Alfeeli, Daniel Cho, Mehdi Ashraf-Khorassani , Larry T. Taylor, Masoud Agah, Sensors and Actuators B, Sensors and Actuators B: Chemical, Volume 133, Issue 1, 28 July 2008, Pages 24-32.

[137] Silva, M. L. P.; Nascimento Filho, A. P.; et. al.; Use of Plasma Polymerized Highly Hydrophobic Hexamethyldissilazane (HMDS) Films for Sensor Development, Sensors an Actuators B-Chemical, 91, pp.362-369, 2003.

[138] Nascimento Filho, A. P.; Silva, M. L. P.; et al.; Use of Plasma Polymerized highly polar organic compound films for sensor development, Sensors and Actuators B-Chemical, 91, pp. 370-377, 2003.

[139] CRC series in chromatography: CRC handbook of chromatography: polymers / editors, Charles G. Smith . [et al.] Boca Raton, Fla.: CRC Press, c1982 183 p.: ill. ; $26 \mathrm{~cm}$ Smith, Charles G., CRC Press; and CRC handbook of chromatography: pesticides and related organic chemicals / authors, Joanne M. Follweiler, Joseph Sherma Boca Raton, Fla. : CRC Press, 1984.

[140] A. Mello, On-Chip Chromatography: The Last Twenty Years, Lab Chip, 2, 48n-54n, 2002.

[141] D’Agostino, R., Plasma Deposition, Treatment, and Etching of Polymers, 550p. Lavoisier, 1990.

[142] Gas Sorption to Plasma-Polymerized Copper Phthalocyanine Film Formed on a Piezoelectric Crystal Shigeru Kurosawa, Naoki Kamo, Daijyu Matsui, and Yonosuke Kobatake Anal. Chem. 1990, 62-65, 353-359.

[143] G. Maggioni, A. Quaranta, S. Carturan, A. Patelli, M. Tonezzer, R. Ceccato, G. Della Mea, Deposition of Copper Phthalocyanine Films by Glow-Discharge-induced Sublimation, Chem. Mater., 17 (2005) 1895-1904. 
[144] R.R. Lima, et. A., "Comparison of adsorbent films obtained by plasma polymerization of oxygenated organic compounds", Sensors and Actuators B: Chem., vol. 130, n ${ }^{\circ} 1$, pp. 1101192008

[145] A.R. Phani, "Structural, morphological, wettability and thermal resistance properties of hydro-oleophobic thin films prepared by a wet process", Applied Surface Science, v. 253, 4, p. 1873-1881, 2006.

[146] Fluorination of polymethylmethaacrylate with tetrafluoroethane using DC glow discharge plasma S. Guruvenket, Ganjigunte R.S. Iyer, Larisa Shestakova, Per Morgen, N.B. Larsen and G. Mohan Rao Applied Surface Science Volume 254, Issue 18, 15 July 2008, Pages 5722-5726.

[147] Plasma deposition of low-dielectric-constant fluorinated amorphous carbon Kazuhiko Endo, Keisuke Shinoda, and Toru Tatsumi J. Appl. Phys. / Volume 86 / Issue 5 /1999, 27392745

[148] Pulsed plasma polymerization of pentafluorostyrene: Synthesis of low dielectric constant films JOURNAL OF APPLIED PHYSICS VOLUME 84, NUMBER 1, 1998, 439444.

[149] Surface and Coatings Technology Volumes 180-181, 1 March 2004, Pages 297-301 Elaboration of a fire retardant coating for polyamide- 6 using cold plasma polymerization of a fluorinated acrylate I. Errifai, C. Jama, M. Le Bras, R. Delobel, L. Gengembre, A. Mazzah.

[150] SAEJOONG OH YUAN ZENG ; Permeation of simple gases through plasma polymerized films from fluorine-containing monomers; JA-KYUNG KOO ; ZURAWSKY W. P. ; Journal of applied polymer science, 1995, vol. 57, nº 11, pp. 1277-1284. [151] Hydrophobic properties of plasma polymerized thin film gas selective membranes $O$. Görbig, S. Nehlsen and J. Müller Journal of Membrane Science Volume 138, Issue 1, 7, 1998, Pages 115-121

[152] The growth and characterization of photonic thin films J.T. Grant, Hao Jiang, S. Tullis, W.E. Johnson, K. Eyink, P. Fleitz and T.J. Bunning Vaccuum Volume 80, Issues 1-3, 14, Pages 12-19.

[153] Detection of deposition rate of plasma-polymerized films by quartz crystal microbalance Shigeru Kurosawa, Tomoya Hirokawa, Kazuya Kashima, Hidenobu Aizawa, Dae-Sang Han, Yasuo Yoshimi, Yuji Okada, Kiyoshi Yase, Jun Miyake, Minoru Yoshimoto and Jöns Hilborn, Thin Solid Films Volume 374, Issue 2, 17 October 2000, Pages 262-267.

[154] Carvalho, Rodrigo Amorim Motta, Obtenção de filme poroso, útil na determinação de umidade e proteção contra radiação ultravioleta, Dissertação de mestrado, EPUSP, 2004.

[155] R. A. M. Carvalho, R. R. Lima, A. P. Nascimento Filho, N. R. Demarquette, M. L. P. Silva, Plasma Polymerized TEOS Films For Nanochannels Formation And Sensor Development, Sensors And Actuators B-Chemical, 108, 955, (2005).

[156] Varela, Hamilton, Malta, Marcos and Torresi, Roberto M. Técnicas in situ de baixo custo em eletroquímica: a microbalança a cristal de quartzo. Quím. Nova, vol.23, no.5, p.664679, Out 2000.

[157] Silva, Maria Lúcia Pereira da; Furlan, Rogério; Ramos, Idalia. Development of Miniaturized Structures and Setups for Research and Teaching of New Concepts in Engineering. In: 9TH International Conference on Engineering Education, San Juan, 2006. 


\section{METODOLOGIA, MATERIAIS E MÉTODOS}

Neste capítulo serão apresentadas as metodologias utilizadas para esta pesquisa, assim como os equipamentos e os materiais utilizados.

\subsection{Metodologia}

Devido às características do filme, que hidrolisa seus radicais carbônicos em água e se torna poroso, seu uso, tanto com compostos em fase gasosa quanto líquida, pode significar a produção de um pré-concentrador, um dispositivo para retenção ou uma fase estacionária. Antes da hidrólise, o filme pode adsorver certa quantidade de água e/ou compostos orgânicos apolares; portanto, pode ser usado, respectivamente, na obtenção de um dispositivo desumidificador ou um pré-concentrador se for possível eluir eficientemente o composto retido. Porém, se a eluição não ocorrer facilmente, ou mesmo não ser possível, pode-se produzir um dispositivo para retenção. Após a hidrólise o excessivo número de radicais $\mathrm{OH}$ pode favorecer o aprisionamento de compostos medianamente polares, funcionando como fase estacionária. Por fim, como o filme é poroso, esta fase estacionária em princípio pode também ser usada para cromatografia por exclusão de tamanho.

Como o filme apresenta nanocanais seu uso para aprisionamento e/ou redução de íons deve ser considerado e pode corresponder a obtenção de um dispositivo para retenção/separação de compostos iônicos.

Para verificar a possibilidade de aplicação do filme na construção dos dispositivos descritos anteriormente, uma série de etapas foram desenvolvidas e são descritas a seguir:

\section{Etapa 1: Filmes de TEOS: caracterização dos filmes quanto às propriedades necessárias para o desenvolvimento de dispositivos miniaturizados.}

Os filmes de TEOS foram depositados em dois reatores, ambos alimentados por fonte de 13,56 MHz, porém um reator planar com eletrodos internos e outro tubular com eletrodos externos, ou seja, o primeiro privilegia o bombardeamento do filme, mas não o segundo. 
Assim, obtém-se uma maior variabilidade em suas deposições, o que permite selecioná-los para uma maior gama de possíveis aplicações.

No reator tubular depositaram-se os filmes, em condições de máxima incorporação de carbono, como previamente estabelecido [1], sobre todos os substratos usados neste trabalho. Os filmes foram testados quanto à adsorção, ou permeação, tanto em fase líquida quanto gasosa. Como reagentes orgânicos utilizaram-se solventes em larga faixa de polaridade (reagentes puros ou em solução) e como inorgânicos soluções aquosas de vários cátions e/ou anions além de larga faixa de $\mathrm{pH}$. Por fim, testes de exposição à radiação ultravioleta foram igualmente processados. Após os testes dos filmes várias estruturas foram construídas para verificar a possibilidade da construção de dispositivos miniaturizados. A Tabela 2.1 sumaria as principais possibilidades. A deposição sobre filme fino de alumínio permite testes de aplicação de potencial elétrico e solução iônica para avaliar a permeação de íons. A deposição sobre canais microusinados em alumínio, latão e acrílico avalia a possibilidade de deposição conforme (microscopia óptica) em topografia tridimensional. Partículas, de sílica e amido, foram utilizadas para otimizar as estruturas fabricadas.

Tabela 2.1 Sumário dos principais substratos utilizados e possíveis estruturas a serem obtidas.

\begin{tabular}{|c|c|c|c|c|}
\hline Substrato & Planar & Tridimensional & $\begin{array}{l}\text { Característica } \\
\text { avaliada }\end{array}$ & Possível Estrutura \\
\hline Acrílico & $\mathrm{X}$ & $X$ & $\begin{array}{l}\text { Adesão e } \\
\text { permeação }\end{array}$ & $\begin{array}{c}\text { Microcanal } \\
\text { tridimensional }\end{array}$ \\
\hline Celofane & $X$ & & $\begin{array}{l}\text { Adesão e } \\
\text { permeação }\end{array}$ & $\begin{array}{c}\text { Planar } \\
\text { (Eletrocromatografia) }\end{array}$ \\
\hline Silício & $\mathrm{X}$ & & $\begin{array}{l}\text { Controle de } \\
\text { processo }\end{array}$ & \\
\hline Alumínio & $\mathrm{X}$ & $X$ & $\begin{array}{c}\text { Adesão, } \\
\text { conformidade e } \\
\text { permeação }\end{array}$ & $\begin{array}{c}\text { Microcanal } \\
\text { tridimensional }\end{array}$ \\
\hline Latão & & $X$ & $\begin{array}{c}\text { Adesão, } \\
\text { conformidade e } \\
\text { permeação }\end{array}$ & $\begin{array}{l}\text { Microcanal } \\
\text { tridimensional }\end{array}$ \\
\hline $\begin{array}{c}\mathrm{SiO}_{2} \\
\text { (microesferas) }\end{array}$ & & $\mathrm{X}$ & $\begin{array}{c}\text { (Fabricação de } \\
\text { dispositivos) }\end{array}$ & $\begin{array}{c}\text { Microcanal } \\
\text { tridimensional }\end{array}$ \\
\hline $\begin{array}{c}\text { Partículas de } \\
\text { Amido } \\
\text { (amido recoberto } \\
\text { com filme à base } \\
\text { de HMDS) }\end{array}$ & & $X$ & $\begin{array}{c}\text { (Fabricação de } \\
\text { dispositivos) }\end{array}$ & Planar (Detecção) \\
\hline
\end{tabular}


No reator planar, que propicia pouca incorporação de carbono [1], depositou-se sobre substratos planares. Além de silício, para controle de processo, foram utilizados substratos de acrílico (peça quadrada de $20 \mathrm{~mm}$ de aresta) e metálico (filme fino de alumínio sobre silício), para verificar a adesão e possível adsorção ou permeação de compostos iônicos. Esses substratos correspondem aos escolhidos para a fabricação de dispositivos miniaturizados, tais como dispositivos fluídicos e eletrodos. A configuração deste equipamento corresponde à comumente utilizada em equipamentos de microeletrônica. Este filme foi utilizado em conjunto com um pré-tratamento de amostra com filme a base de HMDS (Hexametildissilazana), como será explicado posteriormente.

\section{Etapa 2: Deposição de Filmes a base de TEOS em microcanais}

Como as estruturas miniaturizadas construídas possuem microcanais tridimensionais, a metodologia utilizada foi similar à usada em sistemas de cromatografia, pois uma coluna capilar é muito semelhante às estruturas utilizadas. A cromatografia tem por objetivo a separação de compostos - orgânicos, inorgânicos, iônicos, etc. - e pode ocorrer tanto em fase líquida quanto gasosa. No presente caso a maior diferença das estruturas criadas é que estas provavelmente podem também promover a retenção ou pré-concentração. A proposta aqui discutida é resumida na Figura 2.1.

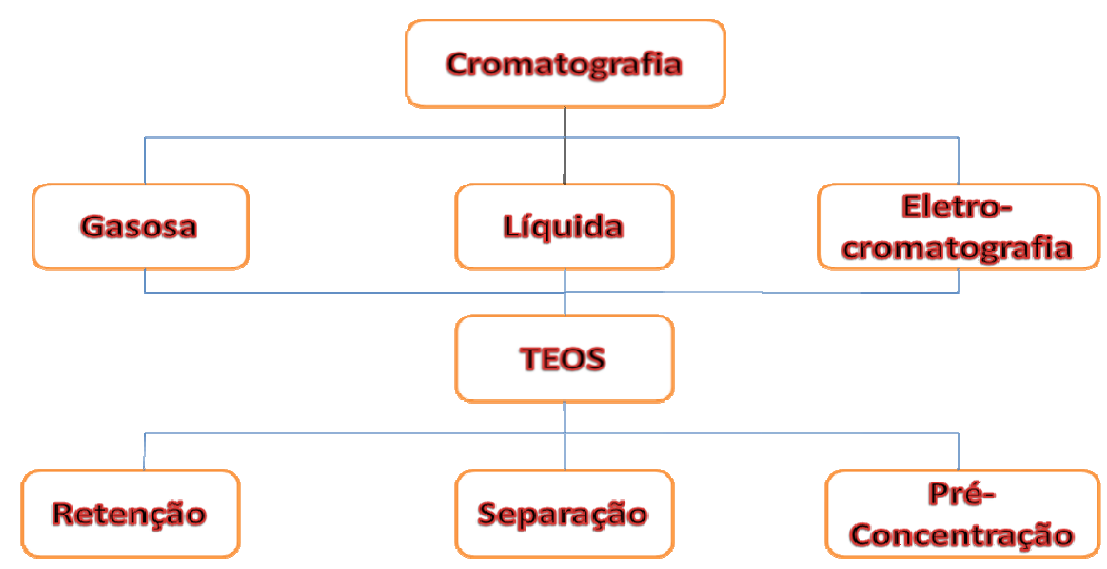

Figura 2.1. Resumo dos testes de otimização do uso do filme em dispositivos.

A montagem de um dispositivo de teste (microcanal tridimensional ou canal planar e admissão/remoção de amostras) exige verificar a integridade da estrutura; tanto em fase gasosa como líquida. A deposição do filme a base de TEOS sobre o microcanal (acrílico, alumínio ou latão) permite não só testar a adsorção de compostos e/ou soluções, em fase gasosa ou líquida, como também a permeação de íons através do corpo do filme. 


\section{Etapa 2a: Otimização das propriedades do filme/dispositivo}

L. M. Silva [2] demonstrou a importância da dispersão lateral em microcanais para a retenção de compostos orgânicos voláteis e propôs o aumento dessa dispersão pelo uso de esferas de cerâmicas não modificadas e L. F. Hernandez [3], em trabalho semelhante, as modificou depositando filme adsorvente. Portanto, partículas de sílica tiveram deposição do filme à base de TEOS em sua superfície e teste em microcanal.

No intuito de verificar a possibilidade de criar um sistema misto, onde um produto adsorve possíveis contaminantes e outro permite a permeação, utilizaram-se partículas modificadas em microcanais cuja superfície possuía outra propriedade química, por exemplo. Assim, utilizaram-se partículas de amido recobertas por filme fino a base de HMDS.

\section{Etapa 3: Deposição de Filmes a base de TEOS em substrato planar}

A deposição do filme a base de TEOS sobre filme fino de alumínio permite testá-lo quanto à permeação de íons através do corpo do filme. A deposição em substrato flexível permite avaliar a permeação em membranas.

\subsection{Equipamentos}

\subsubsection{Equipamentos para obtenção do filme}

Reator Tubular alimentado por fonte de potência de $13,56 \mathrm{MHz}$

O reator tubular com fonte de $13,56 \mathrm{MHz}$ possui uma câmara cilíndrica de vidro com $80 \mathrm{~cm}$ de comprimento e $15 \mathrm{~cm}$ de diâmetro. A injeção de gases neste reator se dá a partir de cilindros de gases ou por reagentes líquidos evaporados por diferença de pressão. O bombeamento é realizado por uma bomba mecânica de duplo estágio acoplada a um filtro de alumina e uma armadilha gelada (de $\mathrm{N}_{2}$ líquido). A bomba está constantemente ligada, pois o sistema de bombeamento é separado da câmara por uma válvula de ângulo reto localizada após a armadilha gelada. Após a abertura da válvula de ângulo reto começa-se a bombear a câmara até se chegar à pressão base de aproximadamente 10 mTorr. Na Figura 2.2 é 
apresentada uma foto do reator tubular, que destaca o sistema de admissão de gases e de bombeamento.

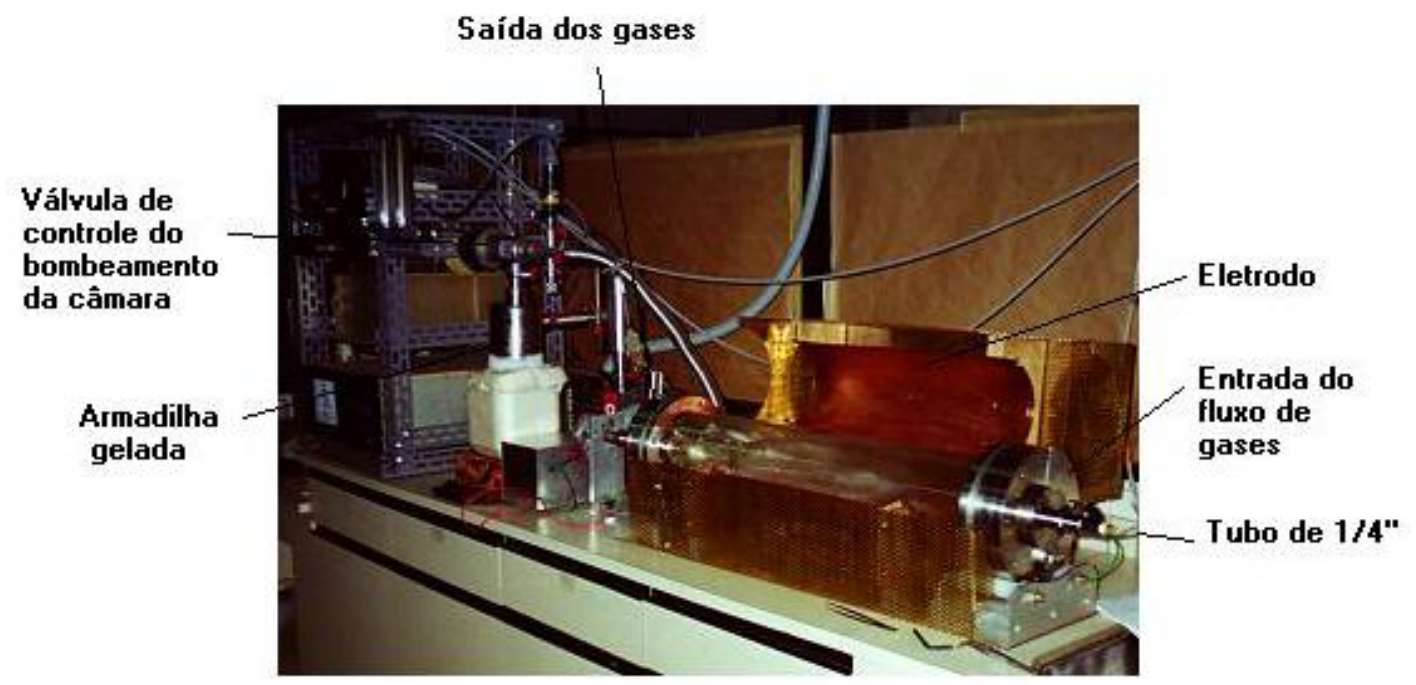

Figura 2.2. Foto do reator tubular alimentado por fonte de $13,56 \mathrm{MHz}$.

A admissão de TEOS acontece por um dos lados do reator através de uma flange de 3/8' e tubulação com mesmo diâmetro, até o tubo de ensaio onde está o reagente. Este sistema permite a menor distância do reagente até a câmara, possibilitando alcançar maiores pressões do reagente na câmara. A Figura 2.3 apresenta um desenho esquemático do reator e do sistema de bombeamento.

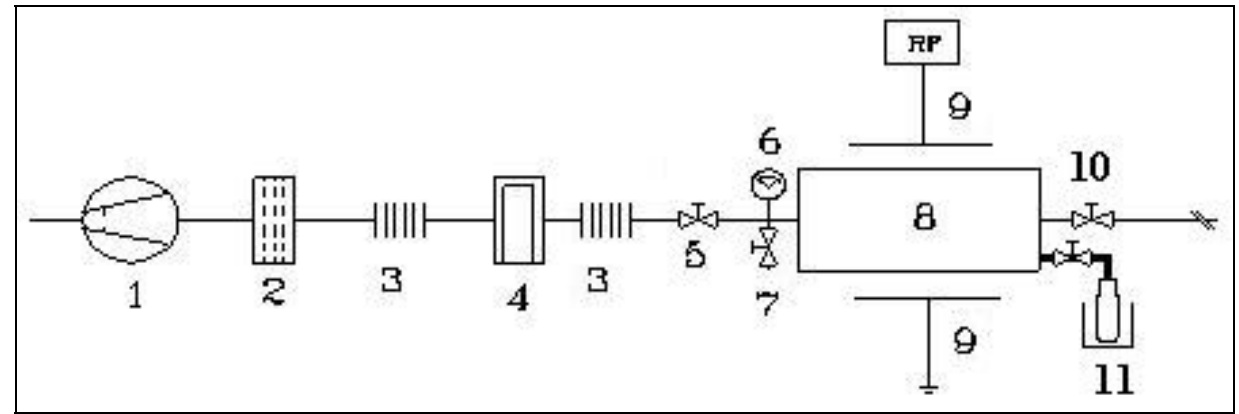

\begin{tabular}{|l|l|}
\hline 1- Bomba mecânica de vácuo; & 7- Válvula para quebra da pressão; \\
2- Filtro de óleo; & 8- Câmara; \\
3- Fole metálico; & 9- Eletrodos; \\
4- Armadilha gelada; & 10- Válvula abre-fecha; \\
5- Válvula de ângulo reto; & 11- Tubo de ensaio com reagente e \\
6- Medidor de pressão Pirani; & recipiente com água; \\
\hline
\end{tabular}

Figura 2.3. Desenho esquemático do reator e do sistema de bombeamento. 
Este reator, em função de sua geometria, faz com que ocorra deposição em toda a superfície das paredes internas da câmara, o que limita o número de deposições entre limpezas, uma vez que é alta a área possível de reação secundária entre filme depositado e atmosfera. Assim, a abertura da câmara, e entrada principalmente de água, pode favorecer mudança da superfície da câmara e favorecer a não reprodutibilidade do processo. Portanto, limpeza da superfície da câmara ocorreu no máximo entre cinco deposições consecutivas.

\section{Reator planar alimentado por fonte de potência de $13,56 \mathrm{MHz}$}

Este reator apresenta três câmaras diferentes, duas para deposição de filme fino e uma para recozimento térmico, já que em uma das duas câmaras de deposição ocorre a deposição com TEOS mais um dopante (boro ou fósforo) para obtenção de óxido de silício dopado que, após o processo, necessita de recozimento. A câmara de reação possui eletrodos internos, possibilidade de deposição sobre uma lâmina de $3^{\prime}$ e o substrato pode ser aquecido até $300^{\circ} \mathrm{C}$.

\subsubsection{Equipamentos para análise das estruturas}

Vários equipamentos são utilizados para a análise do filme e das estruturas, contudo, um merece mais atenção, a técnica de microbalança de quartzo. A técnica é importante porque como demonstrou Nascimento [4], esta técnica pode ser utilizada para caracterização de filmes, substratos, quando estes estão na forma de fita (tape), e estruturas. Deve-se salientar que a técnica não será utilizada neste trabalho do mesmo modo que na área de Química Analítica, onde a análise qualitativa e quantitativa usando tal equipamento é comum. No presente caso será utilizado um sistema desenvolvido para tal fim $^{1}$, que foi denominado como Sistema Semi-automatizado para testes de miniestruturas [5].

O sistema, baseado nas medidas de QCM, utiliza um computador com uma placa de aquisição de dados (modelo NI PCI-6220 M Series Multifunction DAQ Device, National Instruments, EUA) e software Labview ${ }^{\circledR}$ para trabalhar com os resultados da análise. As Figuras a seguir apresentam uma foto do equipamento (Figura 2.4), assim como esquemas de sua construção (Figura 2.5).

\footnotetext{
${ }^{1}$ Desenvolvido em parceria com F. P. Beraldo e L. C. Santos e otimizado neste trabalho.
} 


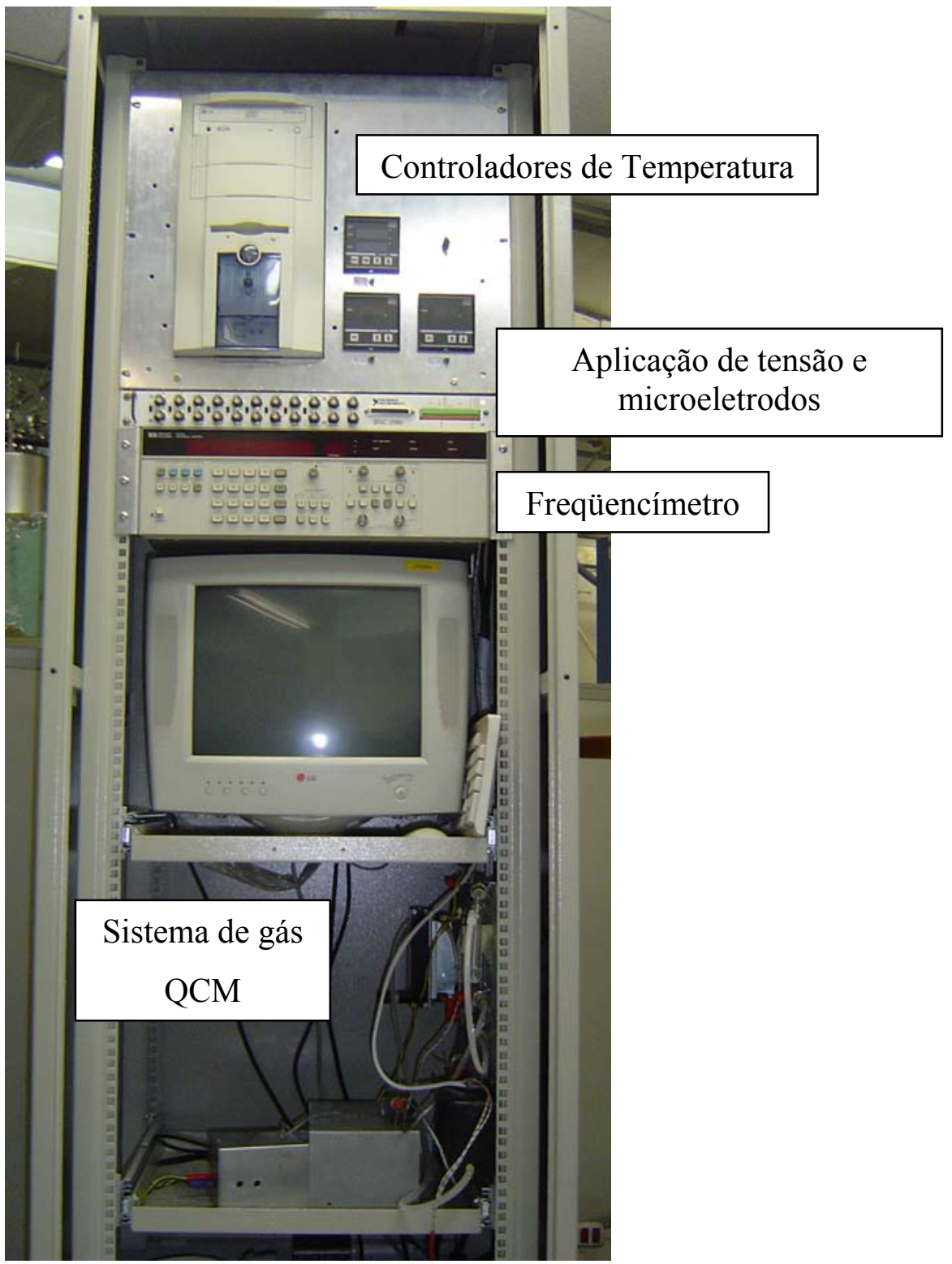

Figura 2.4. Foto do Sistema semi-automatizado para testes de estruturas. 


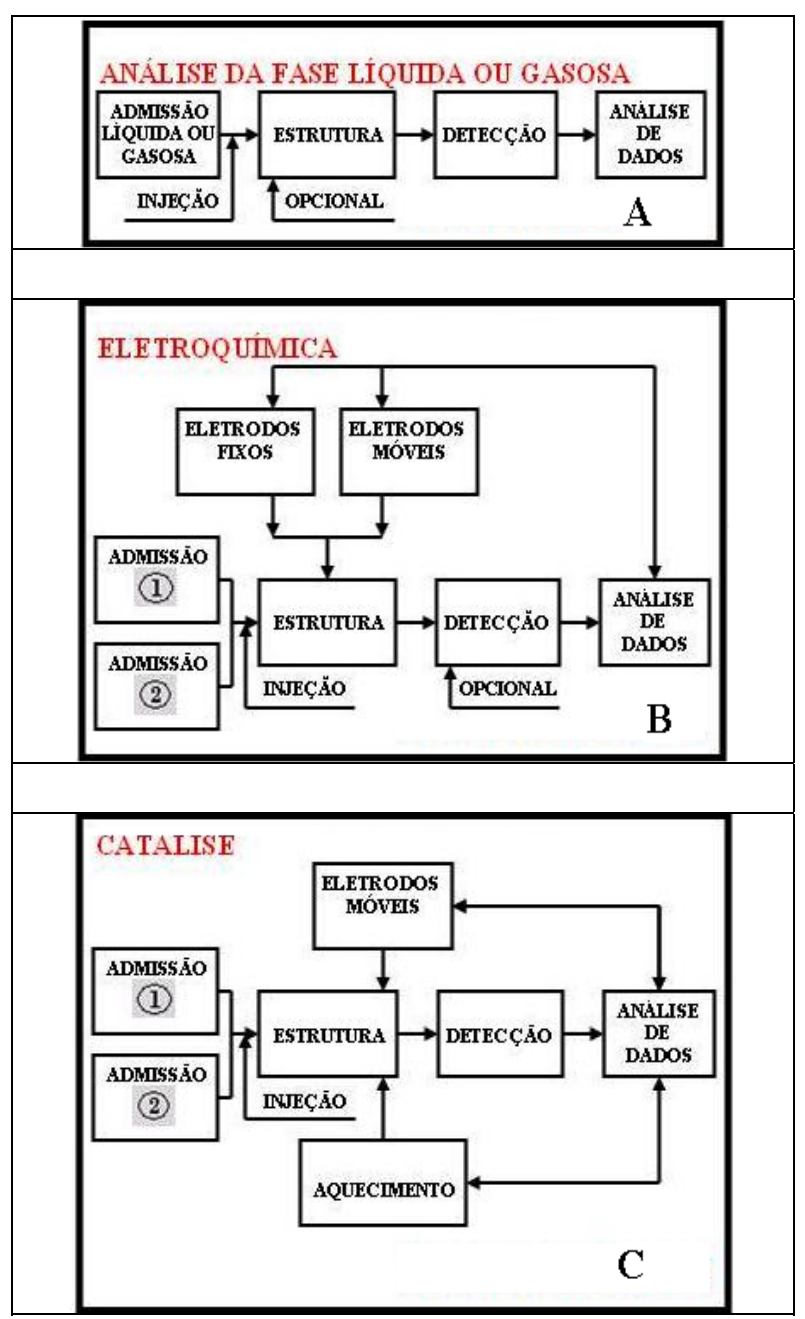

Figura 2.5. Desenho esquemático do Sistema para Análise de Filmes e/ou Estruturas Miniaturizadas: A) sub-sistema para análise, em fase líquida ou gasosa, da adsorção em filmes e/ou estruturas; B) sub-sistema para análise usando eletrodos; C) sub-sistema para análise utilizando aquecimento.

Neste trabalho foram utilizados sistemas de medição QCM gasoso e líquido, acoplado ao sistema de aquecimento de microestruturas com controle de temperatura. Contudo o sistema de microeletrodos não foi usado. Todos estes sistemas foram colocados em um rack de $19^{\prime}$. A medida de freqüência é feita utilizando-se um freqüencímetro e sua variação em função do tempo é plotada através de um programa feito no Labview ${ }^{\circledR}$, assim como a aquisição dos demais sistemas.

O sistema de admissão é constituído de um compressor de ar para aquários (modelo Twister II, 150 L/hora, Equipaquarium Indústria e Comércio Ltda, Brasil) e tubos polyflow ${ }^{\mathrm{TM}}$, de $1 / 4^{\prime}$ de diâmetro externo, com tubulação de silicone, de menor diâmetro, acoplada a estes. Estas tubulações correspondem aos terminais de entrada e saída do sistema e são conectadas à 
estrutura. A bomba de aquário bombeia o ar diretamente até a estrutura ou até um recipiente com água, onde a pressão faz com que o líquido saia pela tubulação até a estrutura.

A aplicação de potencial elétrico foi utilizada para testes de permeação de íons em estruturas de acrílico e metal (alumínio e latão). A estrutura é conectada através de tubos de aço inox, onde também pode ser aplicado o potencial elétrico. Uma fonte de tensão variável é utilizada para a aplicação de potencial elétrico e um multímetro mede a corrente do conjunto. Uma injeção contendo solução, neste caso optou-se por sulfato de cobre II $\left(\mathrm{CuSO}_{4}\right)$, permite a inserção bem próxima à estrutura.

O equipamento foi utilizado de dois modos distintos quanto à detecção. Quando não há necessidade de grande precisão ou muita rapidez na medida, pode-se utilizar a própria placa de aquisição de sinais e um divisor de freqüência; contudo, para testes mais precisos, por exemplo, para permitir testes em estruturas com alta adsorção/retenção ou sob aquecimento, utiliza-se um freqüencímetro de alta resolução (precisão de 0,01 Hz).

Os processos de aquecimento utilizam uma cela composta por tubos de alumínio isolados por resina epóxi, como pode ser visto na Figura 2.6. Nesta figura o sistema encontrase completamente desmontado para permitir sua visualização.

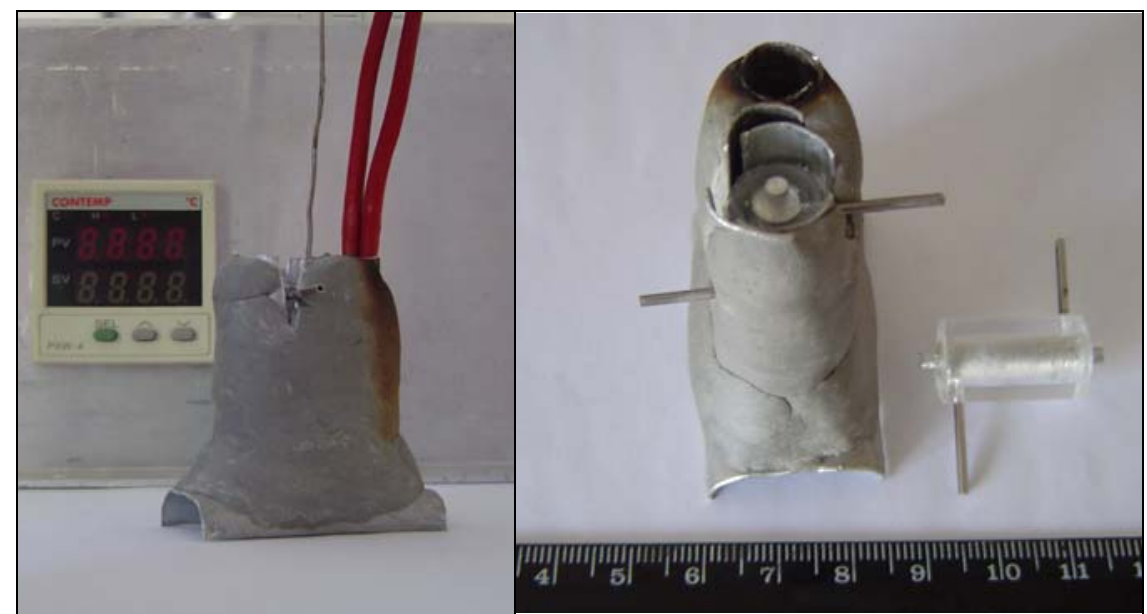

Figura 2.6. Partes e peças do sistema de aquecimento e da cela para acomodação da estrutura. Para comparação adiciona-se também uma estrutura. 


\subsection{Dispositivos}

Uma série de arranjos e/ou estruturas foram utilizadas para testes do filme. As mais importantes são descritas a seguir a as adaptações ao longo do texto no próximo capítulo.

\subsubsection{Estrutura tridimensional}

Para a produção de microestruturas, um filme a base de TEOS de aproximadamente $1000 \AA$ foi depositado pela polimerização por plasma em microcanais tridimensionais, usinados em acrílico e alumínio, e respectivo encapsulamento. Essas microestruturas apresentam um canal com $73 \mathrm{~cm}$ de comprimento e $40 \mu \mathrm{m}$ de profundidade e foram seladas utilizando cola de silicone. A Figura 2.7 apresenta detalhes da microestrutura. $\mathrm{O}$ filme fino a base de TEOS é depositado em "A" e em "B" e, quando necessário, potencial elétrico é aplicado entre "A" (catodo) e "C" (anodo). Uma variação é a existência de capilares maciços (sem canal interno) regularmente dispostos ao longo do encapsulamento, o que permite a aplicação de tensão em vários pontos do canal. Neste caso tem-se um conjunto mais adequado para eletrocromatografia.

Para simular um sistema eletrocromatográfico, foi utilizada solução aquosa de sulfato de cobre II e aplicada uma diferença de potencial (4 Volts) entre o microcanal de alumínio e o capilar de saída. A corrente foi medida para avaliar quanto tempo os compostos iônicos ficam na estrutura.

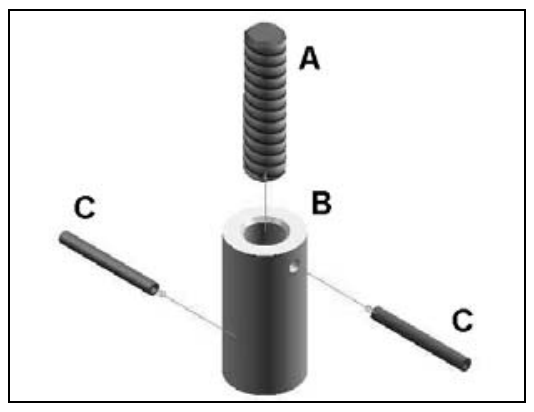

Figura 2.7. Esquema 3D da microestrutura: (A) microcanais (acrílico ou alumínio); (B) cilindro externo (acrílico); (C) entrada e saída do sistema.

Testes de aderência do filme a base de TEOS depositado nos microcanais de acrílico foram realizados. Os testes utilizaram acetona e foram realizados em situação similar a testes feitos em acrílico planar e lâminas de silício [6]. O teste consiste em mergulhar a amostra em 
acetona e analisar em microscópio óptico. Para microcanais de alumínio com filme de TEOS depositado os testes foram feitos com $\mathrm{HCl}$ diluído.

Para melhores resultados de adsorção/retenção modificaram-se superficialmente as estruturas de duas formas:

1-Visando controle da hidrofilicidade e hidrofobicidade, hidrolisa-se o filme fino a base de TEOS presente no núcleo da estrutura e coloca-se em vapor de HMDS formando ligações $\mathrm{CH}_{3}$ para que se torne um adsorvente para compostos apolares.

2-Com o intuito de aumento da área superficial, para sistemas de retenção, adiciona-se ao sistema anterior, esferas de sílica ocas da ordem de $50 \mu \mathrm{m}$ recobertas com filme fino a base de TEOS. Neste caso, é necessário o aquecimento da estrutura para recuperação dos reagentes.

3- Com o intuito de aumento de retenção de macromoléculas, adiciona-se ao sistema esferas de amido recobertas com filme fino a base HMDS. Neste caso, não se pressupõe o aquecimento, pois tratam-se de amostras lábeis.

As microcolunas foram testadas com reagentes em larga faixa de polaridade: nDodecano, n-Hexano, 2-Propanol e água deionizada. Para água como fluído carregador, as microcolunas foram também testadas utilizando sulfato de cobre II (solução aquosa saturada). Os reagentes foram injetados rapidamente $(<<1 \mathrm{~s})$ e em pequena quantidade $(<8 \mathrm{mg})$. Os testes tiveram como objetivo avaliar a retenção e eluição em colunas para determinar o número de pratos teóricos.

\subsubsection{Estrutura planar}

Um arranjo experimental simples foi montado para simular um canal. O arranjo foi construído como segue:

- Uma placa de PVC de $5 \mathrm{~cm}$ x 2,5 $\mathrm{cm}$ é perfurada no centro e um tubo de aço inoxidável, de 1,2 $\mathrm{mm}$ de diâmetro externo é adicionado, formando um sistema de inserção de amostra.

- Uma fita dupla face, recortada para formar um canal, é aderida à placa de PVC.

- O papel celofane, modificado ou não com filme de TEOS, é adicionado sobre a fita dupla face.

- Fitas de papel alumínio são adicionadas para formar contatos nas pontas do canal. 
- O conjunto é então selado com outra placa de PVC, sem qualquer abertura.

A Figura 2.8 mostra esquema do conjunto proposto. O potencial elétrico é aplicado entre os terminais de alumínio e a medida de potencial elétrico é feita entre os terminais e o tubo de aço.

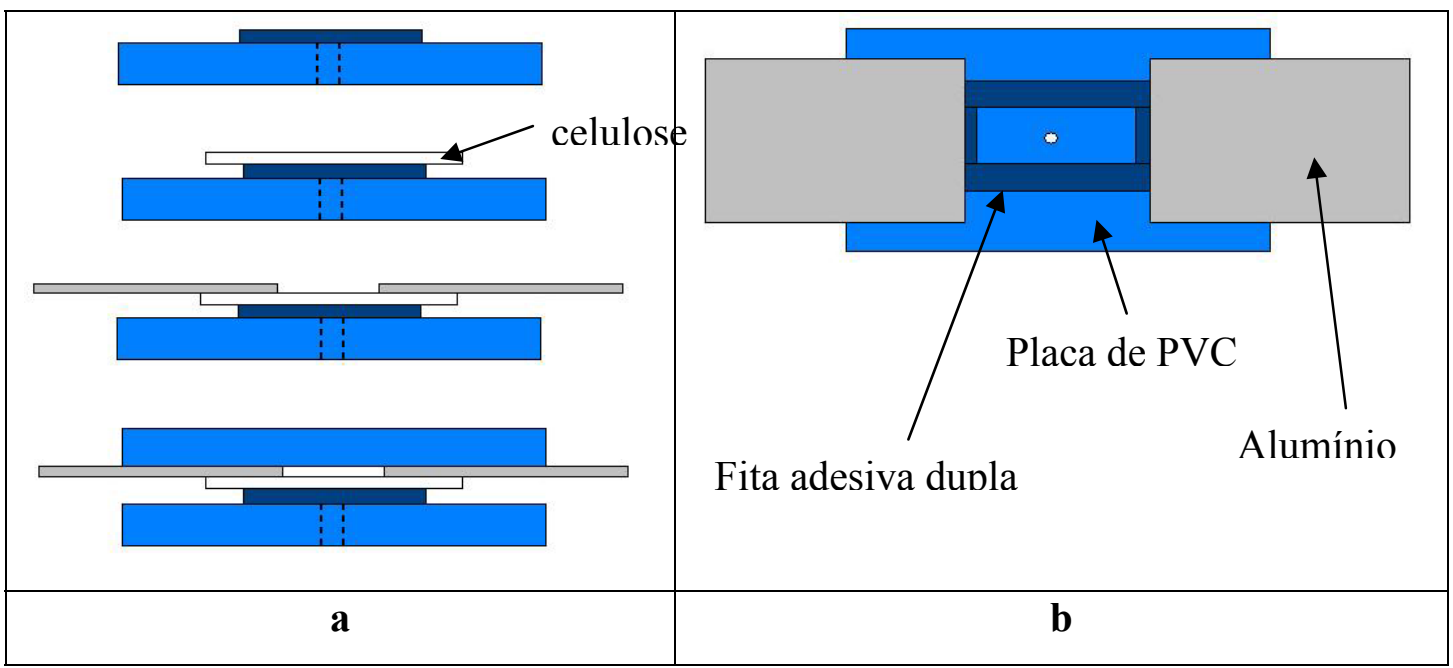

Figura 2.8. Desenho esquemático do conjunto proposto: vista lateral da construção (a) e vista superior (b).

\subsection{Métodos}

\section{Teste de reação com a água}

O filme a base de TEOS é sensível a água e reage com esta, ocorrendo a hidrólise dos radicais carbônicos. Se o filme foi depositado sobre uma microestrutura é possível saber se a reação está ocorrendo, ou já se encerrou, pelo uso da análise por QCM, monitorando-se continuamente a saída da microestrutura. Caso faz-se deliberadamente uso de água para promover a hidrólise no filme, a monitoração deve ocorrer durante a passagem desta na estrutura e a variação da linha de base vai indicar o término da reação. Por outro lado, caso deseja-se verificar eventual reação no filme (envelhecimento, por exemplo) devido ao vapor de água do ambiente, as medidas devem ser processadas em fase gasosa.

Testes de resistência à radiação ultravioleta $(\mathrm{UVA} / \mathrm{UVC})$ 
As amostras são colocadas em dois compartimentos contendo lâmpadas de radiação ultravioleta diferentes (UVC e UVA) de $8 \mathrm{~W}$, com distância de cerca de $10 \mathrm{~cm}$ entre a amostra e a lâmpada. A exposição do filme à ultravioleta inicialmente leva à perda dos radicais carbônicos e à formação de ligações cruzadas e, posteriormente, pode ocorre formação de $\mathrm{SiOH}$. Para avaliar se uma estrutura ou substrato, que não silício, foi influenciado pela ultravioleta, uma lâmina de silício deve ser utilizada para controle de processo e ser analisada por espectroscopia de infravermelho (FTIR).

\section{Análise de Topografia}

Para avaliar o filme na microestrutura utiliza-se microscopia óptica e, eventualmente, eletrônica de varredura.

\section{Teste de permeação}

Os testes são feitos para verificar permeação de íons no corpo do filme. Estes testes utilizam equipamentos, construídos em laboratório, que se baseiam em variações na medida de condutometria ou $\mathrm{pH}$, principalmente. Duas configurações são possíveis.

\section{- Testes em substrato flexível e permeável}

Para testar a influência na permeação de íons pela presença do filme sobre um substrato flexível e poroso, mediu-se a variação da condutância em função do tempo e utilizaram-se soluções aquosas de sais e ácidos, principalmente.

Este experimento foi feito usando um produto ambientalmente correto: papel celofane BAITACA Ltda, como recebido ou recoberto em uma ou nas duas faces pelo filme fino a base de TEOS, ou seja, esse papel foi usado como suporte mecânico para o filme nanoporoso. Portanto, foi possível verificar qual a influência desse filme nanoporoso na permeação de íons em substrato flexível. Foram utilizados compostos iônicos e várias concentrações - $\mathrm{KCl}$ $(0,0114 \mathrm{M}), \mathrm{FeSO}_{4}(1 \mathrm{M})$ e $\mathrm{KMnO}_{4}(0,0125 \mathrm{M})$ - além de $\mathrm{HCl}$ a $\mathrm{NaOH}$ concentrados.

As medidas tiveram duração média de 25 minutos. Para medidas de reprodutibilidade a membrana (papel celofane) e o sistema foram lavados com água destilada. Na Figura 2.9, a seguir, encontra-se uma foto do arranjo formado. 


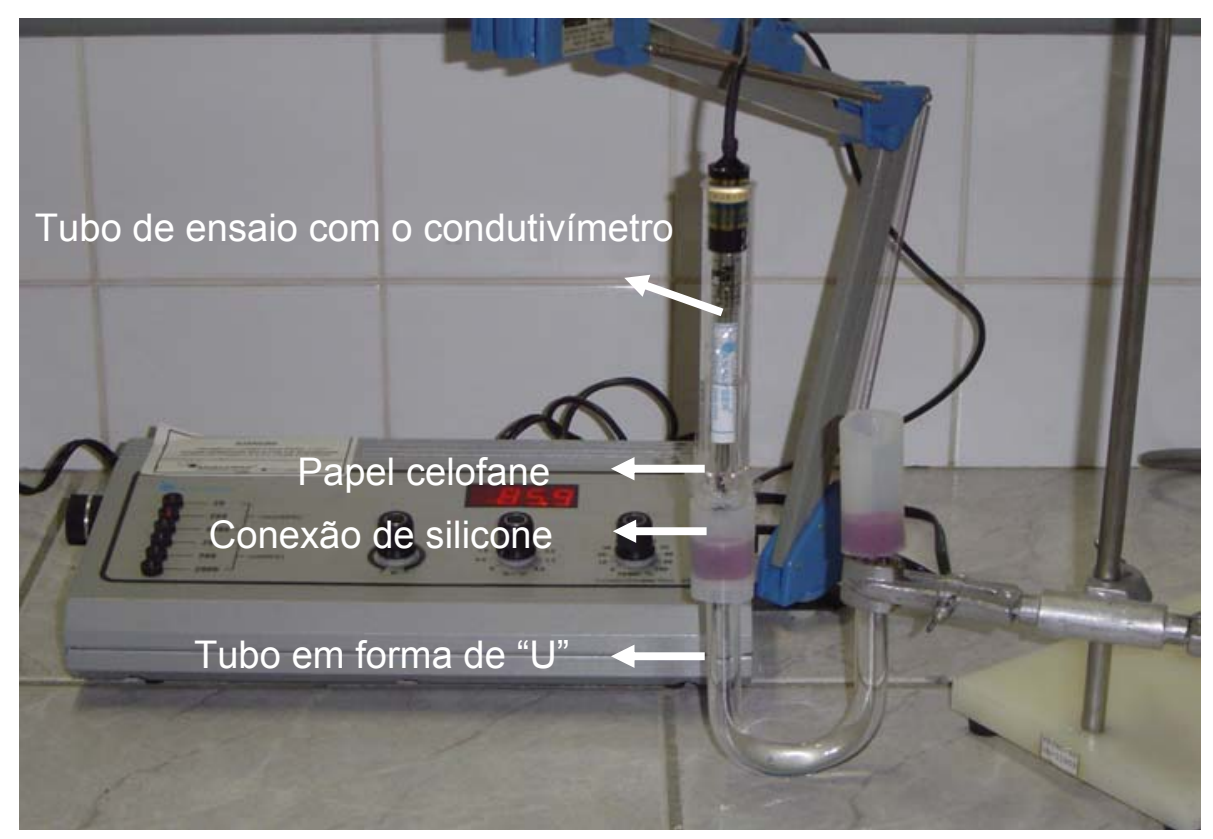

Figura 2.9. Arranjo experimental para testes de Condutividade.

O arranjo consiste essencialmente de um tubo de vidro em forma de "U", proveta que teve seu fundo removido com instrumento de corte - e conexões de silicone. Para o experimento utilizou-se também de suporte universal e garras, um condutivímetro e um cronômetro para medida do tempo.

As conexões de silicone são usadas somente para: a) fixação da proveta e do papel celofane e b) manutenção do nível de água. O tubo em "U" e a proveta separados pelo papel celofane, tratado ou não pela deposição de filme fino a base de TEOS, que atua como membrana seletiva.

O experimento foi realizado da seguinte forma:

- Enche-se completamente o tubo em "U”" com a solução desejada e fixa-se a proveta na extremidade do tubo, com as conexões de silicone. A separação das soluções é feita pelo papel celofane de modo a não deixar formar bolhas, que influenciam a permeação.

- Dentro da proveta, coloca-se a ponta de prova do condutivímetro e cobre-se seu sensor com água destilada. O uso de proveta permite adicionar sempre o mesmo volume de água.

O processo baseia-se na osmose, os íons da solução aquosa atravessam o papel celofane por diferença de concentração, já que a solução possui maior concentração de íons que a água destilada presente na proveta. Para evitar a variação de carga por diferença de 
pressão na membrana, igualou-se a altura dos níveis dos líquidos nos dois lados (tubo em "U" e proveta). A Figura 2.10 apresenta um detalhe do nível dos líquidos.

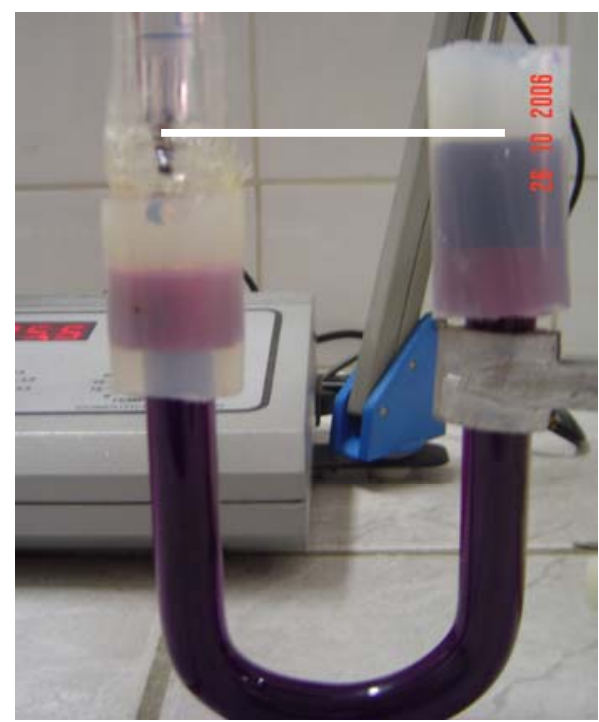

Figura 2.10. Detalhe do sistema utilizado quanto ao nível de solução aquosa de $\mathrm{KMnO}_{4}$ e de água.

Foram feitas no mínimo 6 análises com soluções de $\mathrm{KCl}, \mathrm{FeSO}_{4} \mathrm{e} \mathrm{KMnO}_{4}$, descritas a seguir. Como substratos utilizaram-se papel celofane sem o filme depositado e com o filme a base de TEOS depositado em uma ou nas duas faces do celofane.

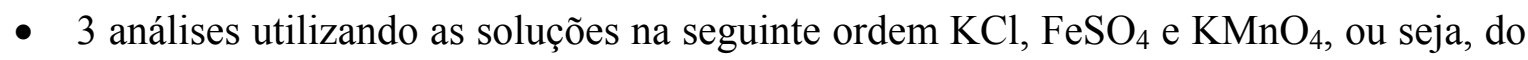
ânion de menor tamanho para o de maior.

- 3 análises do mesmo modo anterior só que na ordem de solução inversa $\mathrm{KMnO}_{4}$, $\mathrm{FeSO}_{4}$ e $\mathrm{KCl}$, e todas as análises passaram por novos testes de reprodutibilidade.

- Para comparação, efetuaram-se medidas utilizando-se também ácidos e bases. Para verificação da capacidade de condução de íons $\mathrm{H}^{+}$e $\mathrm{OH}^{-}$, foram feitas medidas utilizando-se pHmetro (pH300 - Analyser, Brasil) em arranjo experimental idêntico ao utilizado para as medidas de condutividade.

- Por fim, a permeação por reagentes orgânicos foi verificada utilizando-se solução aquosa $10 \%$ em massa de Azul de Metileno. Na proveta é colocado o corante e no tubo em “U”, água. A permeação é seguida utilizando-se câmera digital e cronômetro. 


\section{- Testes em substrato rígido e não permeável}

Lâminas de silício (100), 3" de diâmetro, Silicon Sense (EUA), foram utilizadas como substrato. Para efetuar-se o teste depositou-se por processo de evaporação um filme de 1000 Å de alumínio. Sobre o alumínio, fez-se a deposição de filme fino a base de TEOS em parte do filme de alumínio enquanto outra região foi recoberta, para posteriormente ser possível promover contato elétrico. A deposição do filme de TEOS sobre filme fino de alumínio permite testá-lo quanto à permeação de íons através do corpo do filme. O teste foi feito utilizando-se solução aquosa saturada de sulfato de cobre II e aplicando-se potencial elétrico entre a amostra e o substrato de alumínio utilizando-se fonte DC comum. Neste caso pode ocorrer uma reação eletroquímica.

\subsection{Reagentes e Materiais}

TEOS, um organossilicato de baixa pressão de vapor, massa atômica de 208 Daltons e baixa toxidade, é o principal reagente utilizado para este trabalho. Este reagente é fabricado pela Merck e o grau de pureza utilizado é o industrial. Todos os reagentes são P.A. (para análise), da Casa Americana, e utiliza-se água destilada para preparo de soluções e medidas. Para efetuar medidas em QCM foram utilizados 2-Propanol, Acetona, n-Hexano, n-Dodecano. Para medidas de condutividade foram utilizadas as soluções aquosas descritas previamente. Estas soluções foram produzidas por pesagem e padronizadas por titulação.

O principal substrato utilizado nas deposições é o silício $<100>10-20 \Omega \mathrm{cm}$, Silicon Sense, E.U.A. Também foram depositados filmes sobre cristais piezelétricos de quartzo de 4,096 MHz, 11,0 mm de diâmetro e 0,8 mm de espessura, fabricados pela Hosonic Industral do Brasil Ltda., para realização de medidas em QCM. 


\section{REFERÊNCIAS}

[1] Carvalho, R. A. M.; Obtenção de filme poroso, útil na determinação de umidade e proteção contra radiação ultravioleta. Dissertação (Mestrado). Escola Politécnica, Universidade de São Paulo, São Paulo, 2004.

[2] Silva, L. M. et al. Low cost microstucture for preconcentration of polar and non-polar organic compounds. Materials Forum. Portugal. 2006.

[3] Hernandez, L. F.; Uso de filme fino adsorvente para o desenvolvimento de sistemas de retenção de compostos orgânicos. Dissertação (Mestrado). Escola Politécnica, Universidade de São Paulo, São Paulo. 127p. 2006.

[4] Nascimento, A. P.; Fabricação de sistemas para retenção de compostos orgânicos presentes em fase gasosa ou líquida. Tese (Doutorado). Escola Politécnica, Universidade de São Paulo, São Paulo. 160 p. 2005.

[5] Santos, L. C. et al. Desenvolvimento de testes semi-automatizados de miniestruturas. Revista Brasileira de Aplicações de Vácuo. São José dos Campos. 25. 2. 75-81p. 2006.

[6] Carvalho, R. A. M. et al. Plasma Polymerized TEOS Films For Nanochannels Formation And Sensor Development. Sensors And Actuators B-Chemical. 108. 955. 2005. 


\section{RESULTADOS E DISCUSSÕES}

Neste capítulo são apresentados os resultados obtidos para o filme a base de TEOS, o comportamento deste em microcanais e membranas e, finalmente, prováveis dispositivos com este filme.

\subsection{Propriedades relevantes para filmes à base de TEOS}

Filmes obtidos pela polimerização por plasma de TEOS apresentam propriedades interessantes e que foram estudadas previamente [1], são elas: superfície hidrofóbica, que reage com água apenas se esta se encontra em grande concentração; formação de filmes nanoporosos pela reação com água; reação de cross-link e/ou oxidação quando submetidos à radiação ultravioleta. Estas propriedades são altamente dependentes da concentração de radicais carbônicos presentes no filme e, em trabalho anterior, tais filmes foram obtidos em dois reatores distintos, ambos alimentados por fonte de 13,56 MHz, mas com eletrodo interno ou externo. Eletrodo interno privilegia bombardeamento, o que reduz a concentração de radicais carbônicos e diminui a formação de nanocanais. Contudo, filmes menos porosos podem ser úteis na passivação de eletrodos. Assim, tais filmes foram testados quanto à aderência em substratos e permeação de íons, propriedades não determinadas previamente. Filmes com alta concentração de carbono só serão úteis no desenvolvimento de sensores se apresentarem boa cobertura de degrau, mesmo em substratos flexíveis, o que também foi determinado neste trabalho uma vez que não havia sido estudado anteriormente.

\subsubsection{Filmes com baixa concentração de radicais carbônicos}

O reator utilizado está descrito na metodologia e possui eletrodos internos, planares e alimentados por fonte de 13,56 MHz. 
Testes de aderência e proteção superficial

Testes de aderência sobre acrílico foram feitos utilizando-se uma fita adesiva pouco aderente colada sobre o substrato para formação de uma região sem filme. Após a deposição do filme sobre o acrílico, a fita adesiva foi removida. Uma gota de acetona foi depositada sobre a interface da região com e sem filme. O resultado foi a reação da acetona com o substrato acrílico somente na região sem filme. A Figura 3.1. apresenta a superfície do acrílico após a reação com a acetona, onde é possível observar que o filme impediu a corrosão de continuar e manteve uma clara divisão na interface, demonstrando sua boa aderência e proteção superficial.

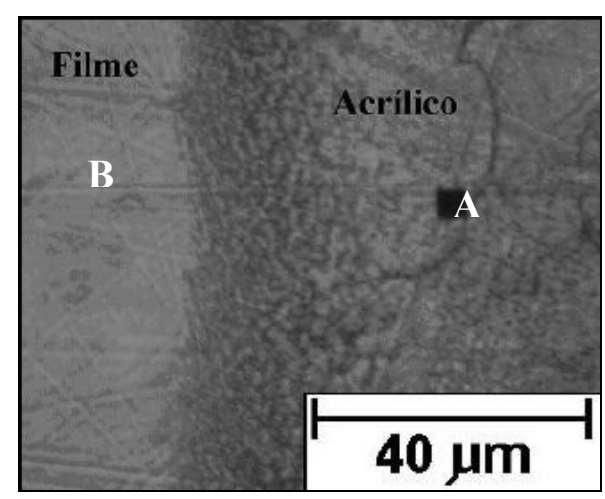

Figura 3.1. Superfície do acrílico com (A) e sem (B) reação com a acetona, devido à proteção conseguida pela deposição do filme (20 sccm de TEOS, $90 \mathrm{sccm}$ de Argônio, $150 \mathrm{~W}$ de potência, pressão de 1 Torr, 5 minutos e temperatura ambiente).

\section{Permeação de íons}

Para teste de permeação de íons o filme foi depositado sobre filme fino de alumínio com uma região do alumínio coberta por um caco de silício para formação de um degrau (região sem filme). Uma gota de solução aquosa saturada de sulfato de cobre II foi depositada sobre o filme e potencial de $4 \mathrm{~V}$ foi aplicado entre a gota e o alumínio (polo negativo), através de contatos. Notase, então, a passagem de corrente quando ocorre a permeação dos íons de cobre pelo corpo do filme. A Figura 3.2. apresenta resultado típico para a superfície do alumínio após a aplicação de potencial elétrico. 


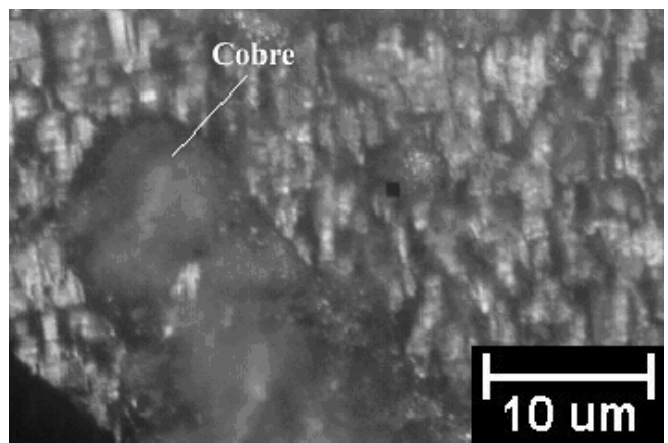

Figura 3.2. Superfície do alumínio após a aplicação de potencial elétrico $(20 \mathrm{sccm}$ de TEOS, 90 sccm de Argônio, $150 \mathrm{~W}$ de potência, pressão de 1 Torr, 5 minutos e temperatura ambiente).

Portanto, os resultados obtidos quanto à permeação de íons e resistência à corrosão indicam que, por não haver grande formação de nanocanais, o filme pode ser útil para a fabricação de sensores ou equipamentos de análise miniaturizados ( $\mu \mathrm{TAS}$ ), como proteção (passivação) de detetor do seguinte modo:

- em medidas ópticas, pois adere em acrílico, é transparente, protege de compostos orgânicos e da radiação ultravioleta, além de possuir superfície hidrofílica em contato com água. Nesse caso, dispositivos miniaturizados que possuam partes ópticas, como lentes, podem se beneficiar da deposição à temperatura ambiente já que por tratar-se de deposição química pode apresentar vantagens se comparado à espirramento catódico (sputtering), como por exemplo, deposição conforme e com alta razão de aspecto;

- em medidas eletroquímicas, pois o filme permite a permeação de íons. A permeação de íons é mais simples que sua posterior remoção, como será visto posteriormente; assim, tal uso restringe-se a sensores descartáveis. Uma possível utilização é para medidas de amostras biológicas, que são complexas e exigem que o pré-tratamento de amostra também remova moléculas de alto peso molecular, como será abordado ainda neste capítulo.

\subsubsection{Filmes com alta concentração de radicais carbônicos}

O reator utilizado está descrito na metodologia e possui eletrodos externos, tubulares e alimentados por fonte de 13,56 MHz. Estes filmes foram previamente caracterizados e, para alta 
concentração de carbono, os filmes apresentam, após imersão em água por no mínimo 60 minutos, uma estrutura porosa [1]. Assim, é necessário avaliar três outras importantes propriedades: deposição em topografia não planar (microcanais), aderência em substrato flexível (celulose) que sofrerá deformação mecânica, além de permeação de íons sob potencial elétrico.

\subsubsection{Deposição em topografia não planar}

Quanto à deposição em topografia não planar, o filme foi depositado sobre uma estrutura tridimensional em formato espiral. Essa estrutura, proposta por Lima [2], foi analisada por Silva [3] quanto ao seu comportamento para retenção de compostos orgânicos voláteis (VOC's) quando um filme adsorvente encontra-se depositado em sua superfície. Silva demonstrou que a estrutura apresenta baixa dispersão lateral do fluxo tanto em fase gasosa como líquida, o que a indica para análise da adsorção de compostos na superfície de filmes finos. Assim, esta estrutura também pode ser usada como coluna cromatográfica, caso o filme adsorvente comporte-se adequadamente como fase estacionária.

A estrutura foi usinada em acrílico e/ou metal (alumínio e latão). Embora os substratos utilizados para fabricação dos microcanais, acrílico e alumínio, não apresentem adsorção dos reagentes testados, uma boa cobertura da superfície é necessária para garantir a reprodutibilidade do dispositivo, pois, por exemplo, se a fase estacionária não cobre totalmente a superfície das colunas capilares, o cromatograma pode apresentar "caudas", ou seja, a curva é assimétrica devido a duas interações distintas ocorrerem simultaneamente: na fase estacionária e no suporte (substrato) [4]. Filmes finos obtidos pela polimerização por plasma de TEOS apresentam boa cobertura de degrau de topografias irregulares, como em produtos naturais [5], e, portanto, foram realizados testes para assegurar que a estrutura tridimensional pode ser reprodutivelmente recoberta pelo filme.

Para garantir que os microcanais usinados em acrílico foram completamente cobertos pelo

filme à base de TEOS, estes microcanais foram mergulhados em acetona e analisados por microscopia óptica. Microcanais não tratados foram também mergulhados em acetona, apenas para comparação. A Figura 3.3 apresenta os resultados típicos para este teste. Como pode ser visto na Figura 3.3 A, superfícies não tratadas reagem facilmente com acetona, mas a tratada não 
reage (Figura 3.3 B). A microscopia óptica mostra também uma superfície menos transparente, o que denota que o filme permanece sobre a superfície do microcanal (detalhe na Figura 3.3 B).

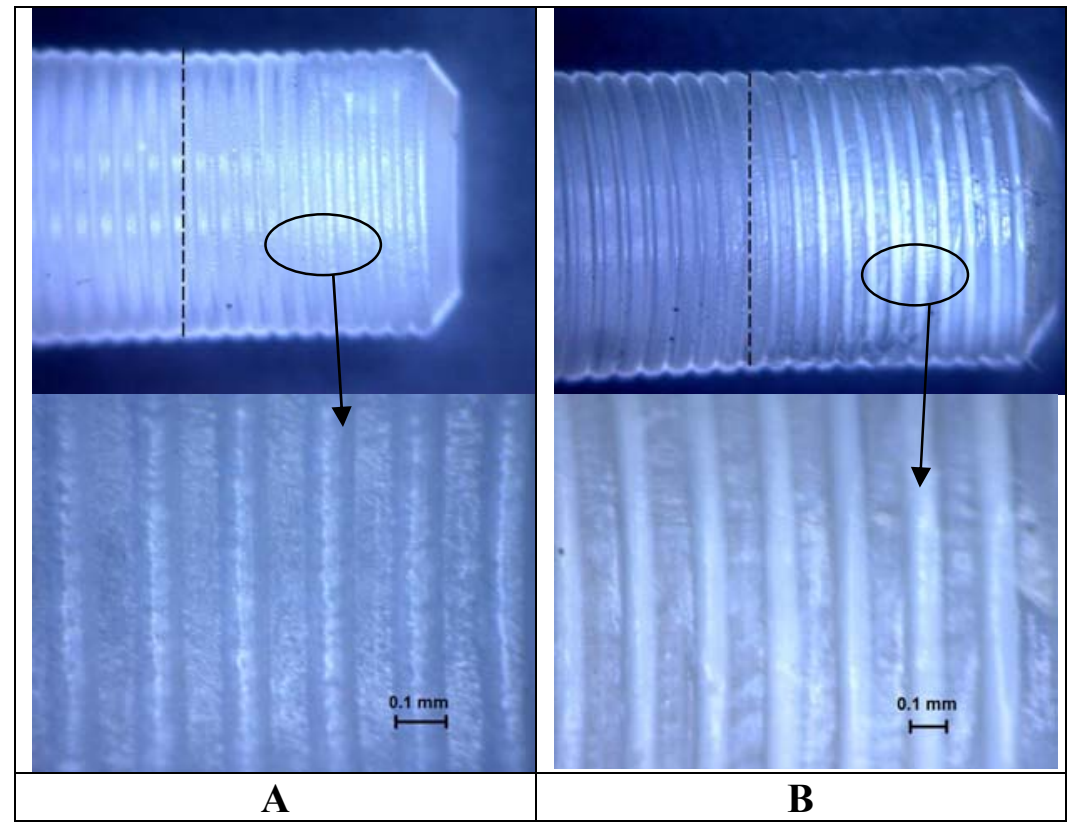

Figura 3.3. Microscopia óptica do microcanais após mergulho em acetona para estrutura sem filme (A) e com filme (B).

O recobrimento dos microcanais usinados em alumínio foi testado pela aplicação de potencial elétrico em microestrutura. Para tanto a microestrutura, formada por núcleo metálico e envoltório em acrílico, foi conectada ao sistema descrito em Materiais e Métodos. Este sistema pode ser usado para bombear ar ou água, portanto, após a reação com água é possível remover o excesso desta presente nos microcanais sem mudança no setup.

A água foi bombeada através da estrutura e um pulso de $10 \mu \mathrm{L}$ de solução aquosa saturada de sulfato de cobre II foi inserido, utilizando-se uma seringa. Um potencial de $5 \mathrm{~V}$ foi aplicado entre o núcleo da microestrutura e a tubulação de aço inoxidável da saída (núcleo encontra-se negativo). As figuras 3.4 e 3.5 apresentam microscopia óptica da tubulação de entrada e do núcleo da microestrutura, feito em alumínio, respectivamente. 


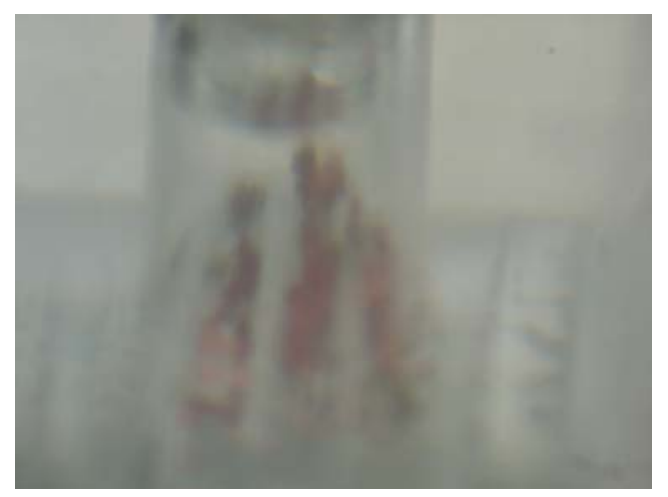

Figura 3.4. Tubulação de entrada da estrutura.

Nota-se através da Figura 3.4 que ocorreu a formação de cobre muito próxima à tubulação de inox, onde foi aplicado o potencial elétrico, porém não na parte externa da microestrutura, que é fabricada em acrílico.

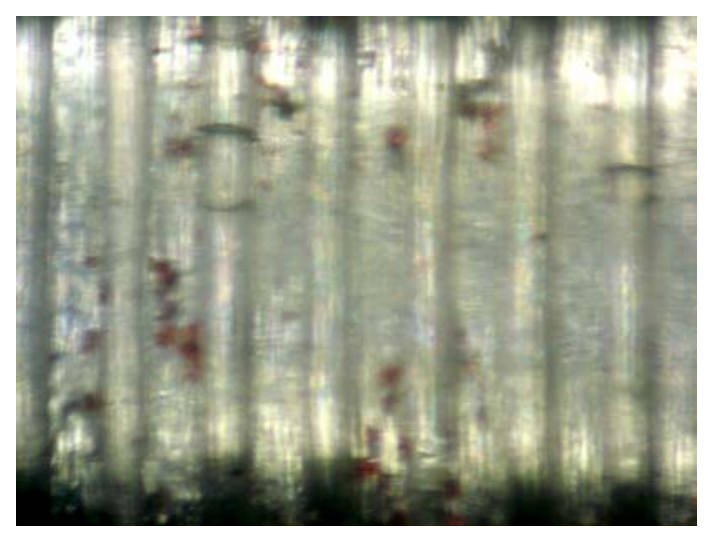

Figura 3.5. Núcleo de alumínio da microestrutura após aplicação de potencial elétrico.

A Figura 3.5 mostra um núcleo de alumínio parcialmente recoberto por clusters de cobre, porém, o aparecimento destes núcleos exige a aplicação de potencial elétrico por vários minutos (> 5min.). Como a reação entre alumínio e íons de cobre é espontânea, caso o filme não estivesse recobrindo a superfície deveria ocorrer uma reação apenas por imersão na solução, não requerendo a aplicação de potencial elétrico. Além disso, essa reação deveria ocorrer homogeneamente em toda a extensão do canal, ou seja, sem a formação de cluster.

A Figura 3.6 apresenta em maior detalhe o perfil do núcleo da microestrutura em alumínio, visto por microscopia óptica, após exposição. É possível observar que a deposição do filme apresenta boa cobertura de degrau e aderência à estrutura. 


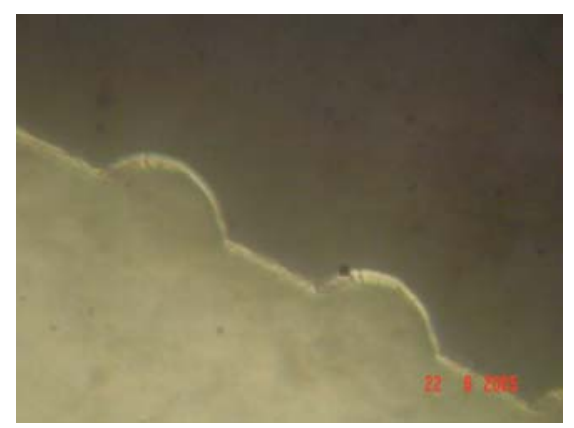

Figura 3.6. Análise por microscopia óptica após deposição do filme nos microcanais usinados $(150 \mathrm{X})$.

Portanto, é possível a fabricação de microcolunas, com microcanais de alumínio e acrílico, e a deposição de um filme fino de TEOS obtido pela polimerização por plasma, conforme, com boa cobertura de degrau e aderente ao substrato.

As estruturas também foram testadas quanto à integridade. Para tanto, utilizou-se a passagem de gás nitrogênio (fase gasosa) ou água (fase líquida) e ambas as possibilidades de construção (acrílico/acrílico - acrílico/metal) mostraram boa selagem.

\subsubsection{Deposição em substrato flexível e poroso}

Testes foram processados para avaliar se o filme fino à base de TEOS mantinha-se em um substrato flexível, após a deformação deste. O teste avaliou a passagem de compostos orgânicos e inorgânicos. Como composto orgânico de teste utilizou-se azul de metileno por ser este solúvel em água, colorido e com massa molecular menor que 1 mil Daltons, ou seja, pode ser usado como traçador [6] para simular moléculas pequenas em amostras biológicas. Os testes usaram solução aquosa $10 \%$ em massa de azul de metileno. Como compostos inorgânicos foram utilizados íons em solução aquosa, como explicado em Materiais e métodos. As soluções aquosas foram testadas de duas maneiras distintas: por difusão dos íons ou pelo uso de potencial elétrico como força dirigente (driving force).

A Figura 3.7 mostra a variação de cor pela passagem do azul de metileno pela celulose, modificada ou não com filme fino à base de TEOS. Inicialmente, para celulose não tratada é possível verificar a permeação do corante quase instantaneamente enquanto para celulose com 
um filme fino depositado em um dos lados o início da permeação é mais lento, ocorrendo em cerca de cinco minutos. Contudo, para um tempo de observação de cerca de uma hora não há variação, com celulose tratada ou não e exposta ou não ao UV. Esse resultado é esperado, pois nestas condições o filme deve estar completamente hidrolisado, como será comentado posteriormente.

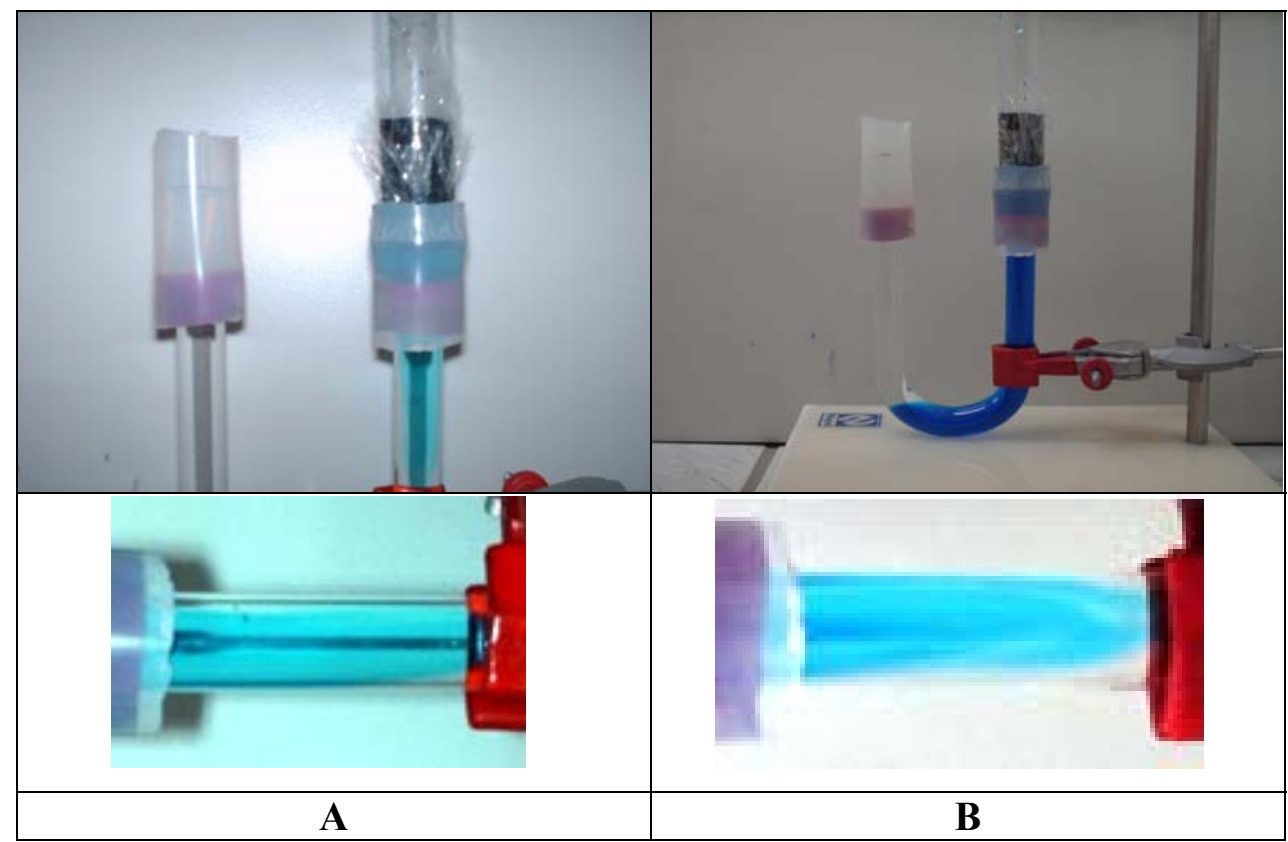

Figura 3.7. Variação de cor pela passagem da solução de azul de metileno para (A) celulose e (B) celulose modificada e respectivos detalhes.

Para permeação de íons procedeu-se à aplicação de potencial elétrico utilizando película de alumínio, como descrita na metodologia, em celulose modificada ou não com filme a base de TEOS. A Figura 3.8 mostra o arranjo montado. Aplicou-se inicialmente potencial elétrico negativo na região com água e posteriormente positivo e após intervalos de cerca de 3 minutos a condutividade foi medida. Deste modo, pode-se avaliar a permeação dos íons positivos (cátions) e negativos (ânions). A medida foi processada por cerca de 2 horas e, após tais medidas, o conjunto foi fotografado. A Figura 3.9 mostra foto do conjunto após a aplicação do potencial elétrico. É possível observar que não só ocorreu a passagem de íons de cobre como também a redução deste, devido ao potencial elétrico aplicado.

O uso do mesmo arranjo, mas sem a aplicação da tensão, não favorece a passagem dos íons por longo tempo (até meia hora) quando a celulose é tratada com filme a base de TEOS em ambos os lados. Esse resultado é coerente com medidas obtidas em estudo anterior [1]. 


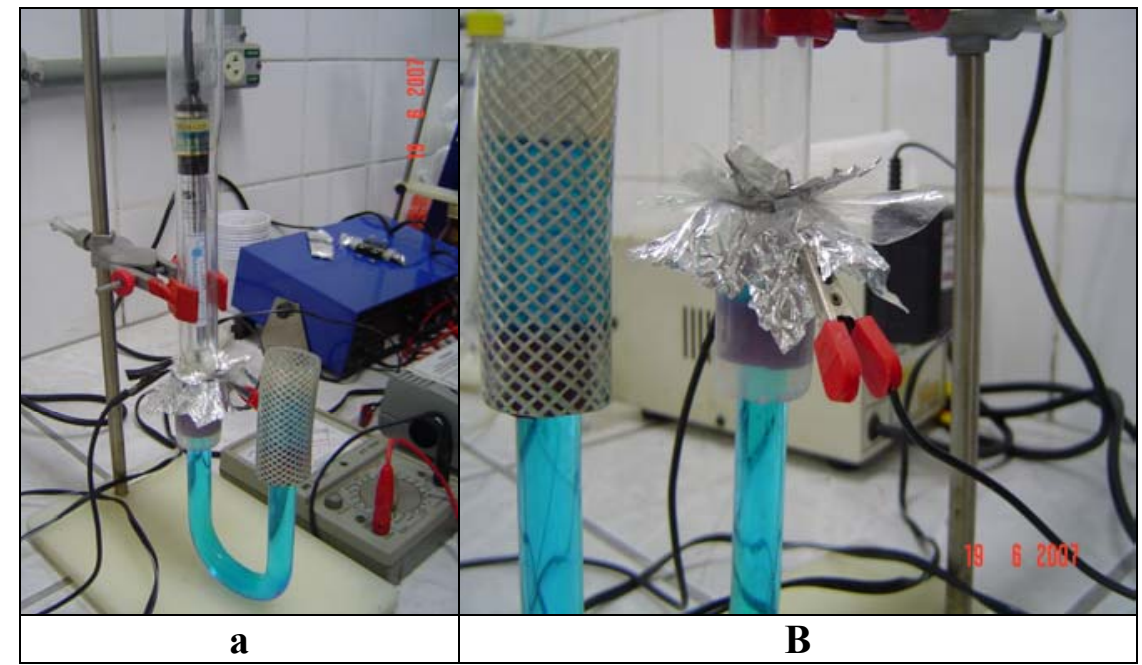

Figura 3.8. Arranjo montado para aplicação de potencial elétrico, utilizando película de alumínio, na membrana de celulose, modificada ou não com filme a base de TEOS, e solução aquosa saturada de sulfato de cobre II: (a) arranjo e (b) detalhe da aplicação de potencial elétrico.

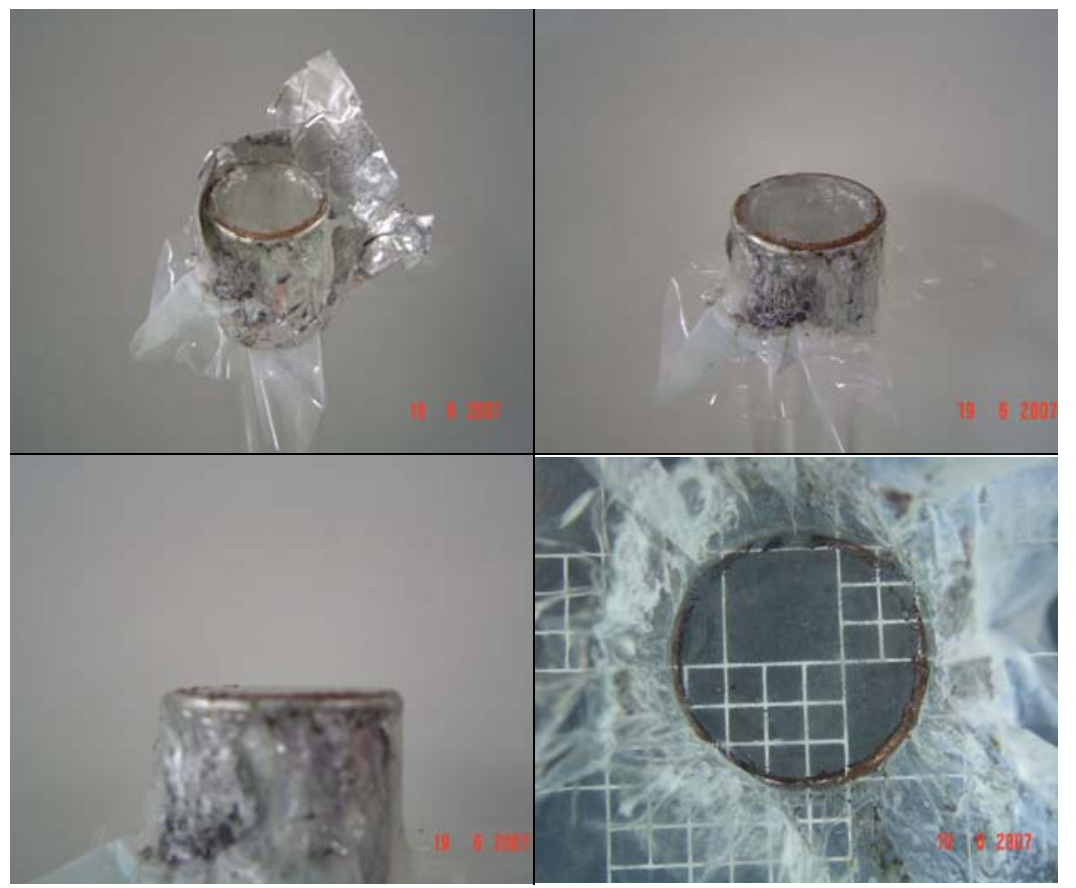

Figura 3.9. Fotos da região da membrana e das películas de alumínio após a aplicação do potencial elétrico. 


\subsubsection{Deposição em substrato rígido e não poroso}

O teste de difusão consistiu na imersão da amostra do filme fino, depositada sobre silício, em solução aquosa saturada de sulfato de cobre II e avaliação por FTIR. O filme foi monitorado, a cada 5 minutos, durante uma hora de imersão. Obteve-se uma banda em $640 \mathrm{~cm}^{-1}$ após esse tempo, mas esta pode ser facilmente removida por dip em água. Portanto, a difusão não é privilegiada nesses nanocanais. A Figura 3.10 apresenta FTIR típico.

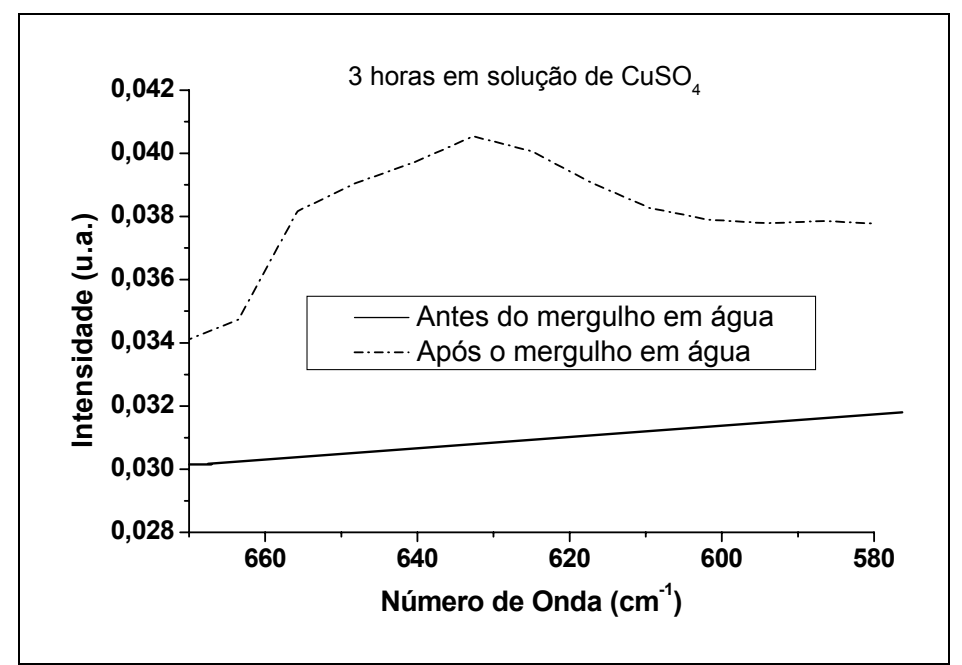

Figura 3.10. Espectro típico para imersão em solução aquosa saturada de sulfato de cobre II.

O teste de permeação de íons utilizou como amostra filme fino de alumínio depositado sobre silício e recoberto por filme a base de TEOS. A permeação é testada pela aplicação de tensão, nesse caso $4 \mathrm{~V}$, entre o alumínio (contato negativo) e solução aquosa saturada de sulfato de cobre II.

Como já mencionado, a permeação de cobre permite que este atinja o alumínio, reaja e deposite na forma metálica. Ocorreu a passagem de corrente pelo sistema, fato não observado quando o teste é feito com água deionizada, e a formação de clusters de cobre no filme, como mostra a Figura 3.11. 


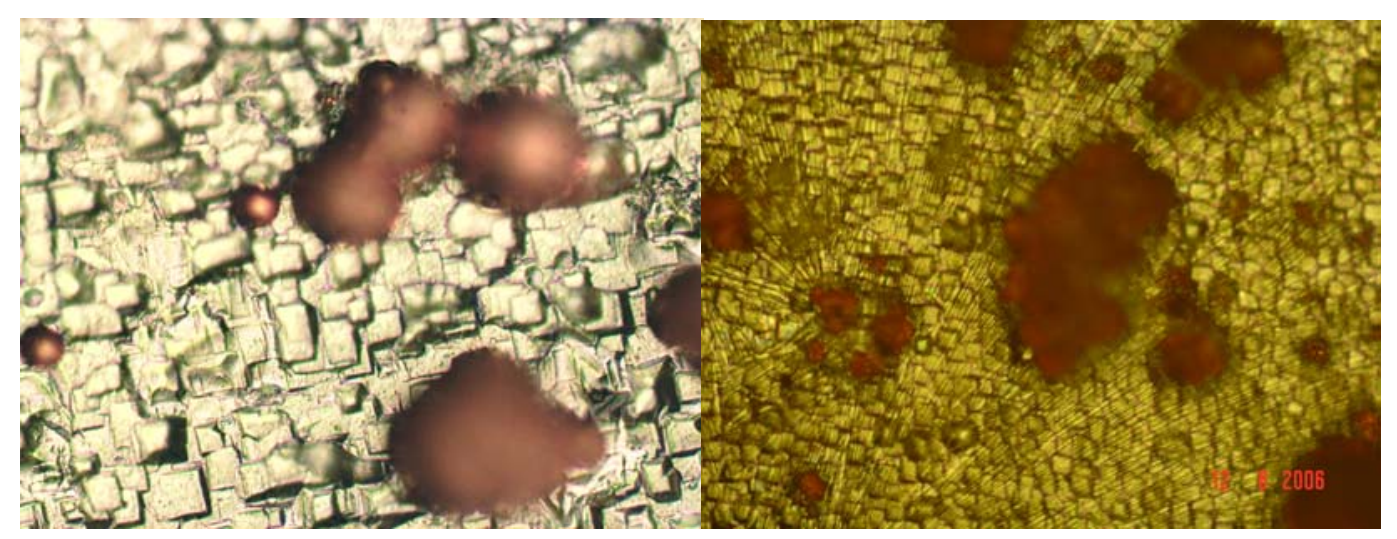

Figura 3.11. Clusters de cobre formados através da aplicação de potencial elétrico em solução aquosa saturada de sulfato de cobre II.

O filme com clusters de cobre foi submetido à análise MEV (Microscopia Eletrônica de Varredura) com EDS (Energy Dispersive X-ray analysis). A Figura 3.12 apresenta um espectro das principais espécies presentes na amostra. Para comparação o filme de TEOS foi depositado sobre silício e mergulhado em solução de sulfato de cobre por uma hora, e seco em jato de nitrogênio. A Figura 3.13 apresenta o resultado da análise.

Enquanto a Figura 3.12 apresenta a detecção simultânea de picos de enxofre e cobre, indicando que provavelmente ocorreu a permeação de sulfato de cobre no filme, a Figura 3.13 não mostra a presença de cobre sobre o filme após o mergulho. Portanto, o filme a base de TEOS é útil na permeação de íons se uma diferença de potencial é aplicada.

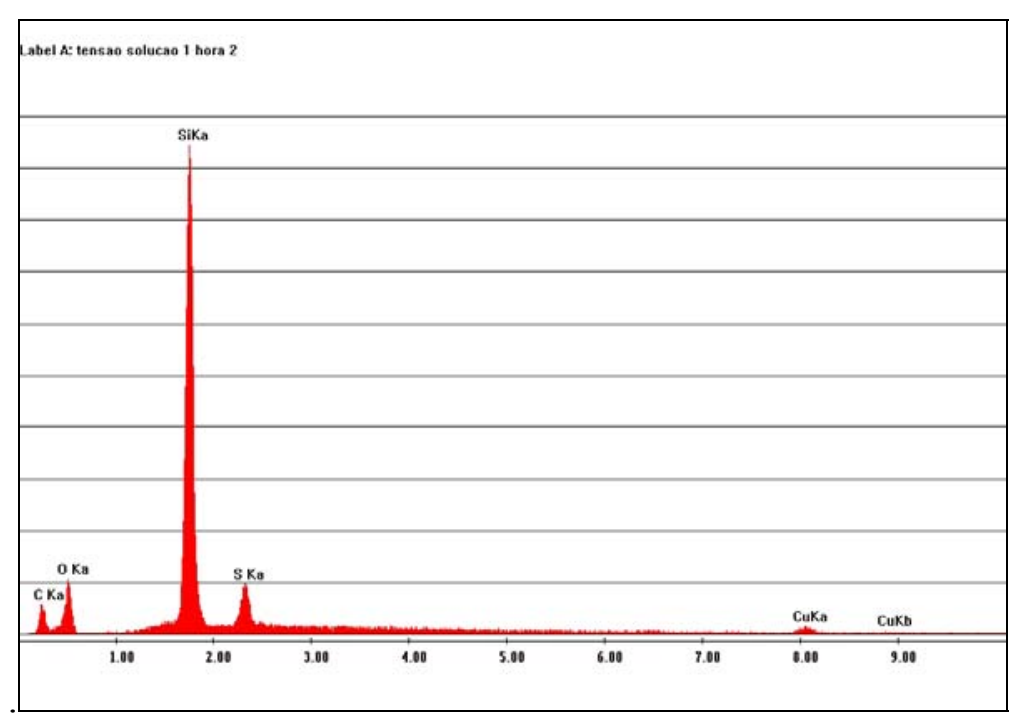

Figura 3.12. Espectro de EDS das principais espécies presentes após aplicação de potencial elétrico. 


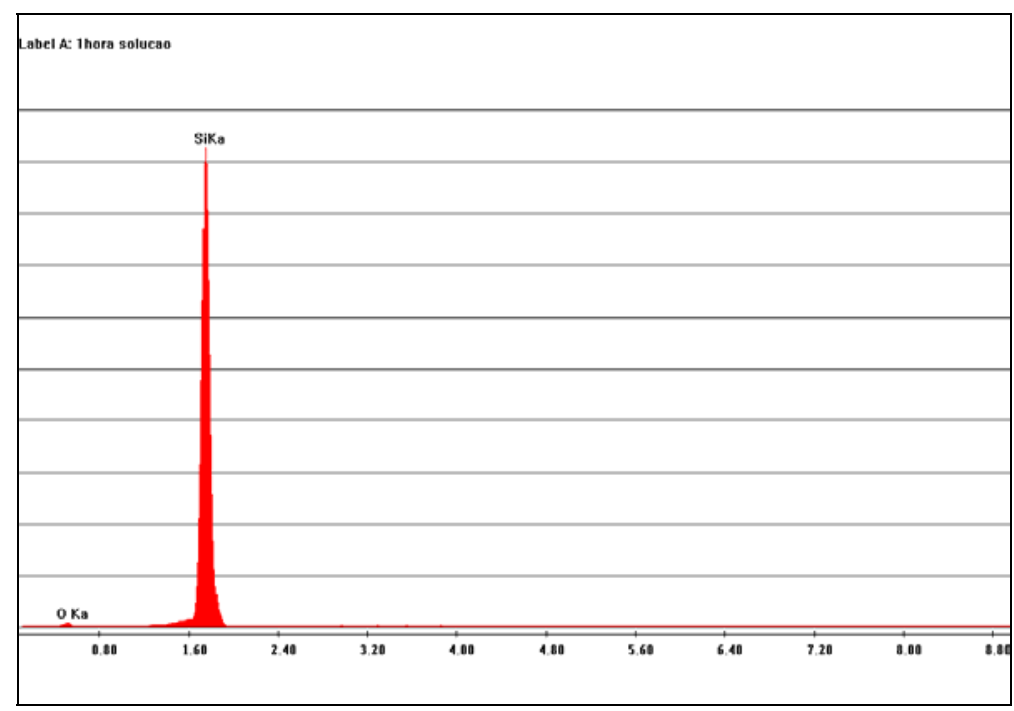

Figura 3.13. Espectro de EDS das principais espécies presentes após mergulho na solução aquosa de sulfato de cobre II.

Os filmes obtidos com nanocanais são úteis, provavelmente, no desenvolvimento de dispositivos baseados na adsorção/permeação de compostos orgânicos e/ou inorgânicos, o que exige um melhor modelamento do comportamento desses compostos nesse filme, tanto na superfície quanto no corpo. Além disso, o filme a base de TEOS permite que substratos flexíveis se comportem, dentro de um pequeno intervalo de tempo, como membranas seletivas uma vez que o azul de metileno não permeia tão rápido pelo substrato, ou seja, provavelmente é possível fazer dispositivos para pré-tratamento de amostras baseado na retenção seletiva de compostos. 


\subsection{Modelamento do comportamento do filme à base de TEOS}

Testes foram efetuados para determinar o comportamento do filme tanto em estruturas (microcanais) como em membranas (celulose) para determinar os mecanismos físico-químicos ocorrendo nestes casos.

As medidas processadas nesse trabalho são bastante dependentes da microbalança de quartzo, portanto, algumas considerações sobre o modo de análise dos resultados obtidos com esta técnica são feitas a seguir.

A microbalança de quartzo (QCM) foi utilizada como um detetor, porém não específico, de modo semelhante ao que ocorre em um cromatógrafo. Nesta técnica a variação de freqüência é proporcional à massa retida sobre o cristal piezelétrico de quartzo. Assim, o resultado é sempre apresentado como uma variação de freqüência $(\Delta \mathrm{F})$ em função do tempo. A variação normalmente é negativa porque a freqüência diminui com a adsorção de compostos na superfície do cristal; contudo, em alguns casos, observa-se uma variação positiva, pois para melhorar a sensibilidade da técnica, um filme adsorvente é depositado sobre o cristal e este pode reter alguns compostos por longo tempo. No presente caso, isto ocorre especialmente se compostos orgânicos apolares estão sendo testados em fase líquida, onde o líquido carregador - o equivalente da fase móvel em cromatografia - é água. A maior afinidade do solvente pelo filme torna muito difícil remover o composto mesmo que a água for utilizada por vários minutos.

A forma do pico obtido por esta técnica, neste caso, depende de uma série de fatores, de modo semelhante ao que ocorre em cromatografia de acordo com o método de inserção/eluição de amostra (Anexo 1). Caso pequenas quantidades de amostra sejam utilizadas, provavelmente o formato da curva do composto removido é próximo de uma gaussiana, devido à dispersão do fluído na fase móvel ao longo do caminho (eddy diffusion). Neste caso o tempo que a mostra exige para atingir o detetor (tempo de retenção) indica se houve maior ou menor interação com o filme. Se uma grande quantidade de amostra é inserida, o comportamento de escoamento desta amostra dentro da fase móvel pode apresentar uma grande liberação (variação grande na freqüência) seguida de mudança mais lenta, o que é compatível com a existência de dois modos de percurso de fluído: um com pouca interação, por dificuldade de atingir a superfície devido ao regime de escoamento no canal, e outro com maior interação com a superfície do filme. Neste caso a avaliação da área, se comparada a uma medida sem a existência do filme, permite estimar 
a quantidade de amostra que é retida neste filme. Adição de amostras seqüencialmente (uma inserção de amostra seguida pela adição de outras, com compostos distintos da primeira) permite avaliar a afinidade da primeira amostra pelo filme e, também, pelo formato da curva e sua área se é possível pré-concentrar tal composto. Assim, torna-se possível entender os principais mecanismos físico-químicos que estão ocorrendo, mesmo que apenas qualitativamente.

Portanto, o sinal da microbalança de quartzo, o tempo para obtê-lo e seu formato pode mudar por uma série de motivos alguns inerentes aos processos de interação do filme com a amostra outros pertinentes ao modo de inserção desta amostra.

\subsubsection{Filme fino depositado em microcanais tridimensionais}

Esses filmes foram testados tanto em fase gasosa como em fase líquida, para adsorção de compostos orgânicos e para a retenção de compostos iônicos.

\subsubsection{Testes em fase gasosa}

As estruturas foram utilizadas, após a deposição de filme à base de TEOS na superfície, de modo similar às colunas cromatográficas. Para tanto foram conectadas ao sistema de medição QCM em fase gasosa e medidas de variação de freqüência foram feitas admitindo-se seqüencialmente n-hexano, 2-propanol e água, sempre nesta ordem. A importância da ordem de admissão deve-se à polaridade das moléculas. No cristal utilizado como sensor utiliza-se um filme adsorvente à base de HMDS. O filme à base de TEOS foi depositado em condições que favorecem a maior formação de radicais carbônicos.

A medida consistiu na injeção de um pulso do reagente no gás carregador, no caso nitrogênio ou ar. Os valores usados para os pulsos foram de $50 \mu \mathrm{l}$ para todos os reagentes $(33 \mathrm{mg}$ para n-hexano, $40 \mathrm{mg}$ para 2-propanol e $50 \mathrm{mg}$ para água). $\mathrm{O}$ alto volume admitido permite saturar a superfície do filme e avaliar seu comportamento físico-químico. 


\section{Referência}

Para avaliação das estruturas modificadas pela deposição do filme fino, faz-se necessária a definição de valores de referência; portanto medidas iniciais dos valores de QCM sem a adição da estrutura e de uma estrutura sem filme depositado foram feitas utilizando nitrogênio como gás de arraste. Resultados típicos são mostrados nas figuras 3.14 e 3.15 .

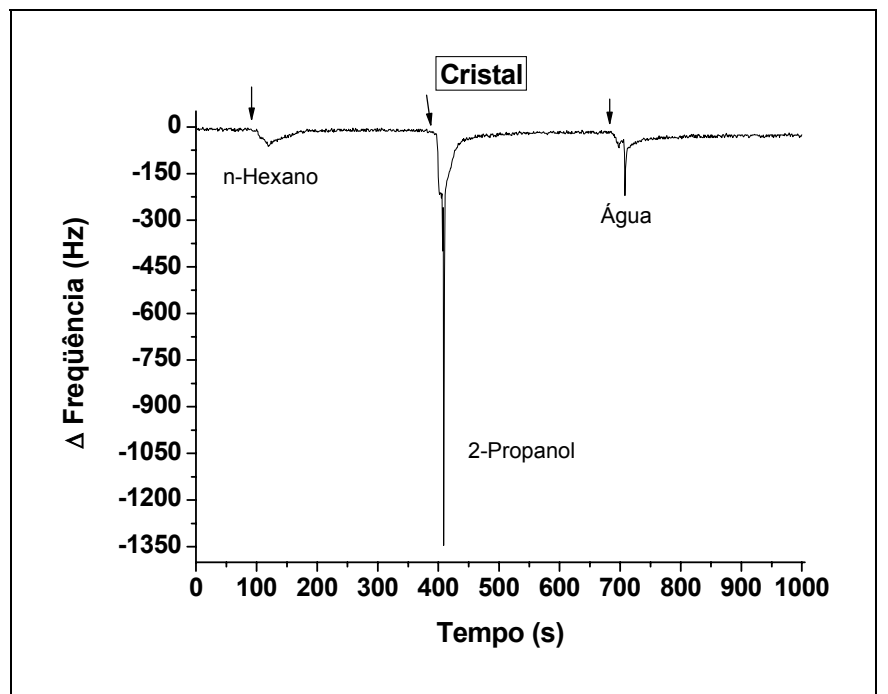

Figura 3.14. Medidas de QCM sem estrutura e nitrogênio como gás de arraste. As setas indicam o momento da injeção dos reagentes.

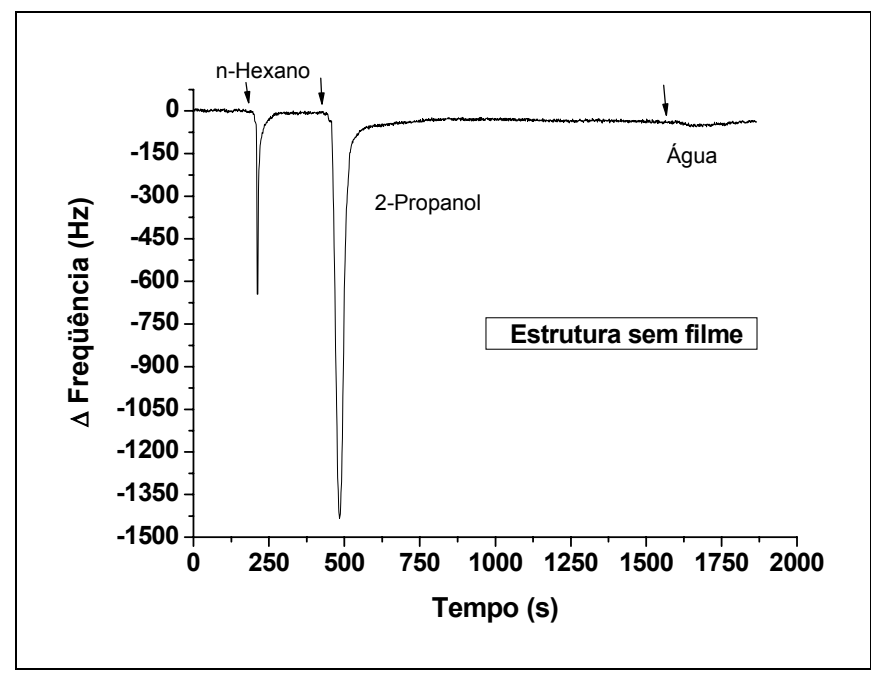

Figura 3.15. Medidas de QCM com estrutura sem filme e nitrogênio como gás de arraste. As setas indicam o momento da injeção dos reagentes. 
Os altos valores obtidos ( $\Delta \mathrm{F}$ muito maior que $100 \mathrm{~Hz})$ são esperados devido à grande quantidade de amostra inserida. É importante notar que para qualquer das figuras o pulso apresenta-se bem definido e com formato aproximado de gaussiana, como esperado em um sistema de cromatografia, exceção à água inserida na microestrutura. $\mathrm{O}$ tempo decorrido entre a inserção do composto e sua detecção (tempo de retenção) é curto para qualquer composto antes da inserção da estrutura. Quando a microestrutura está presente a remoção de n-hexano é rápida ( 100 s), pois não há interação com a superfície de acrílico. Para 2-propanol o tempo é ligeiramente maior o que torna o formato do pico mais amplo, água, porém, apresenta maior interação e sua remoção demora, dificultando a determinação do pico.

\section{Filme "como depositado"}

As medidas feitas no microcanal com filme depositado, mas antes deste com a reação com a água, portanto antes da reação de hidrólise e formação de nanocanais, usou pulsos de reagentes e procedimentos idênticos aos da referência e resultados típicos são apresentados nas figuras $3.16,3.17$ e 3.18 .

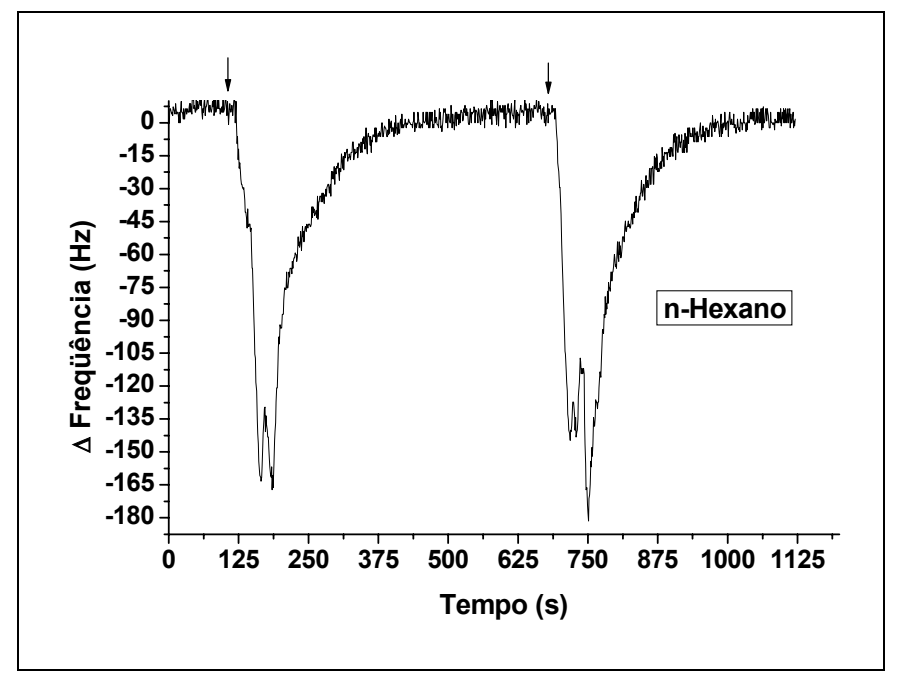

Figura 3.16. Variação de freqüência em função do tempo para injeção de n-hexano antes da reação com a água. As setas indicam o momento da injeção dos reagentes. 
Para n-hexano o tempo para o início da saída do reagente de dentro do microcanal é compatível com o obtido para a estrutura sem filme depositado, porém o pico é amplo, denotando interação com a superfície, provavelmente devido à nanocanais espúrios formados durante a deposição ou ao caráter hidrofóbico do filme. Os valores obtidos para duas inserções seqüenciais são similares $(\sim 160 \mathrm{~Hz})$, indicando que há reprodutibilidade na medida, ou seja, não há modificação da superfície significativa pela adição do composto e, provavelmente, a remoção é próxima de quantitativa.

Para 2-propanol não há reprodutibilidade do comportamento com a aplicação de dois pulsos seqüenciais: o primeiro mostrou, como esperado, valor mais baixo que para n-hexano, o que indica adsorção forte na superfície do filme.

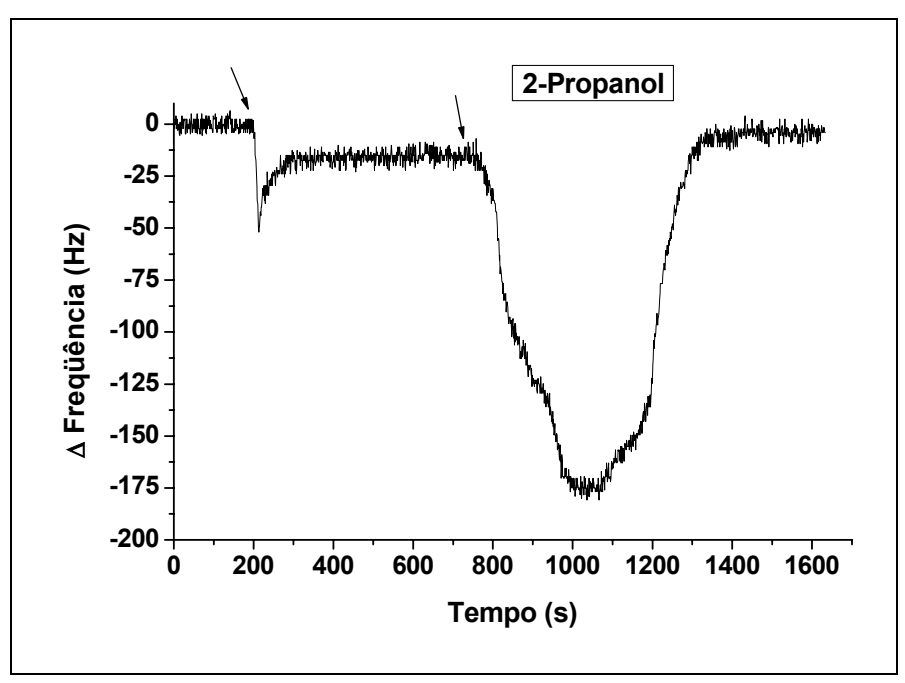

Figura 3.17. Variação de freqüência em função do tempo para injeção de 2-propanol antes da reação com a água. As setas indicam o momento da injeção dos reagentes.

Como os locais prováveis de adsorção, nesse caso, têm-se o oxigênio presente nos radicais carbônicos, O-Et, e no esqueleto, $\mathrm{Si}-\mathrm{O}-\mathrm{Si}$, do filme, pois o oxigênio do filme e o radical $\mathrm{OH}$ de 2-Propanol podem apresentar interações dipolo permanente/dipolo permanente. No segundo pulso houve grande variação, tanto do sinal como do formato da curva. A grande variação no sinal indica saturação da superfície do filme - ou mesmo a saída de n-Hexano anteriormente adsorvido, além disso, o grande intervalo de tempo para a saída do reagente indica grande interação com o filme. 


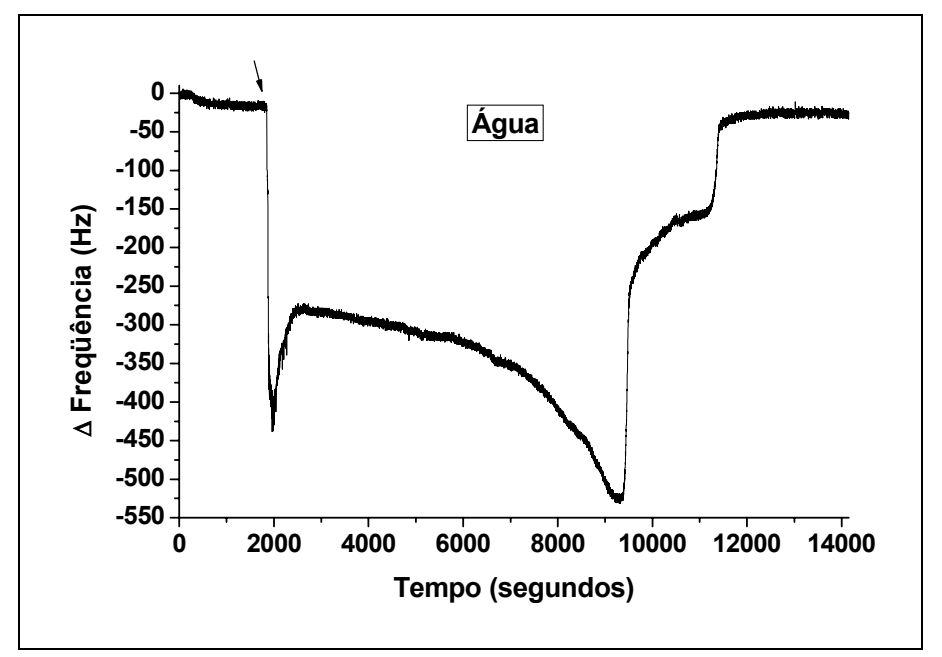

Figura 3.18. Variação de freqüência em função do tempo para injeção de água.

Para pulso de água a medida apresenta uma variação maior $(500 \mathrm{~Hz})$ que as anteriores e tempo muito longo de interação. A rápida queda inicial ( 2000 s) aparentemente denota que houve pouca interação com o filme, porém, o alto valor obtido não é esperado para a água (pulso com intensidade maior que o previsto), por fim nota-se que próximo a 3000 segundos a freqüência volta a cair - após pequena subida - provavelmente devido à competição entre a água e os reagentes inseridos anteriormente e também a início da reação de hidrólise. Assim, a água, mesmo em vapor apresenta interações fortes com o filme depositado na estrutura. Esse resultado não é totalmente similar às medidas obtidas com a deposição direta do filme sobre cristais piezelétricos (PQC) [1], o que demonstra que as pequenas dimensões podem estar favorecendo fenômenos secundários.

\section{Filme após a hidrólise}

Após as medidas iniciais a estrutura foi submetida à passagem de água na fase líquida durante 30 minutos, tempo mínimo necessário para a reação de hidrólise ocorrer significativamente, como avaliado por QCM (descrito posteriormente). Com este procedimento ocorre a formação de nanocanais, o que favorece a permeação dos contaminantes e aumenta o tempo de dessorção. Os testes para o filme hidrolizado seguiram os mesmos procedimentos que para filme "como depositado" e os resultados são apresentados nas figuras 3.19 a 3.23. 


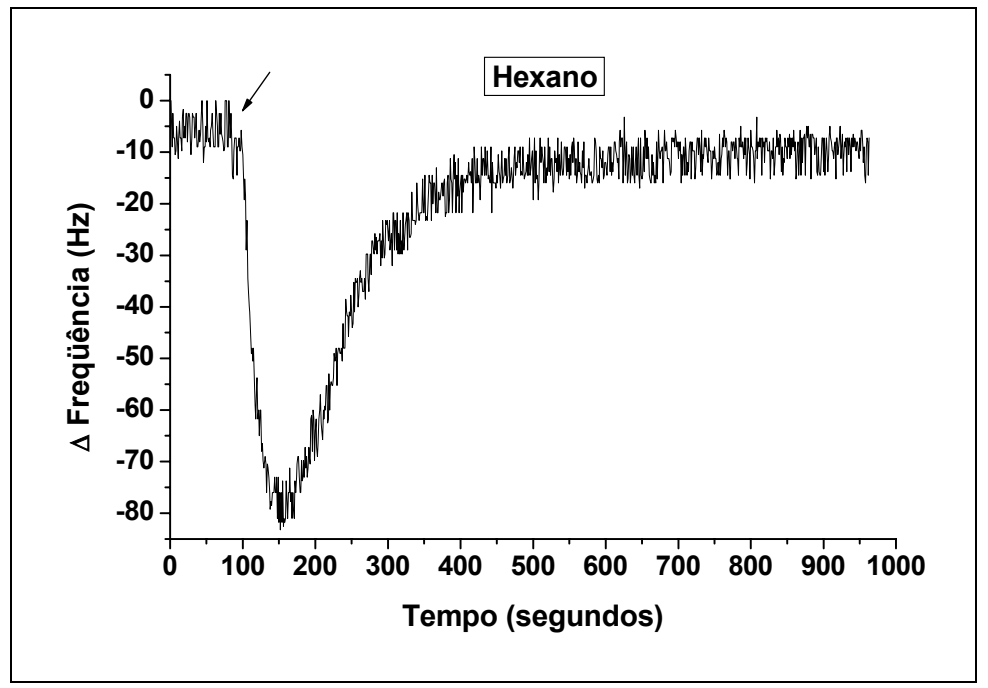

Figura 3.19. Variação de freqüência em função do tempo para injeção de n-Hexano após a reação com a água.

A injeção de n-Hexano após a reação com a água leva a obtenção de um pico com formato semelhante ao anterior (Figura 3.20) e no mesmo tempo de retenção, contudo a máxima variação de freqüência é cerca de duas vezes menor, assim, aparentemente apresenta ocorre uma adsorção maior, este resultado provavelmente se dá devido à retenção do n-Hexano nos nanoporos do filme, o que é corroborado com a adição de 2-Propanol em seqüência.

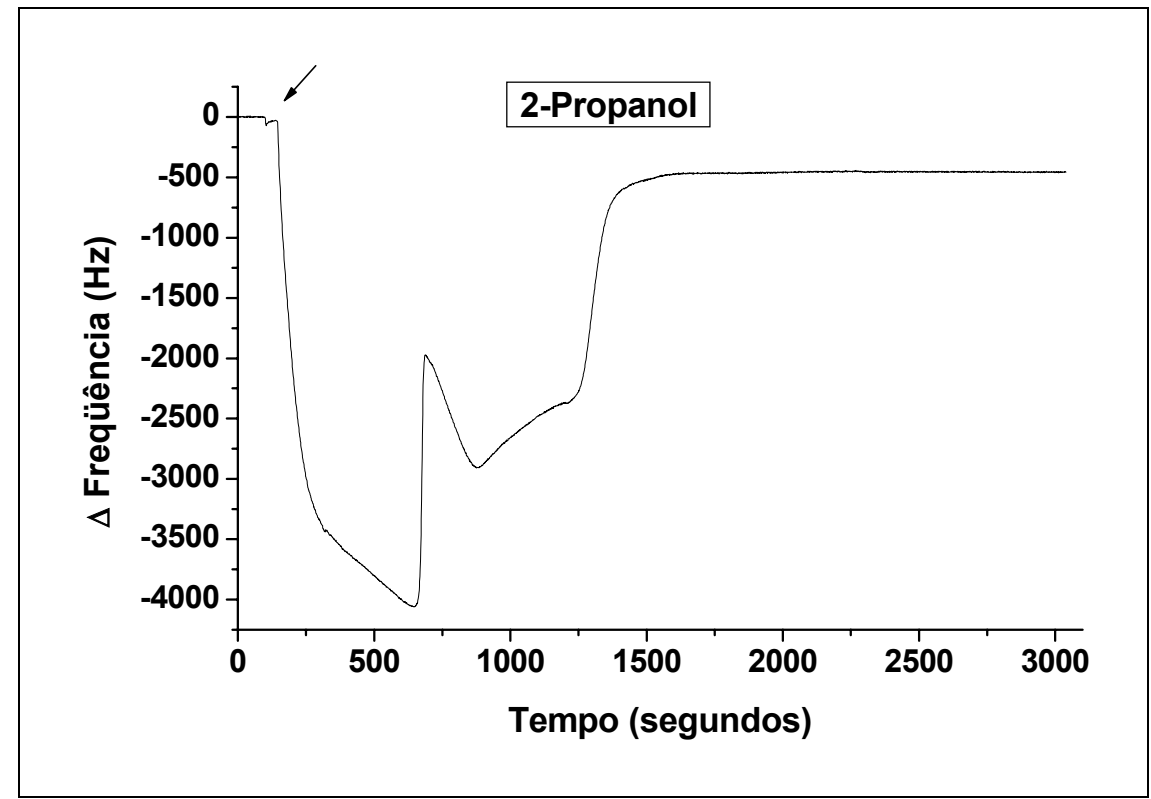

Figura 3.20. Variação de freqüência em função do tempo para injeção de 2-Propanol após a reação com a água. 
Para a injeção de 2-Propanol ocorre uma grande variação da freqüência e variações abruptas durante a medida, que provavelmente devem-se à disputa pelos canais, entre 2-Propanol e reagentes anteriormente admitidos e aprisionados no filme - como água e n-Hexano, sendo mais favorável a permeação e adsorção de 2-Propanol, devido às prováveis pontes de hidrogênio entre os radicais $\mathrm{OH}$ do filme e da molécula. Assim, a competição pelos nanocanais pode explicar as variações abruptas.

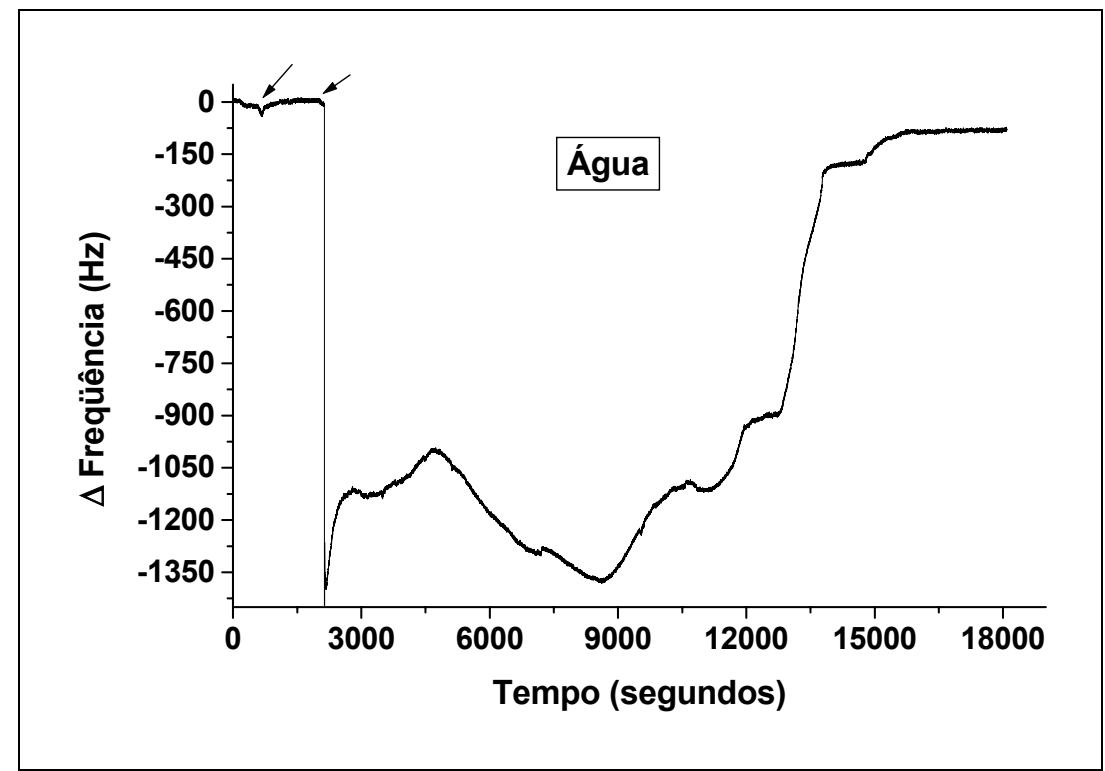

Figura 3.21. Variação de freqüência em função do tempo para injeção de água após a reação com a água. As flechas indicam admissão de água.

A injeção de $0,05 \mathrm{ml}$ de água não mostrou variação significativa na medida do detetor, portanto deve ter ocorrido a permeação da água pelo corpo do filme. Nova injeção de $0,05 \mathrm{ml}$ foi feita e nota-se variação grande e rápida, portanto a água não é mais adsorvida, devido ao excesso de água no filme e a dessorção de espécies anteriormente adsorvidas começa a ocorrer, devido à competição pelos nanocanais. As figuras 3.22 e 3.23 apresentam mais detalhadamente o primeiro e segundo pulsos. 
A primeira inserção de água, que não apresentou variação significativa na saída do detetor, permite estimar o máximo que pode ser retido nessa estrutura, que funcionaria como desumidificador. Tal hipótese será avaliada posteriormente.

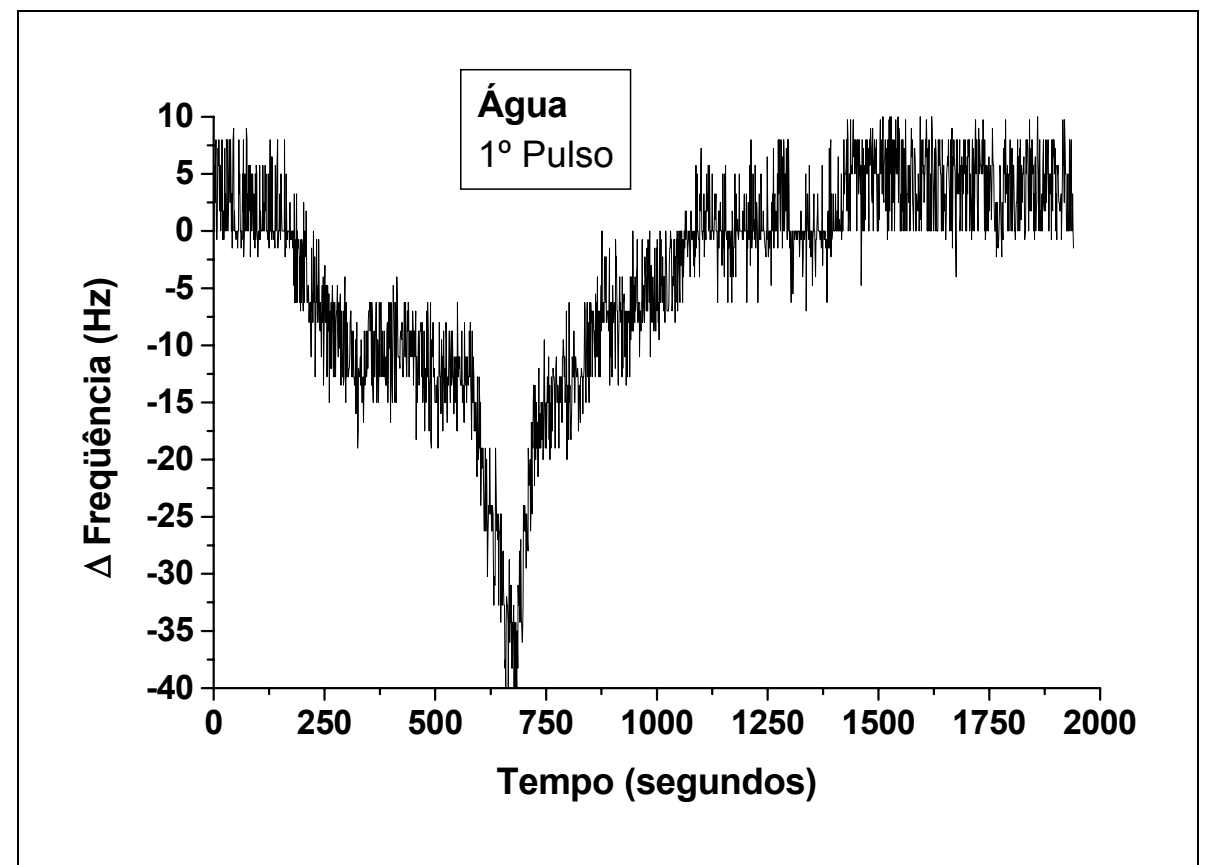

Figura 3.22. Variação de freqüência em função do tempo para injeção de água após a reação com a água $\left(1^{\circ}\right.$ Pulso). 


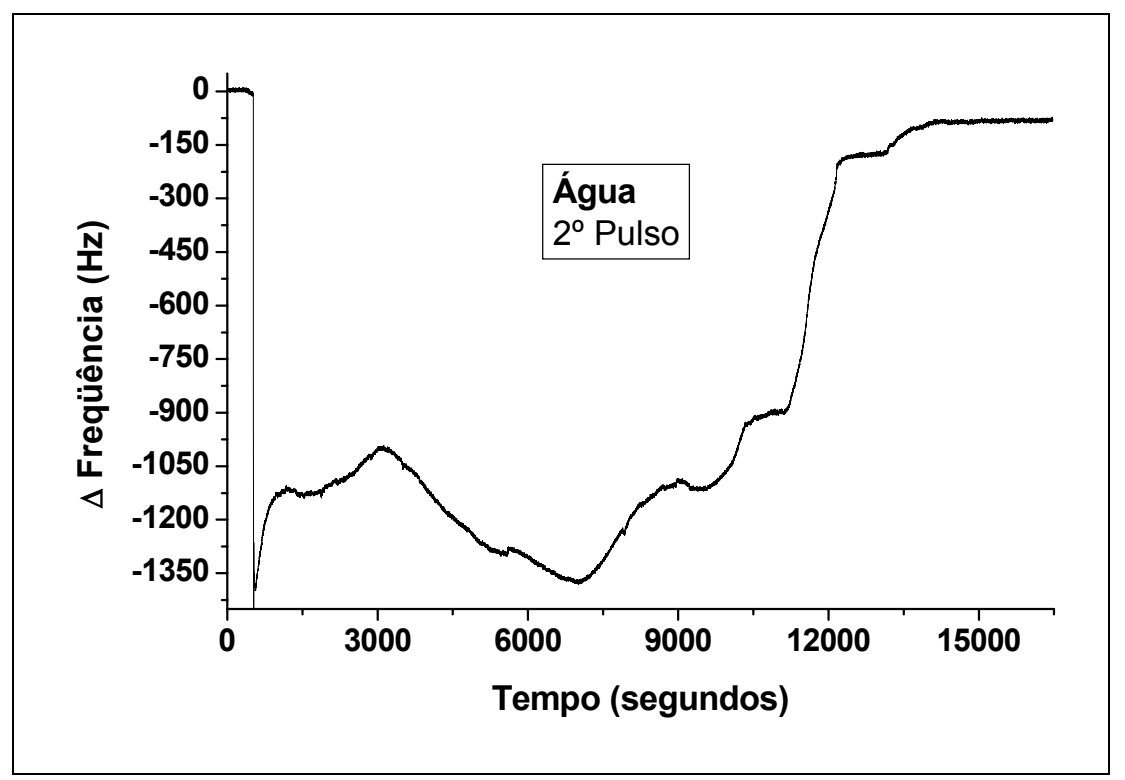

Figura 3.23. Variação de freqüência em função do tempo para injeção de água após a reação com a água ( $2^{\circ}$ Pulso). 


\subsection{Dispositivos propostos utilizando filme fino à base de TEOS}

O modelo físico-químico descrito anteriormente baseia-se, essencialmente, em adsorção, permeação e reação, de hidrólise ou eventualmente óxido-redução. A adsorção é útil em processos cromatográficos - ou seja, separação de componentes de uma mistura - e/ou na préconcentração, durante o pré-tratamento de amostras para posterior análise; a permeação, a hidrólise e a óxido-redução podem ser usadas na retenção de interferentes, também no prétratamento de amostras.

Dentro desta perspectiva três dispositivos em várias configurações foram propostos e testados e suas principais características, isto é prováveis respostas, são sumariadas na Tabela 3.1. Canais tridimensionais com o filme recém depositado podem ser usados na retenção de compostos orgânicos em fase gasosa (dispositivo 1). Se a estes canais forem adicionadas partículas de sílica, também tratadas com filme à base de TEOS de modo semelhante ao proposto por Hernandez [7] para filme a base de acetaldeído, ocorrerá a retenção de compostos orgânicos em maior volume (dispositivo 2). Após a hidrólise o filme pode reter maior quantidade de compostos orgânicos, tanto em fase líquida quanto gasosa, (dispositivos 3 e 4), mas é provável que a presença de água em sua superfície impeça tal comportamento, o que pode ser minimizado pelo condicionamento dessa superfície pela exposição à HMDS. Para remoção de íons em fase líquida (dispositivo 5) é necessário que a tensão seja aplicada de modo mais homogêneo. O uso de canais menores, que, portanto podem ser obtidos em substrato planar, pode apresentar vantagens na separação prévia de íons no pré-tratamento de amostras (dispositivo 6). Contudo, a remoção e/ou separação de íons pode também ocorrer pelo uso de membranas, tendo essas algumas vantagens, tanto de construção como de uso. Uma possível construção é a cavidade selada, que Carvalho [8] utilizou para testar catálise de filmes finos e Nascimento para avaliar substratos quanto à adsorção [9]. Porém, nenhum dos casos pressupõe como modo de operação do dispositivo a permeação dos reagentes pelo substrato, como ocorre nos testes deste trabalho (dispositivo 7). Por fim, detecção em amostras complexas, como comentado anteriormente, apresenta dificuldades, entre outras coisas, pela passivação de eletrodos. Assim, a obtenção de pré-tratamentos de amostras que iniba reação/oclusão das superfícies destes eletrodos, é de grande valia (dispositivo 8). 
De modo geral, três dispositivos (microcanal tridimensional ou planar e membranas) em várias configurações foram testados. As vantagens dos dois últimos é a possibilidade de fabricação em fluxo contínuo (roll-to-roll), uma tendência importante na área de microeletrônica e, consequentemente em MEMS, como alertou Nascimento [9]. Isto é de fácil implantação neste caso porque a produção de filmes com alta concentração de carbono usando o reagente TEOS exige pouco bombardeamento do substrato, o que foi conseguido pelo uso de eletrodos externos, ou seja, a adaptação da deposição para fluxo contínuo não é difícil. A maioria das medidas utilizou QCM como sistema de detecção e, quando isto não ocorre, o modo de detecção é explicado no texto.

Tabela 3.1. Resumo dos comportamentos obtidos para o filme produzido pela deposição por plasma de TEOS.

\begin{tabular}{|c|c|c|c|}
\hline Dispositivo/configuração & $\begin{array}{l}\text { Comportamento físico- } \\
\text { químico associado } \\
\text { (esperado) }\end{array}$ & Modo de operação & Testes propostos \\
\hline $\begin{array}{l}\text { 1. Microcanal tridimensional/ } \\
\text { filme recém depositado }\end{array}$ & $\begin{array}{l}\text { a) Separação de } \\
\text { compostos apolares } \\
\text { b) Retenção de água e } \\
\text { alcoóis em fase gasosa }\end{array}$ & $\begin{array}{l}\text { a) Como coluna } \\
\text { cromatográfica (adição de } \\
\text { mistura e análise) } \\
\text { b) Como pré-coluna } \\
\text { cromatográfica }\end{array}$ & $\begin{array}{l}\text { a) Adição de compostos apolares e avaliação da formação } \\
\text { ou não de dois picos, em várias temperaturas distintas. } \\
\text { Avaliação do envelhecimento do filme } \\
\text { b) mesmo teste que em a) }\end{array}$ \\
\hline $\begin{array}{l}\text { 2. Microcanal tridimensional } \\
\text { empacotada/ filme } \\
\text { condicionado (hidrólise) }\end{array}$ & $\begin{array}{l}\text { Retenção de compostos } \\
\text { orgânicos em fase gasosa }\end{array}$ & $\begin{array}{l}\text { Similar à pré-coluna } \\
\text { cromatográfica }\end{array}$ & $\begin{array}{l}\text { Avaliação da não existência de picos por longo tempo } \\
\text { após a admissão de pequena amostra. Teste de quantidade } \\
\text { máxima admitida antes de ocorrer detecção }\end{array}$ \\
\hline $\begin{array}{l}\text { 2. Microcanal tridimensional } \\
\text { empacotada/ filme recém } \\
\text { depositado }\end{array}$ & $\begin{array}{l}\text { Retenção de compostos } \\
\text { orgânicos em fase gasosa }\end{array}$ & $\begin{array}{l}\text { Similar à pré-coluna } \\
\text { cromatográfica }\end{array}$ & $\begin{array}{l}\text { Avaliação da não existência de picos por longo tempo } \\
\text { após a admissão de pequena amostra. Teste de quantidade } \\
\text { máxima admitida antes de ocorrer detecção }\end{array}$ \\
\hline $\begin{array}{l}\text { 3. Microcanal tridimensional/ } \\
\text { filme condicionado (hidrólise) }\end{array}$ & $\begin{array}{l}\text { Separação de compostos } \\
\text { orgânicos em fase gasosa }\end{array}$ & Similar a 1 & Similar a 1 \\
\hline $\begin{array}{l}\text { 4. Microcanal tridimensional/ } \\
\text { filme condicionado (hidrólise) } \\
\text { e submetido a vapor de HMDS }\end{array}$ & $\begin{array}{l}\text { Separação de compostos } \\
\text { orgânicos em fase gasosa }\end{array}$ & Similar a 1 & Similar a 1 \\
\hline $\begin{array}{l}\text { 5. Microcanal tridimensional/ } \\
\text { filme condicionado (hidrólise) } \\
\text { e submetido a vapor de HMDS }\end{array}$ & $\begin{array}{l}\text { Separação de compostos } \\
\text { em fase líquida }\end{array}$ & $\begin{array}{l}\text { Admissão de mistura de } \\
\text { composto orgânico e } \\
\text { inorgânico }\end{array}$ & $\begin{array}{l}\text { Devido ao comportamento fluídico destes canais [9], } \\
\text { mesmo se houver interações fortes, a capacidade é } \\
\text { pequena. Portanto, é preciso avaliar o máximo de 2- } \\
\text { propanol retido nos canais por longo tempo (vários } \\
\text { minutos). Assim, inicialmente admite-se 2-proanol e } \\
\text { posteriormente avalia-se a eluição deste }\end{array}$ \\
\hline $\begin{array}{c}\text { 6. Microcanal tridimensional/ } \\
\text { filme condicionado (hidrólise) } \\
\text { e aplicação de tensão }\end{array}$ & $\begin{array}{l}\text { Retenção de compostos } \\
\text { iônicos por óxido- } \\
\text { redução }\end{array}$ & Similar a $1 \mathrm{~b}$ & $\begin{array}{c}\text { Adição de pequena amostra de solução aquosa no fluido } \\
\text { (água) e remoção desta. Desmonte da estrutura. Avaliação } \\
\text { da área de canais com deposição }\end{array}$ \\
\hline $\begin{array}{l}\text { 7. Canal planar, filme recém } \\
\text { depositado e aplicação de } \\
\text { tensão }\end{array}$ & $\begin{array}{l}\text { Separação de compostos } \\
\text { iônicos em fase líquida }\end{array}$ & Similar a 1a & $\begin{array}{c}\text { Adição de solução aquosa de compostos iônicos e } \\
\text { avaliação do tempo para percorrer o canal. Avaliação da } \\
\text { oxidação dos eletrodos }\end{array}$ \\
\hline 8. Membrana & $\begin{array}{l}\text { Remoção de compostos } \\
\text { iônicos }\end{array}$ & Pré-tratamento de amostras & $\begin{array}{l}\text { Adição de solução aquosa de compostos iônicos em um } \\
\text { dos lados da membrana e aplicação de tensão (cavidade } \\
\text { selada [8]) }\end{array}$ \\
\hline $\begin{array}{l}\text { 9. Construção de camadas } \\
\text { sobre eletrodos: filme recém } \\
\text { depositado /partículas de } \\
\text { amido recobertas por filme a } \\
\text { base de HMDS }\end{array}$ & $\begin{array}{l}\text { Retenção de compostos } \\
\text { orgânicos de grande peso } \\
\text { molecular em fase } \\
\text { líquida e detecção de } \\
\text { outros componentes da } \\
\text { mistura }\end{array}$ & Pré-tratamento de amostras & $\begin{array}{l}\text { Amostra deve percorrer duas camadas e ser detectada a } \\
\text { seguir (uso de traçadores) }\end{array}$ \\
\hline
\end{tabular}




\subsubsection{Microcanais tridimensionais}

\subsubsection{Filme recém depositado}

Microestruturas foram seladas e testadas em duas condições diferentes: após a deposição e após a exposição à água por diversas horas. Para todos os testes, o nitrogênio foi usado como o gás carregador.

Para determinar não só a reprodutibilidade como também a forma de eluição, colunas com o filme recém depositado foram testadas com diversas injeções seqüenciais dos reagentes. Todas as injeções utilizaram $10 \mu \mathrm{L}(<10 \mu \mathrm{g})$ de reagente em larga faixa de polaridade e a primeira injeção foi também utilizada para medida de pratos teóricos da coluna. $\mathrm{O}$ uso de $10 \mu \mathrm{L}$ corresponde à máxima injeção de amostra de uma coluna cromatográfica e, neste caso devido ao pequeno comprimento do canal, também a uma condição de saturação da superfície. Assim, serão obtidos os menores valores possíveis para o número de pratos teóricos.

A seqüência de injeções ocorreu em escala crescente de polaridade, portanto as injeções correspondem a ciclos com n-Hexano, 2-Propanol e água. A Figura 3.24 apresenta os dados de QCM para a primeira seqüência de injeção de colunas recentemente depositadas e, apenas para comparação, de canais sem filme, como já apresentado anteriormente.

Pela comparação das figuras 3.24 A e 3.24 B observa-se que, para compostos orgânicos o formato dos picos é semelhante, contudo seus valores máximos são bem diferentes, devido à retenção de grande parte do composto na superfície. Para água, como esperado o formato do pico indica interação forte com a superfície e, novamente, os valores são menores que os obtidos em colunas sem filme, tanto na intensidade quando na área.

A Tabela 3.2 apresenta o tempo de retenção e o número de pratos teóricos obtidos na coluna utilizada imediatamente após a deposição do filme a base de TEOS, e, para comparação, o mesmo número de pratos teóricos foi calculado para uma coluna sem fase estacionária. Como pode ser visto na Tabela 3.3, para n-Hexano e 2-Propanol o tempo de retenção e número de pratos teóricos são mais altos em uma coluna com filme recém depositado quando comparada a uma coluna sem fase estacionária. Além disso, o tempo de retenção do n-Hexano está de acordo com os resultados obtidos usando os canais tridimensionais modificados por um filme adsorvente, obtido pela deposição por plasma de ésteres [7], e que é de aproximadamente 30 
segundos. Portanto, devido à alta quantidade de produto utilizado em cada injeção, a capacidade de retenção é excedida e algum reagente é detectado. Contudo, esse reagente detectado também sofreu interação como filme, como a interação é mais fraca, o reagente não foi retido apenas "atrasado em sua saída". A diferença no tempo de retenção para n-Hexano e 2-Propanol na coluna sem fase estacionária é provavelmente devido à alguma interação entre a superfície de acrílico e moléculas de 2-Propanol, o mesmo podendo ocorrer para água. A água interage fortemente com a superfície das colunas com filme recém depositado, e conseqüentemente o tempo de retenção é semelhante ao obtido para 2-propanol. Muito embora esta interação possa levar à reação de hidrólise, a quantidade injetada não foi suficiente para mudar as propriedades da superfície do filme após diversos ciclos de injeção.

Tabela 3.2. Tempo de retenção e Número de Pratos Teóricos obtidos em uma coluna com filme recém depositado e em uma coluna sem filme.

\begin{tabular}{|c|c|c|c|c|c|c|}
\hline \multirow{2}{*}{} & \multicolumn{2}{|c|}{ n-Hexano } & \multicolumn{2}{c|}{ 2-Propanol } & \multicolumn{2}{c|}{ Água } \\
\cline { 2 - 7 } & TR (s) & NPT & TR (s) & NPT & TR (s) & NPT \\
\hline Coluna com filme & 32 & 463 & 134 & 94 & 115 & 247 \\
\hline $\begin{array}{c}\text { Coluna sem fase } \\
\text { estacionária }\end{array}$ & 9,6 & 1,7 & 16,4 & 4,3 & 301,3 & 0,3 \\
\hline
\end{tabular}

RT - Tempo de Retenção

NTP - Número de Pratos Teóricos

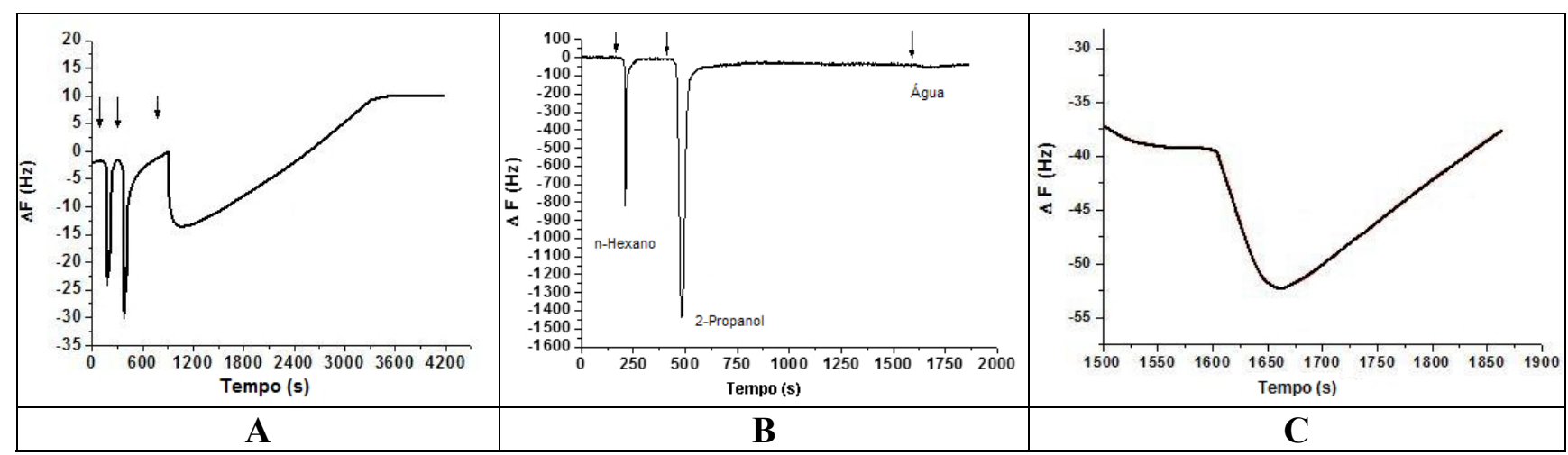

Figura 3.24. Seqüência de injeções de $10 \mu \mathrm{L}$ de n-Hexano, 2-Propanol e água em coluna com

filme recém depositado (A) e coluna sem filme (B). Pequeno sinal (C) devido à injeção de água.

As setas indicam o tempo da injeção.

As colunas mostraram boa reprodutibilidade uma vez que, mesmo utilizando uma grande quantidade de reagente, o tempo de retenção é aproximadamente o mesmo após 10 ciclos 
completos de injeções. Os dados estão de acordo com os resultados obtidos utilizando produtos naturais, onde filme fino à base de TEOS pôde manter suas características em ambiente saturado de água por pelo menos uma semana [1].

Testes da estrutura como uma microcoluna cromatográfica foram feitos usando solução aquosa de n-Hexano (solução saturada) e 2-Propanol (1\% 10\%, 20\% e 50\% em volume) em injeções seqüenciais. Entre as injeções seqüenciais, injeções de água foram também processadas, apenas para comparação. Soluções aquosas de n-Hexano e 1\% de 2-Propanol não mostraram qualquer variação da linha de base, indicando que a retenção ocorreu nestas condições. Entretanto, soluções aquosas de 10\%, 20\% e 50\% de 2-Propanol saíram rapidamente do canal. Provavelmente 2-Propanol é o principal reagente a deixar a coluna nestas condições, já que água reage com o filme e libera compostos orgânicos (álcool etílico); portanto, demora muito tempo para que a linha de base retorne ao seu valor original. A Figura 3.25 apresenta os resultados típicos para n-Hexano (solução saturada), 2-Propanol (10\% em volume) e água.

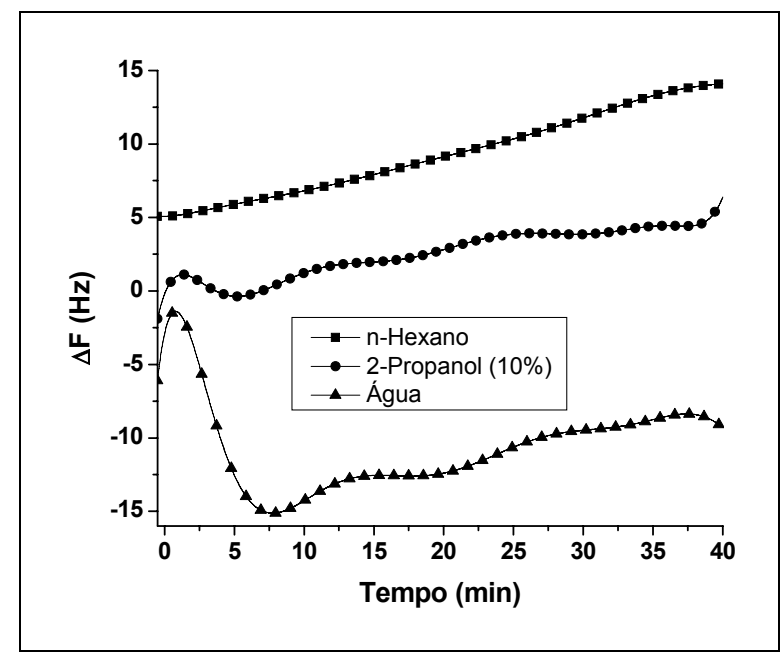

Figura 3.25. Variação da freqüência em função do tempo para solução aquosa, saturada de nHexano e de 10 \%vol. de 2-Propanol, e água.

Embora o comportamento desta coluna seja reprodutível, este não corresponde ao que se exige de uma coluna cromatográfica. Contudo, este sistema pode ser usado para retenção ou préconcentração de compostos orgânicos em pré-tratamento de amostras. A quantidade máxima de reagente retido pode ser estimada e é aproximadamente $1 \mu \mathrm{L}$ para todos os compostos presentes nas soluções aquosas testadas. Este valor similar para todos os compostos provavelmente é 
devido à presença de água, que define como ocorre o processo de retenção através de interações fortes com a superfície.

Já que a água tem uma importância fundamental para o processo de retenção, injeções seqüenciais de água e 2-Propanol foram igualmente testadas. A Figura 3.26 apresenta resultados típicos para diversas seqüências de injeções de água (Figura $3.26 \mathrm{~A}$ ) ou solução aquosa de $20 \%$ de 2-Propanol (Figura 3.26 B). É possível observar comportamentos similares nas duas figuras e que correspondem à rápida variação, devido à excessiva quantidade de analito injetada, e a lenta dessorção, devida à reação da água - pura ou presente na solução aquosa.

A dificuldade de remoção dos reagentes de dentro da coluna permanece mesmo que esta seja aquecida a $100{ }^{\circ} \mathrm{C}$. Se a coluna é mantida sem uso durante 6 meses em ambiente sem controle de umidade (envelhecimento), o comportamento de retenção de 2-propanol se acentua, provavelmente devido à reação da superfície com a umidade do ar durante o tempo de estocagem.

Assim, este dispositivo não é indicado para pré-concentração, mas como pré-coluna cromatográfica, para retenção de compostos orgânicos polares e água. A possibilidade de reter 1 $\mu \mathrm{L}$ de amostra, mesmo quando esta é uma solução aquosa diluída, apresenta a vantagem de permitir a inserção dessa pré-coluna mediatamente antes do split do cromatógrafo e um possível uso é em cromatógrafos miniaturizados [10] quando da análise de ar, para impedir que VOC's (volatile organic compounds) atrapalhem a análise, uma vez que esta depende de colunas baseadas em peneiras moleculares [4].

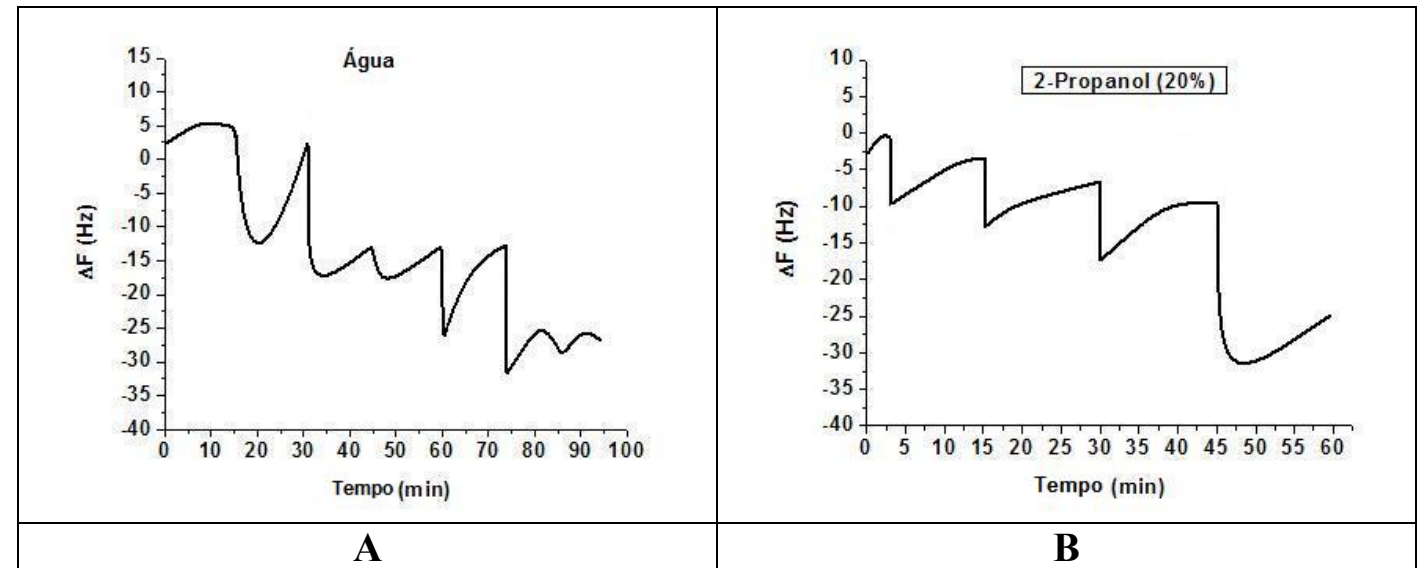

Figura 3.26. Variação da freqüência em função do tempo para diversas seqüências de injeções de $10 \mu \mathrm{L}$ de água (A) ou solução aquosa de $20 \%$ de 2-Propanol (B). 


\subsubsection{Filme recém depositado e canal empacotado}

Com a finalidade de aumentar a área superficial, foram inseridas partículas esféricas de óxido de silício nos canais da microestrutura tridimensional. Essas partículas foram igualmente modificadas pela deposição por plasma de TEOS. As medidas utilizaram sistema de medida com 10 casas decimais $(0,01 \mathrm{~Hz})$ e o conjunto foi aquecido a $80{ }^{\circ} \mathrm{C}$ ou a $100{ }^{\circ} \mathrm{C}$, que apresentaram resultados semelhantes. Os testes utilizaram $10 \mu \mathrm{L}$ de reagentes injetados em ordem crescente de polaridade. A Figura 3.27 apresenta um possível resultado para aquecimento a $100^{\circ} \mathrm{C}$. Quando da inserção de n-hexano ou n-dodecano (Figura 3,27 A e B, respectivamente), o sinal é pequeno porque houve retenção, mesmo em temperatura alta. Assim, as esferas facilitaram a remoção de maior quantidade de reagente no canal, porém, a adição de 2-Propanol permite a dessorção dos reagentes anteriormente adsorvidos (Figura 3.27 D). Para água, o aumento da temperatura favorece a reação de hidrólise e por este motivo o comportamento não é reprodutível se vários ciclos de inserção são repetidos. Para a água (Figura 3.27 C) a remoção de compostos apolares aparentemente não é tão imediata como com 2-Propanol. É importante observar que o comportamento de dessorção de compostos apolares pelo uso de 2-Propanol se mantém em temperatura ambiente ou alta; além disso, a comparação das áreas dos picos indica que a remoção dos compostos apolares é aproximadamente quantitativa. Portanto, o conjunto se comporta como um pré-concentrador permitindo a coleta de cerca de $10 \mu \mathrm{L}$ de reagentes apolares e posterior eluição com 2-Propanol. Um possível uso é para melhorar o limite de detecção de sensores de compostos apolares, como os usados em análise de gasolina; porém, uma dificuldade é a reação com a água, que gera irreprodutibilidade do sistema. Esse arranjo apresenta a vantagem de não necessitar do aquecimento para a remoção das amostras, porém, outra limitação é o envelhecimento do filme e a Figura 3.28 apresenta a modificação na intensidade do sinal quando da eluição com $10 \mu \mathrm{L}$ de 2-Propanol à temperatura ambiente. Muito embora o comportamento da curva seja semelhante, a menor intensidade indica uma competição do 2-Propanol pelos sítios ativos que a lenta hidrólise formou no período, o que diminui a quantidade de material removido.

Portanto, de modo geral, tanto o canal livre como o empacotado recoberto por filme recém depositado apresenta dificuldades de reprodutibilidade se água está presente em grande quantidade ou há estocagem, o que sugere o uso de estruturas descartáveis. 


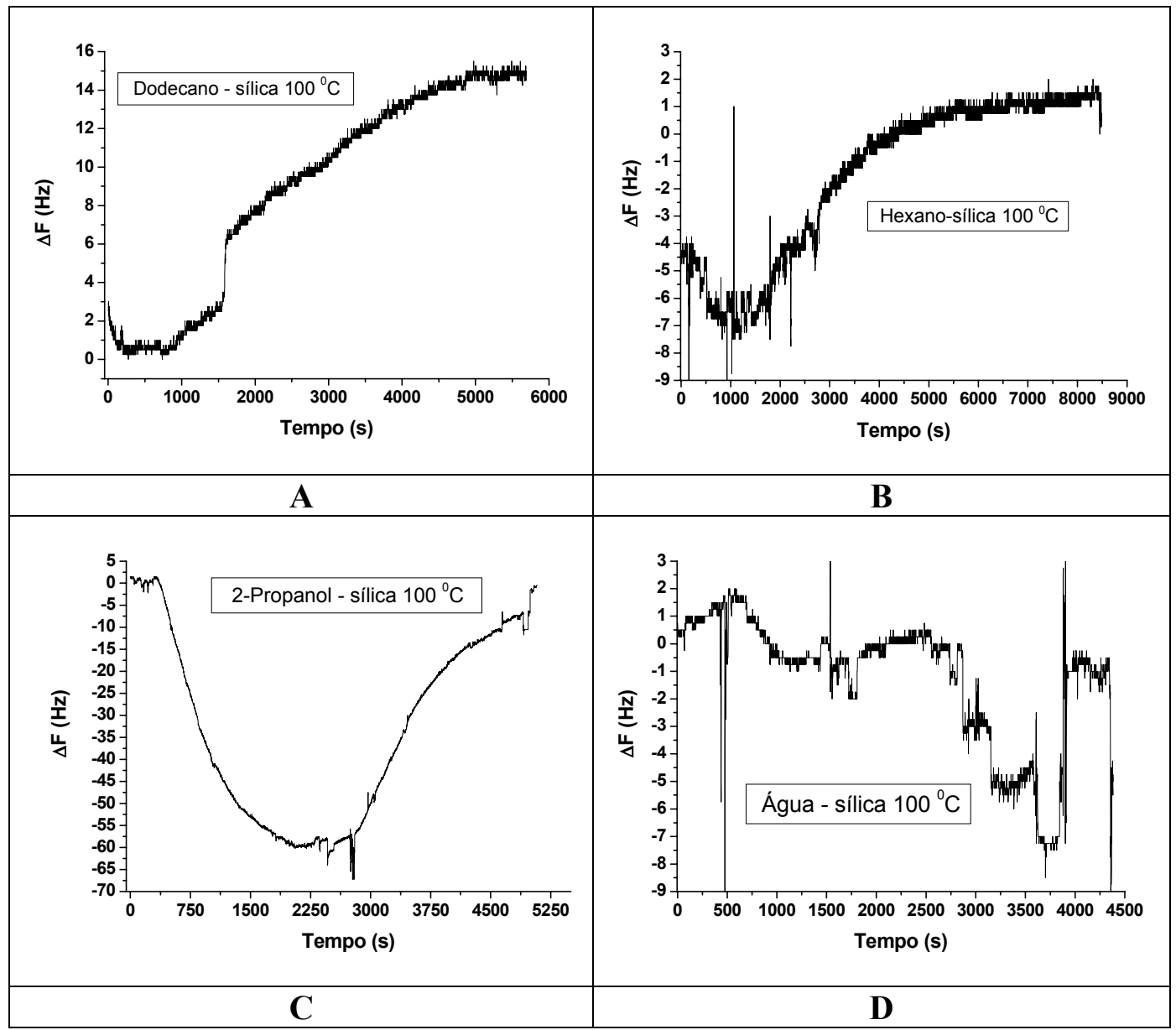

Figura 3.27. Inserção de $10 \mu \mathrm{L}$ e $100{ }^{\circ} \mathrm{C}$ de: (A) n-Dodecano; (B) n-Hexano; (C) 2-Propanol e (D) água.

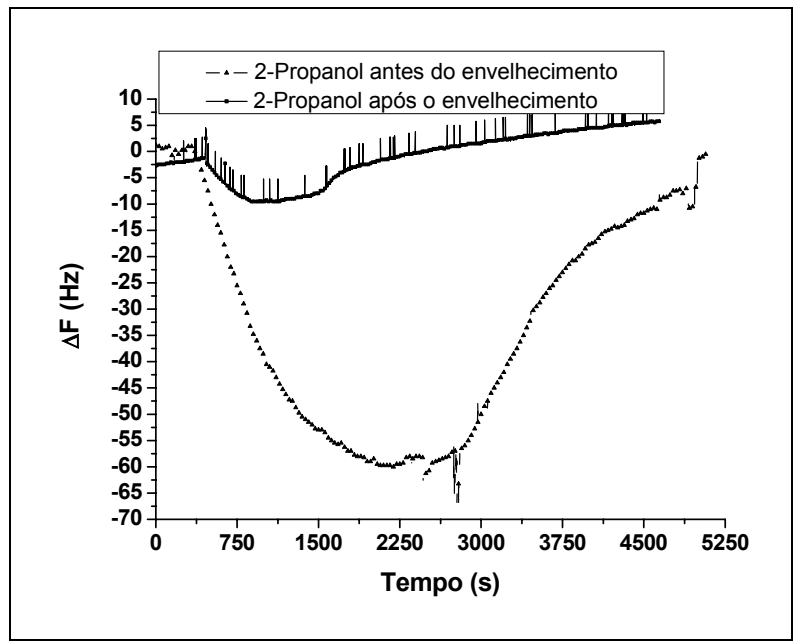

Figura 3.28. Eluição de n-Hexano usando $10 \mu \mathrm{L}$ de 2-propanol a temperatura ambiente: filme recém depositado ou após seis meses de estocagem. 


\subsubsection{Filme após a reação com água}

Nesta coluna condicionada, os testes foram conduzidos de maneira similar aos da coluna com filme recém depositado. Após condicionamento, a coluna foi testada utilizando injeções seqüenciais de n-Hexano e 2-Propanol e os reagentes mostraram comportamento semelhante ao obtido antes da hidrólise. Assim, n-Hexano apresentou uma banda com forma bem definida enquanto 2-Propanol apresentou uma cauda e longo tempo de dessorção. Estes comportamentos indicam uma fraca interação do n-Hexano com a superfície e uma intensa para o 2-Propanol.

Entretanto, o tempo de retenção pode mudar de acordo com o condicionamento. Se após o condicionamento, para remover a água aprisionada na coluna, esta é exposta ao fluxo de nitrogênio por curto período de tempo, o tempo de retenção obtido para a maioria dos compostos é baixo e similar ao obtido com uma coluna com filme recém depositado (Figura 3.18). Por outro lado, se a coluna é completamente seca, pela passagem de fluxo de nitrogênio por várias horas, o tempo de retenção apresenta diferença significativa e os reagentes demoram um tempo maior para sair da coluna. Portanto, há disputa entre as moléculas de água e os reagentes pelos sítios ativos, além da provável interferência dos nanocanais formados pela hidrólise; estes nanocanais também podem reter água facilmente, a qual necessita de um longo período ser removida (“secagem”). A Figura 3.29 mostra resultados típicos.

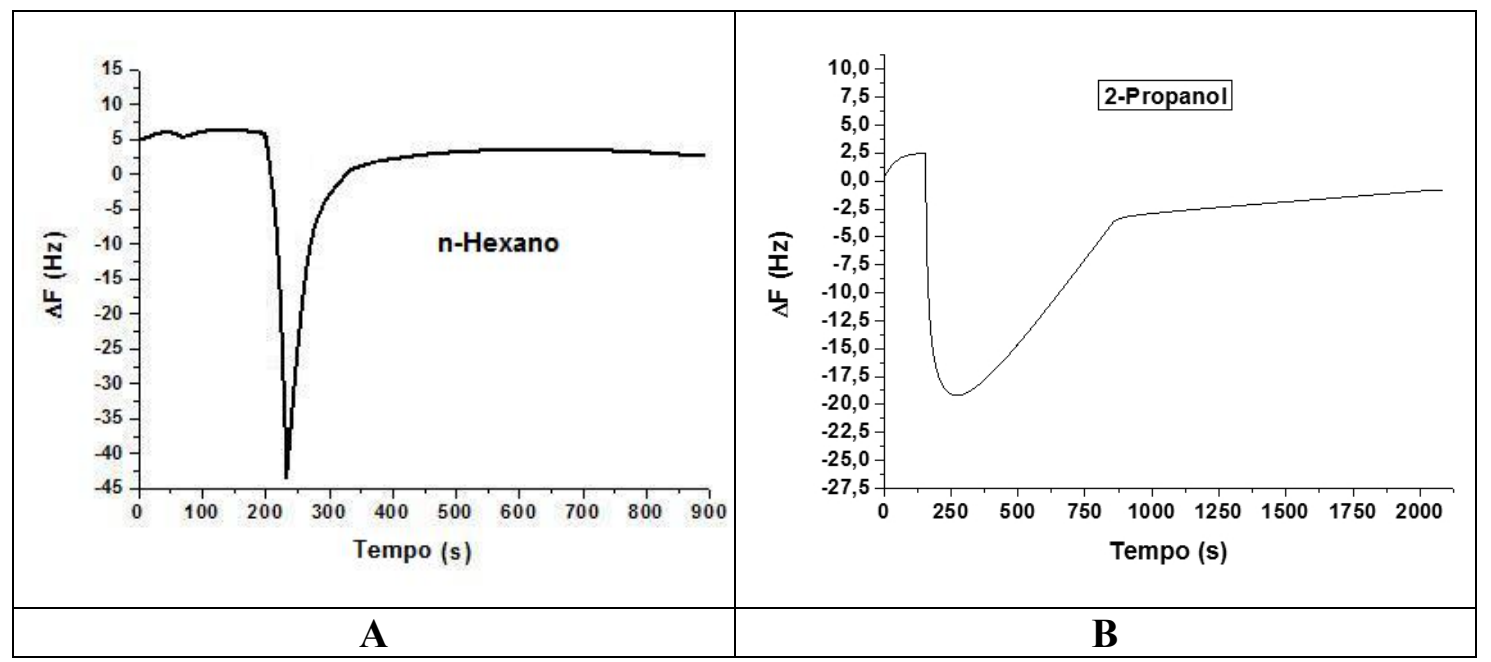

Figura 3.29. Variação da freqüência em função do tempo para n-Hexano (A) e 2-Propanol (B) após condicionamento da microcoluna por longo período de tempo. 
Para garantir que a influência dos nanocanais fosse bem avaliada, as medidas foram realizadas em ordem de crescente de polaridade, utilizaram injeções de $10 \mu \mathrm{L}$ de cada reagente e sistema de medida com 10 casas decimais. As figuras 3.30A e 3.30B apresentam resultados para n-Dodecano e n-Hexano, respectivamente. O comportamento observado é oscilatório devido à presença de nanocanais, o tempo de retenção é alto porque a medida ocorreu em temperatura ambiente e observa-se que a saída de n-Hexano ocorre em menor tempo do que n-Dodecano. Quando se analisam compostos semelhantes em fase cromatográfica porosa, espera-se a saída do composto em ordem inversa do tamanho; contudo, isto não ocorre neste caso porque o volume de medida permite a saturação da superfície com n-Dodecano por longo tempo.

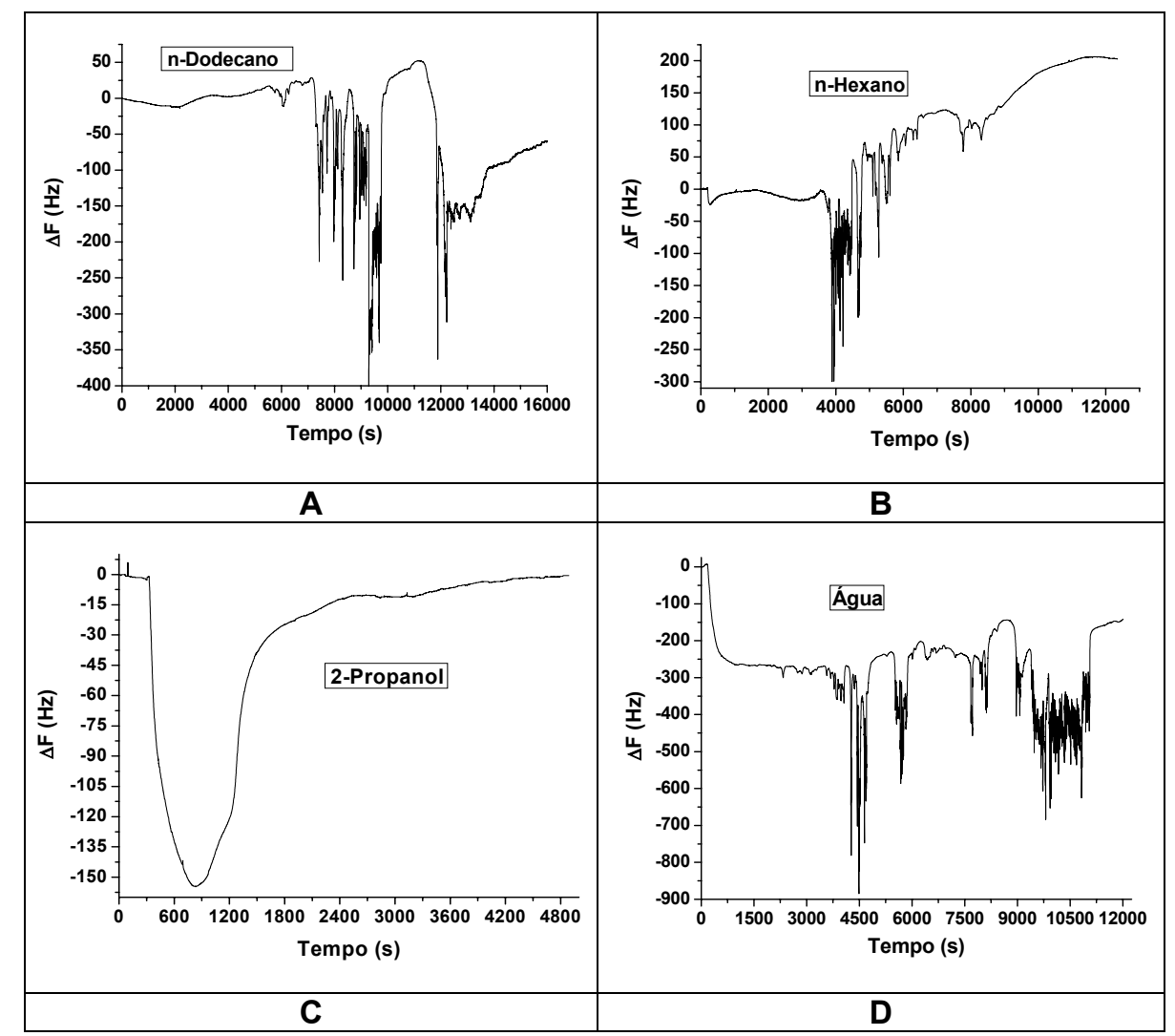

Figura 3.30. Medida de QCM gasoso com $10 \mu \mathrm{L}$ de injeção de n-Dodecano (A), n-Hexano (B), 2-propanol (C) e água (D).

A Figura 3.30C revela dois aspectos importantes da adição de 2-propanol. O primeiro é seu tamanho, menor do que o n-Hexano, o que pode ajudar a penetrar nos nanocanais (fenômeno físico), e o segundo sua interação com a superfície do filme fino à base de TEOS que o faz competir pela superfície, neste fenômeno ele vai remover outros compostos adsorvidos e/ou 
permeados (comportamento químico). É notado que, de modo semelhante à Figura 3.27, ocorre a formação de uma gaussiana muito larga e rápida, pois apresenta aproximadamente 700 segundos como liberação dos compostos contra aproximadamente 4000 segundos para o n-Hexano e 6000 segundos para o n-Dodecano. Portanto, o 2-Propanol removeu n-Hexano dos canais e/ou da superfície, o que torna esse conjunto útil para ser utilizado como pré-concentrador, especialmente porque a avaliação das áreas das curvas indica que a eluição é aproximadamente quantitativa.

A Figura 3.30D apresenta o resultado da adição de água à coluna, que corresponde a um comportamento semelhante ao apresentado por 2-Propanol. Ocorre uma queda logo após a injeção devido à rápida adsorção de água no filme, o que libera facilmente os compostos adsorvidos e/ou permeados anteriormente, ou seja, a queda no comportamento do gráfico é rápida. A linha de base não retorna novamente ao valor inicial, o que indica que a liberação de reagentes aprisionados é contínua. Os picos maiores presentes ao longo da medida referem-se ao fato de alguns compostos apresentarem maior facilidade do que outros para saírem da estrutura.

Para evitar a saturação da superfície à temperatura ambiente, a injeção deve utilizar valores menores que $4 \mu \mathrm{g}$ de n-Dodecano e a Figura 3.31 apresenta duas injeções seqüenciais de $4 \mu \mathrm{g}$, onde pode-se observar tanto o comportamento oscilatório (Figura 3.31A) quanto a saturação, que facilita a remoção do reagente na segunda injeção (Figura 3.31B).

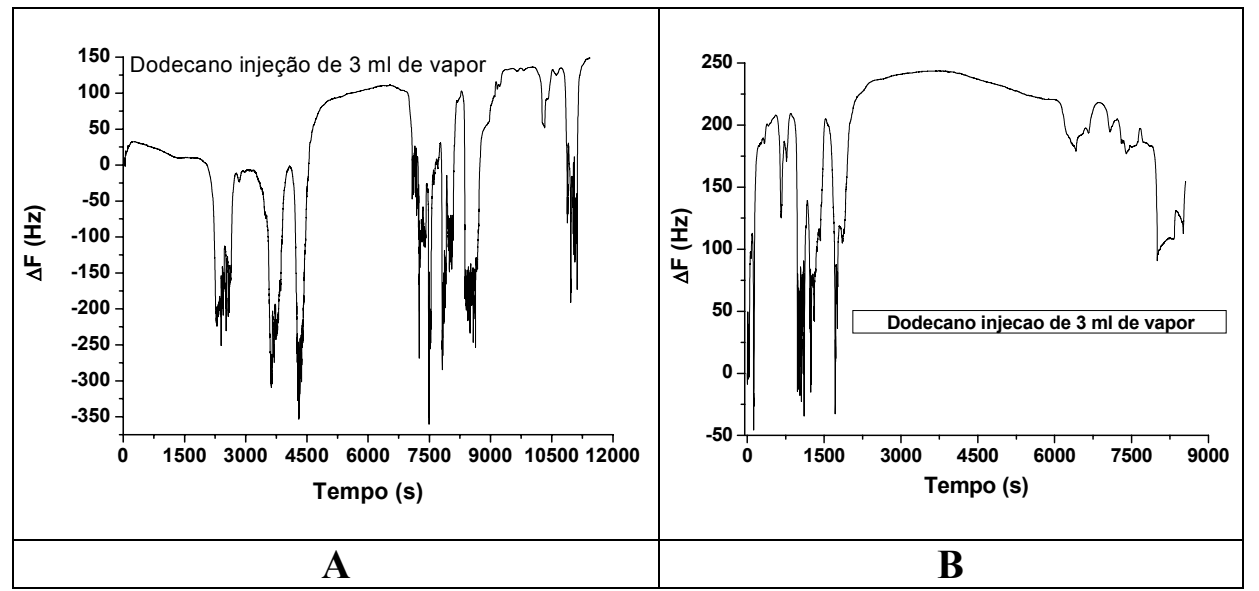

Figura 3.31. Injeções seqüenciais de $4 \mu \mathrm{g}$ de n-Dodecano: $1^{\mathrm{a}}$ (A) e $2^{\mathrm{a}}$ (B) injeção.

$\mathrm{O}$ aquecimento em temperatura de $80{ }^{\circ} \mathrm{C}$ elimina o comportamento oscilatório e permite que grande parte do n-Dodecano (Figura 3.32A) ou n-Hexano (Figura 3.32B) seja repetidamente removido. Neste caso a eluição continua ocorrendo com o uso de 2-Propanol (Figura 3.32C) enquanto a água sai lenta e continuamente do canal (Figura 3.32D). 


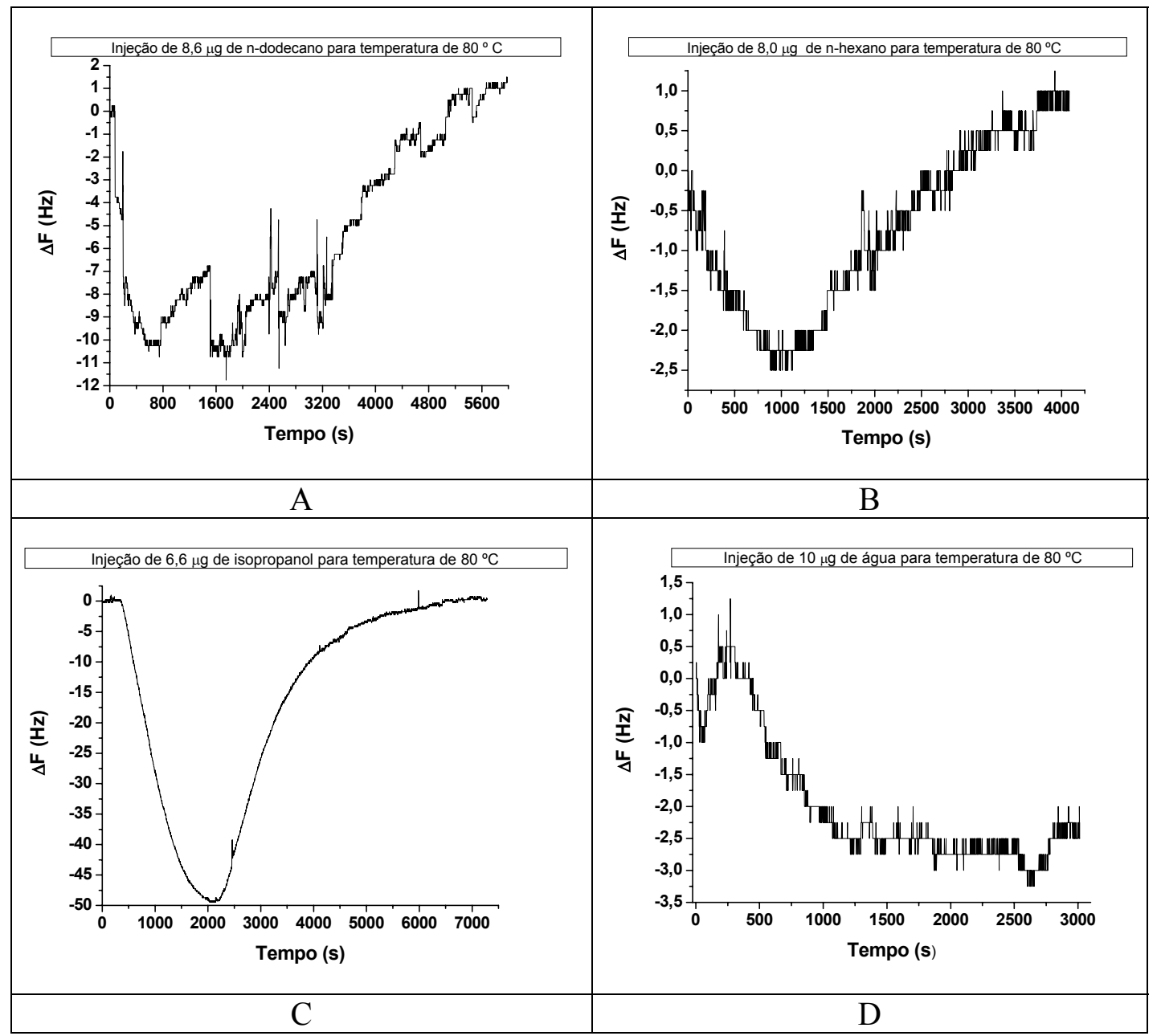

Figura 3.32. Medida de QCM gasoso e injeção de n-Dodecano (A), n-Hexano (B), 2-Propanol

$$
\text { (C) e água (D). }
$$

Avaliação da reprodutibilidade/limites de uso da coluna

Para melhor compreender o comportamento da estrutura quando usada como coluna cromatográfica, esta foi testada continuamente, isto é, em injeções seqüenciais. Cada injeção corresponde a um tempo mínimo de uma hora de análise (com fluxo contínuo de gás) e os principais resultados encontram-se na Tabela 3.3. A adição de água ( $1^{\mathrm{a}}$. Injeção) atrasa a saída dos outros componentes e para a injeção subsequente ( $2^{\mathrm{a}}$. Injeção) a eluição decorre mais rápida, novamente porque o reagente não interage com a superfície, que se encontra saturada. $\mathrm{O}$ uso apenas de reagentes apolares (n-Hexano e n-Dodecano) mostra já na segunda aplicação (4a . Injeção seqüencial) uma superfície saturada e que interage pouco com o reagente, gerando dois 
tempos de retenção curtos - correspondentes à perda de reagente que não interagiu com a superfície - e outro maior, com valor semelhante ao obtido para a injeção anterior $(22,81$ min e 22,94 min, respectivamente). Assim, o uso da estrutura como coluna cromatográfica só será possível se reagentes polares, como água, não forem simultaneamente admitidos nestas ou estiverem em pequena quantidade.

Tabela 3.3. Injeções seqüenciais e a os principais tempos de retenção obtidos. Os resultados são mostrados na ordem de injeção.

\begin{tabular}{|c|c|c|c|}
\hline $\begin{array}{c}\text { Misturas injetadas } \\
\text { (\% em vol.) }\end{array}$ & \multicolumn{3}{|c|}{ Tempos de retenção (min) } \\
\hline $\begin{array}{c}\text { 2-Propanol:n-Hexano: } \\
\text { água (1:1:1) }\end{array}$ & 72,38 & 74,34 & 76,12 \\
\hline $\begin{array}{c}\text { 2-Propanol:n-hexano: } \\
\text { água (1:1:1) }\end{array}$ & 19,95 & 22,58 & 34,00 \\
\hline $\begin{array}{c}\text { n-Hexano:n-Dodecano } \\
\text { (1:1) }\end{array}$ & 22,81 & 27,68 & -- \\
\hline $\begin{array}{c}\text { n-Hexano:n-Dodecano } \\
(1: 1) *\end{array}$ & 4,39 & 10,70 & 22,94 \\
\hline \multicolumn{3}{|c|}{ * - superfície saturada e injeção de $50 \mu \mathrm{L}}$. \\
\hline
\end{tabular}

Desde que as amostras tenham menor volume de reagentes $(<1 \mu \mathrm{L})$ o uso destas estruturas como colunas cromatográficas, ou seja, obtendo-se os valores de tempo de retenção semelhantes (por exemplo, próximo a 22 minutos, como 22,81 min e 22,94 min citados anteriormente) em várias inserções distintas é possível. Porém, essa coluna apresenta tempo de retenção alto provavelmente devido aos nanocanais.

Os resultados indicaram que a microestrutura pode agir como uma coluna cromatográfica para compostos apolares, mas não para polares, devido à forte interação e formação de pontes de hidrogênio. Assim, o fator de separação para compostos apolares e coluna extremamente seca, isto é, semelhante à de Figura 3.24, foi calculado utilizando-se uma solução de 50\% de n-Hexano $+50 \%$ de n-Dodecano e temperatura ambiente. A Figura 3.33 apresenta os resultados típicos onde o fator de separação obtido é de 0,8 aproximadamente, ou seja, é possível a separação. Este fator de separação pode aumentar ligeiramente com o aumento da temperatura, porém, devido ao grande tempo de adsorção dos reagentes o número de pratos teóricos é baixo, o que não favorece melhor fator. 


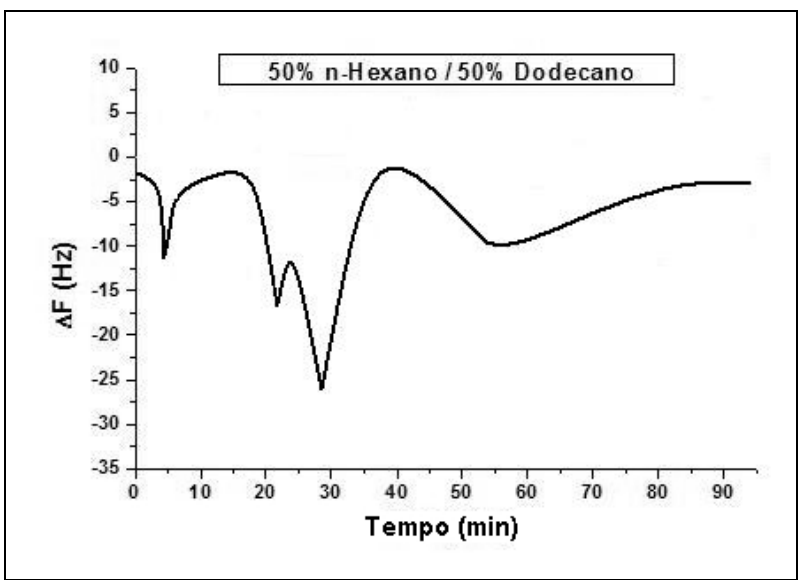

Figura 3.33. Variação da freqüência em função do tempo para injeção de $10 \mu \mathrm{L}$ de solução de $50 \%$ de n-Hexano $+50 \%$ de n-Dodecano.

Para avaliar o principal interferente, água, para uma condição onde a coluna foi exposta a grande quantidade de água, a adição de mistura $50 \%$ em vol. de n-Dodecano e n-Hexano corresponde a uma rápida saída da estrutura (Figura 3.34), pois a permeação da mistura nos microcanais é baixa. A saída dos reagentes provavelmente ocorre por simples exclusão de tamanho, mas as medidas não podem ser quantitativas, ou mesmo semi-quantitativa. Nestas condições a coluna não pode ser usada para análise, mas pode ser adequada para processos e, de fato, Carvalho [11] já utilizou arranjo semelhante como microreator.

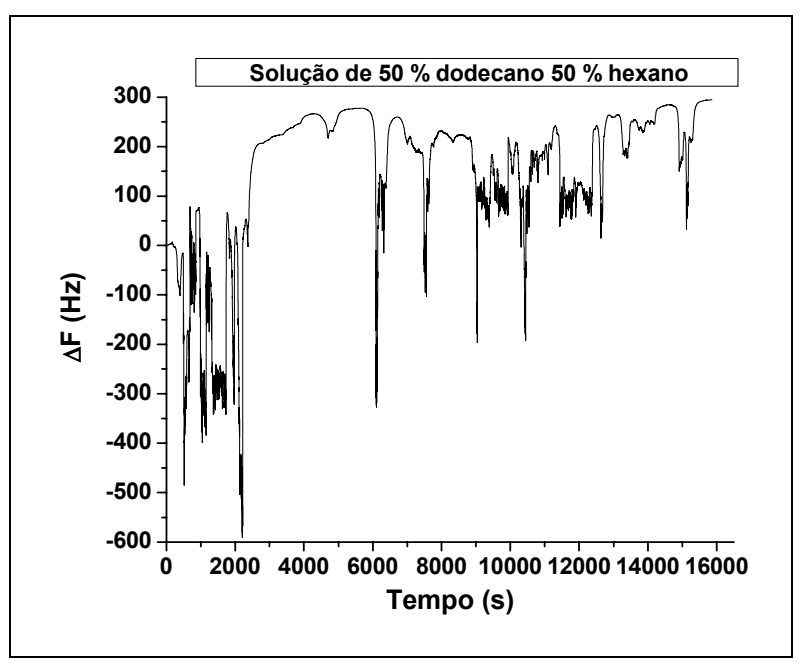

Figura 3.34. Medida de QCM gasoso para solução 50 \% em vol. de n-Dodecano + n-Hexano. 


\subsubsection{Filme após a reação com água e exposição a vapor de HMDS}

As medidas após a modificação superficial do filme ocorreram na ordem crescente de polaridade dos reagentes, de modo semelhante às medidas anteriores. A Figura 3.35 apresenta resultados típicos $\mathrm{O}$ n-Dodecano, mostrado na Figura 3.35a, apresenta o comportamento oscilatório, os valores de diferença de freqüência menos acentuados e requer um maior tempo para que picos maiores (a 8000 e 16000 segundos) sejam obtidos. Provavelmente o reagente está saturando a estrutura, mas a interação é maior que a do filme antes da exposição ao HMDS e apenas uma pequena quantidade sai por longo período de tempo. A adição de n-Hexano (Figura 3.35b) permite a remoção de material fracamente adsorvido, que ocorre em aproximadamente 1000 segundos. O segundo pico obtido, em aproximadamente 5000 segundos, deve-se provavelmente a remoção do próprio n-Hexano. A adsorção de compostos polares também é possível e com o sistema contaminado em sua superfície por compostos apolares (n-Dodecano e n-Hexano) a injeção de 2-Propanol, composto polar, leva à eluição (Figura 3.35c). Nota-se uma gaussiana alargada, mas que se inicia rapidamente devido à expulsão dos compostos presentes no filme ocasionada pela interação do 2-Propanol, que deve ser forte, pois a eluição ocorre rapidamente, ou seja, um comportamento útil na pré-concentração. A injeção de água após o uso de 2-Propanol (Figura 3.35d) indica a remoção de compostos. Isto deve ocorrer por interação com o 2-Propanol adsorvido nos nanocanais do filme, o que permitiu a retenção de água. A molécula de água, menor que a de álcool, tem uma maior facilidade de expulsar o que tiver agregado no filme. 


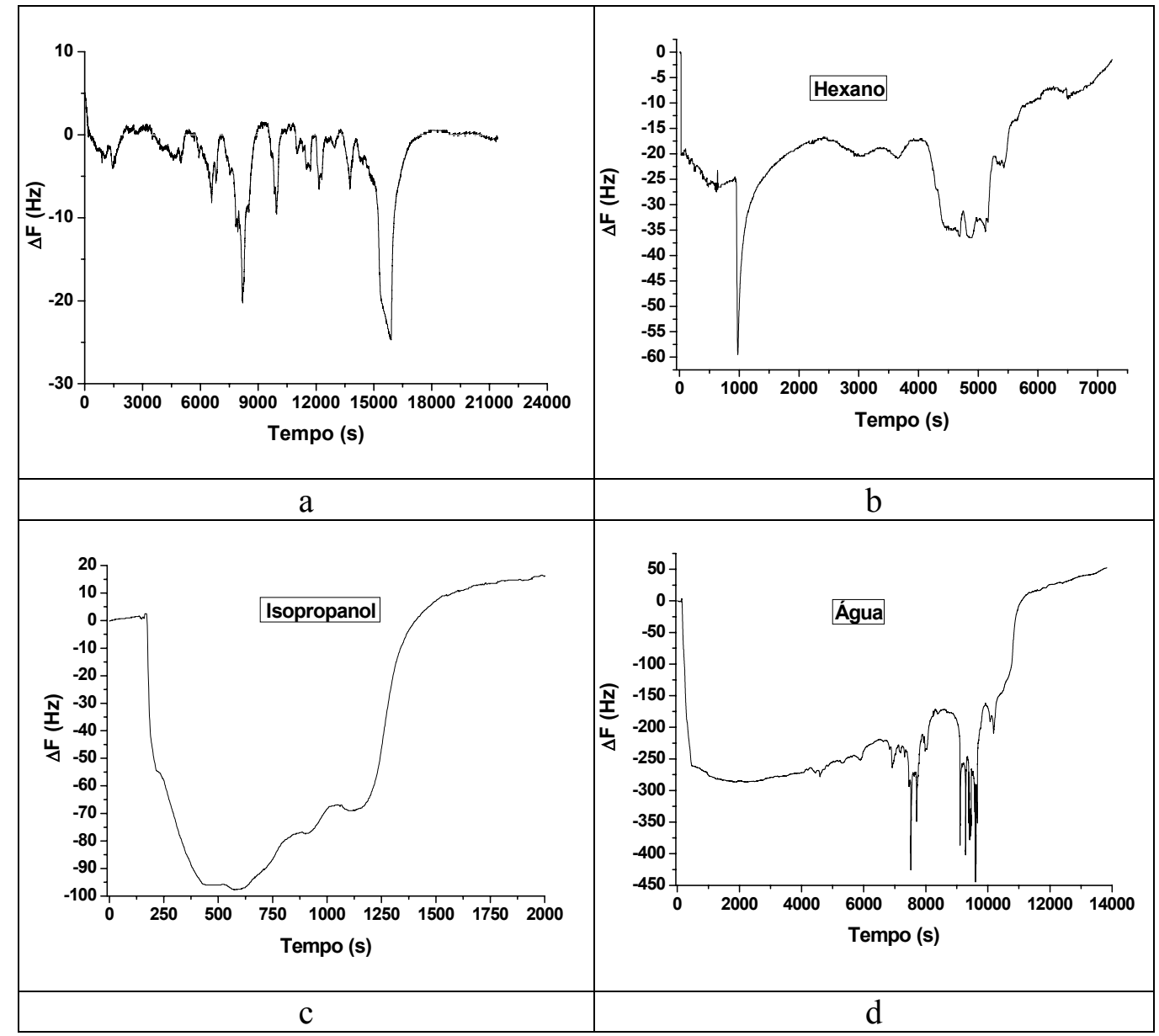

Figura 3.35. Medida de QCM gasoso: (a) n-Dodecano, (b) n-Hexano, (c) 2-Propanol e (d) água.

Se na superfície encontram-se adsorvidos compostos polares (2-Propanol e água) a estrutura tem um comportamento de fase estacionária polar. A injeção da mistura $50 \%$ em vol. de n-Dodecano + n-Hexano não permite a separação dos compostos e estes deixam a coluna rapidamente, como pode ser visto na Figura 3.36. Observe-se que o tempo de retenção é dez vezes menor que os observados para a coluna sem exposição ao HMDS (da ordem de 20 minutos). 


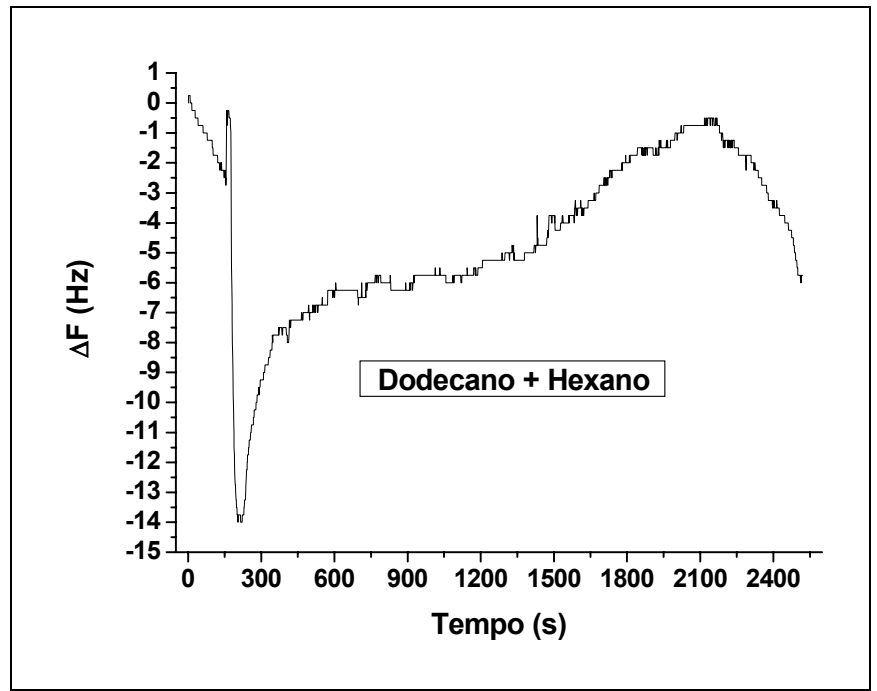

Figura 3.36. Medida de QCM gasoso para mistura $50 \%$ em vol. de n-Dodecano + n-Hexano.

A comprovação de que compostos apolares podem deixar a coluna rapidamente é feita por nova adição de n-Hexano (Figura 3.37) e claramente nota-se o mesmo comportamento observado para Figura 3.36.

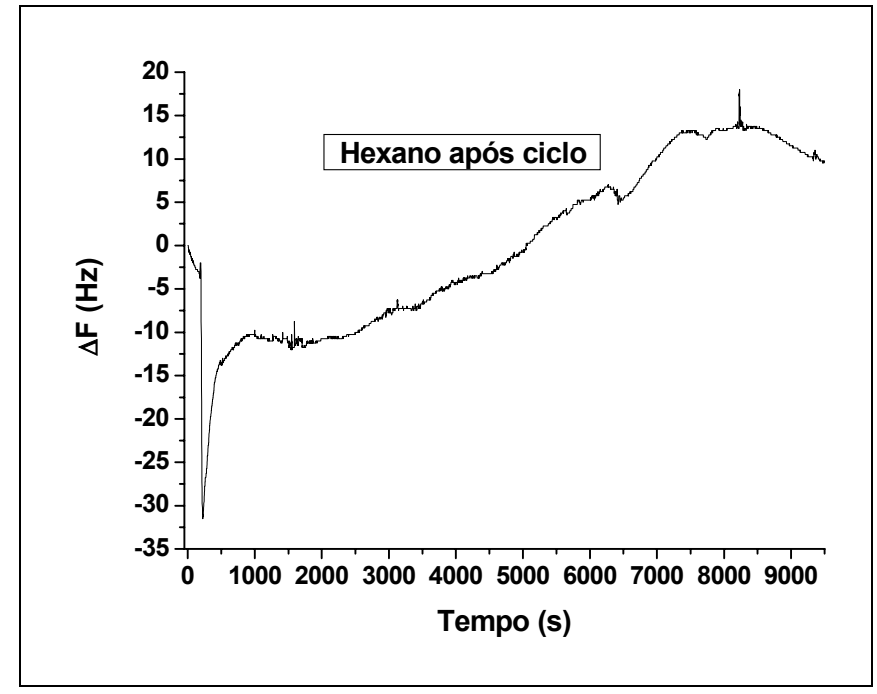

Figura 3.37. Medida de QCM gasoso para n-Hexano.

A reprodutibilidade da superfície foi avaliada com aquecimento a $80{ }^{\circ} \mathrm{C}$, injeção seqüencial de $10 \mu \mathrm{L}$ do mesmo reagente por, no mínimo, três vezes. A seqüência de inserção dos reagentes deu-se em ordem crescente de polaridade. 
A injeção de seqüencial de n-Hexano pode ser vista na Figura 3.38. As duas primeiras injeções permitem a remoção de material adsorvido enquanto a última corresponde a eluição do composto. Neste caso o tempo de retenção diminui em $50 \%$, como pode ser observado pela comparação com a Figura 3.35.

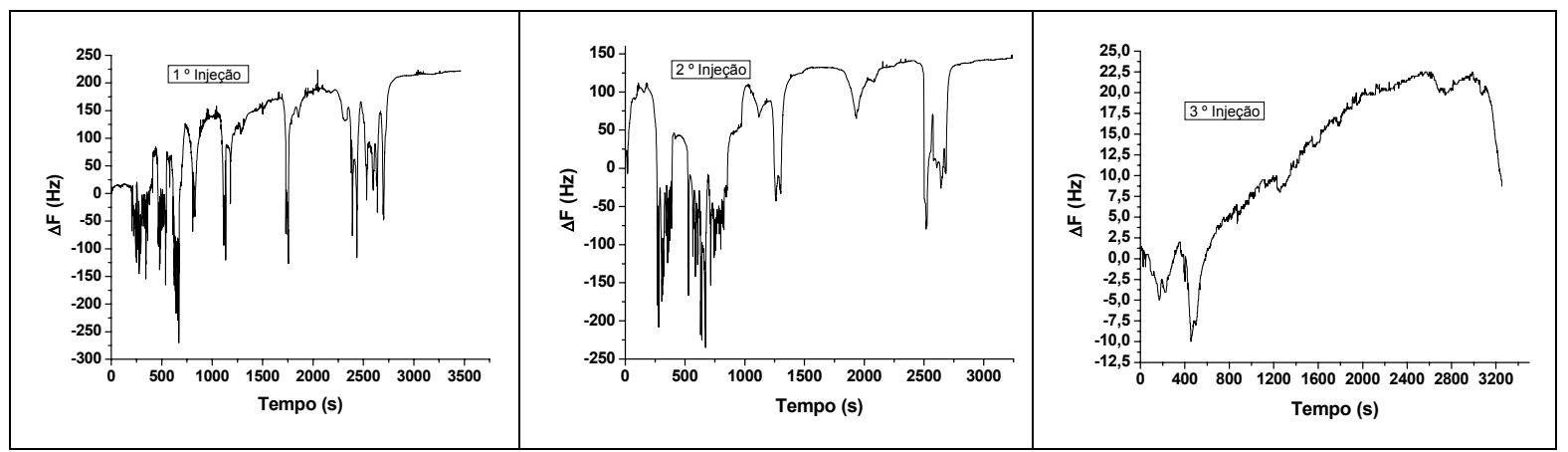

Figura 3.38. Injeção de seqüencial de n-Hexano.

A adição de n-Dodecano apresenta comportamento similar ao encontrado em n-Hexano como indica a Figura 3.39. Inicialmente ocorre pouca dessorção e por isso a linha de base aparenta estar ruidosa. Posteriormente, o reagente começa a deixar a coluna de modo similar ao encontrado para n-Hexano, com dessorção simultânea de outros compostos. Contudo, devido a seu tamanho, a eluição ocorre em tempo maior do que para n-Hexano $(1600 \mathrm{~s}$ e $500 \mathrm{~s}$, respectivamente).

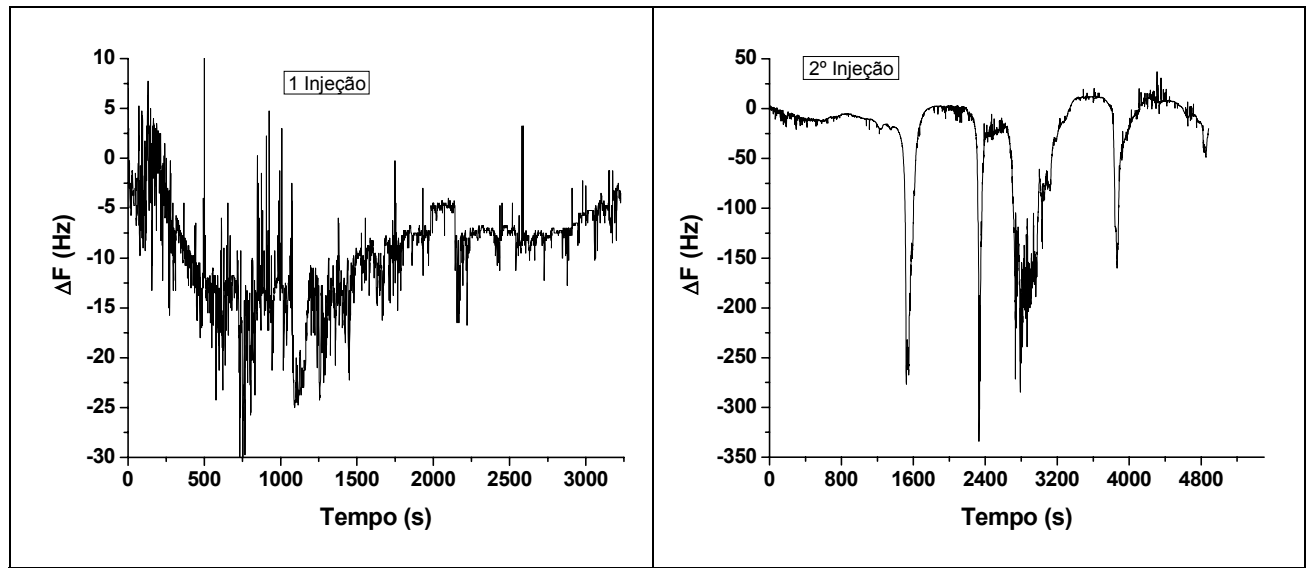

Figura 3.39. Injeção de seqüencial de n-dodecano.

A adição de 2-Propanol mostra resultados bastante reprodutíveis e na Figura 3.40 encontram-se resultados típicos. A banda larga obtida também indica interações fortes com o substrato. A análise de 2-Propanol não apresenta diferença no tempo de retenção se comparada a medidas em temperatura ambiente (Figura 3.52), portanto, não há melhoras no número de pratos 
teóricos $(\sim 70)$. Provavelmente isto decorre do alto volume adicionado de reagente, o que torna o fator de capacidade da coluna crítico. Contudo, a vantagem da adição de grande volume é a verificação do comportamento da coluna em condições desfavoráveis.

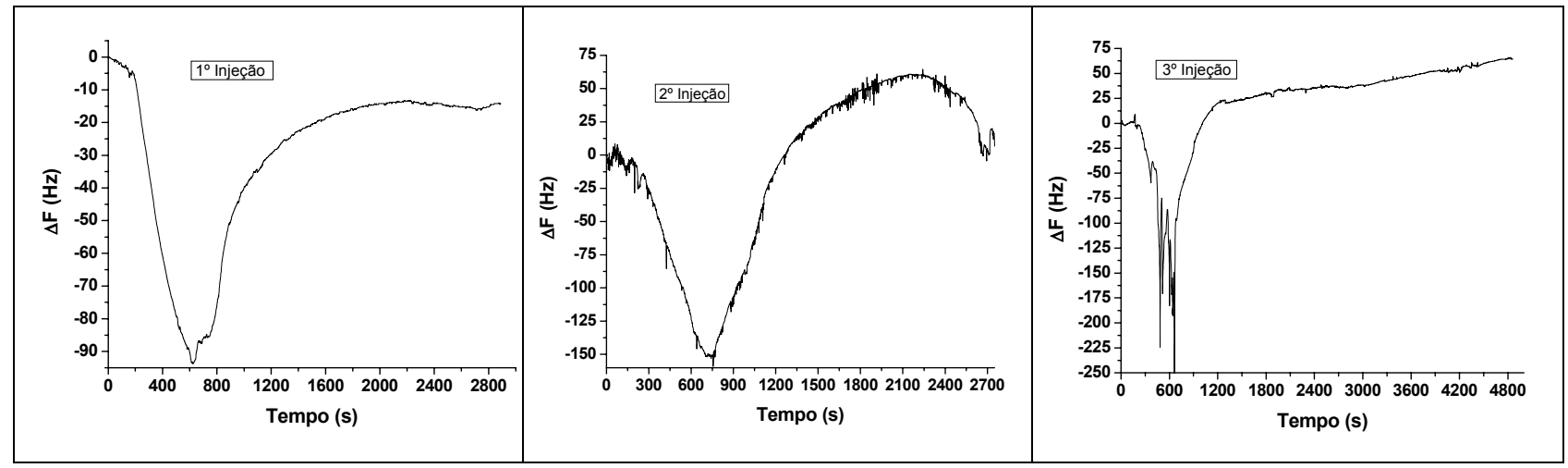

Figura 3.40. Injeção de seqüencial de 2-Propanol.

A injeção de água na coluna não permite separação desta e o reagente distribui-se por todo o filme devido ao aquecimento, facilitando a remoção de 2-Propanol ainda existente. A Figura 3.41 apresenta resultados típicos.

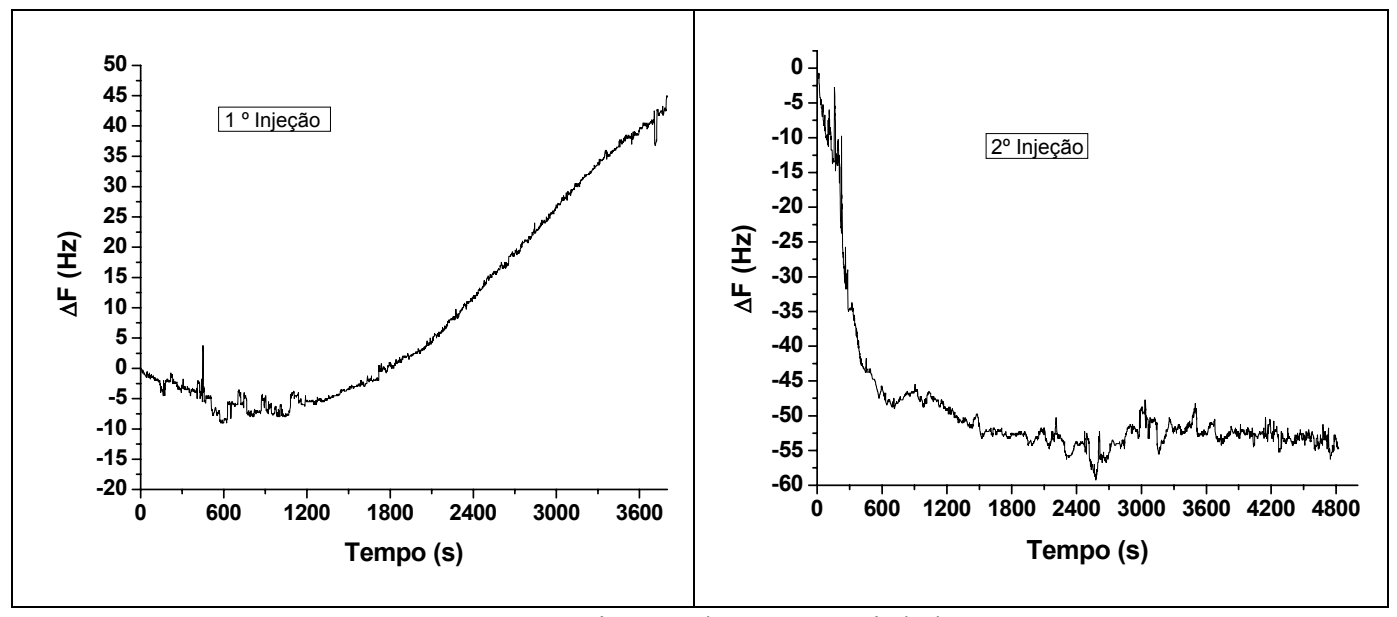

Figura 3.41. Injeção de seqüencial de água.

Portanto, a modificação superficial por exposição a vapor de HMDS efetivamente ocorreu e permitiu, de forma similar, a adsorção tanto de compostos apolares quanto de compostos polares. A posterior remoção desses reagentes ocorre de forma mais rápida nessa microcoluna, reduzindo o tempo de análise, diferentemente da estrutura com filme fino à base de TEOS e condicionada por imersão em água, que adsorve preferencialmente compostos polares e dificulta a remoção de alguns compostos, como água. O grande volume de n-Dodecano adsorvido e a 
facilidade de remoção deste utilizando 2-Propanol indicam que essa coluna é adequada para préconcentração de compostos orgânicos, o que é bastante útil na análise de VOC's.

Sob aquecimento, esta coluna mostrou-se reprodutível para uso na análise de n-Hexano e 2-Propanol, dois compostos importantes para determinação de VOC's. Um provável protótipo, contudo, deve utilizar inserção de quantidade menores de $1 \mu \mathrm{L}$, e o número de pratos teóricos é pequeno, correspondendo a 20 e 70, para n-Hexano e 2-Propanol, respectivamente. É importante observar que as colunas cromatográficas capilares, de modo geral, apresentam tamanhos que variam de 10 a 100 m, ou seja, são maiores do que as testadas aqui. Pode-se considerar seu uso também como pré-coluna em cromatógrafos miniaturizados, para uso em campo.

\subsubsection{Microcanais tridimensionais e medidas em fase líquida}

Estes microcanais tridimensionais já foram testados anteriormente em fase líquida, quanto à pré-concentração de compostos orgânicos [9], mas existem algumas dificuldades em seu uso, pois a molécula atinge a superfície do canal apenas por difusão, que é lenta. Além disso, os filmes à base de TEOS também irão apresentar competição da água pela superfície do filme. Por outro lado, filmes após a exposição à HMDS são hidrofóbicos, o que pode favorecer a adsorção de compostos orgânicos.

A análise da coluna em fase líquida (água como fluído) e detecção por QCM não apresenta retenção significativa de compostos orgânicos usando o filme à base de TEOS condicionado, isto é, após hidrólise. Para o filme que foi exposto ao HMDS, tanto compostos polares quanto apolares foram retidos por vários minutos - de 30 minutos à uma hora - no sistema; contudo, a quantidade é pequena, certamente menor que $1 \mu \mathrm{L}$, ou seja, na faixa de 0,1 $\mu \mathrm{L}$. A remoção destes compostos aprisionados requer muito volume de fluído. Assim, o uso do filme em cromatografia líquida provou ser inadequado pelo grande tempo de retenção e não foi possível encontrar uma condição em que este filme funcionasse como pré-concentrador. Quanto à retenção de compostos orgânicos em fase líquida, posteriormente será definida uma estrutura que apresenta melhores propriedades.

Quanto à retenção de compostos iônicos, testes usando potencial elétrico e solução aquosa saturada de sulfato de cobre II foram efetuados. A aplicação de potencial elétrico mostrou-se 
efetiva por dois aspectos: o controle da corrente consumida indica que o processo pode ser quantitativo e ocorre em amostras em que não há controle de contaminação da água por compostos orgânicos.

Devido ao pequeno volume do canal $\left(9.10^{-4} \mathrm{~cm}^{3}\right)$ a inserção de amostra deve ser na ordem de $n L$, o que é de difícil implantação, portanto valeu-se de um artifício. Os testes usaram água DI e fluxo de $1 \mathrm{ml} / \mathrm{min}$. A esse fluxo adicionou-se pequenos pulsos (entre 10 e $100 \mu \mathrm{L}$ ) de solução aquosa saturada de sulfato de cobre, que será removido da estrutura pelo fluxo de água em cerca de $60 \mathrm{~ms}$; após a remoção desta uma pequena película ${ }^{1}$ uma amostra de cerca de $100 \mathrm{~nL}$, ou máximo de $90 \mathrm{nmol}$ de sulfato de cobre, resta sobre a superfície do canal.

A Tabela 3.4 apresenta os resultados das medições de corrente e potencial elétrico para solução aquosa saturada de sulfato de cobre. As soluções foram produzidas utilizando-se água DI, para evitar contaminações de outros sais. A aplicação de potencial elétrico na estrutura sem a presença da solução apresenta corrente zero durante a passagem de água DI. Após primeiro pulso de solução a corrente sobe rapidamente chegando a $0,25 \mathrm{~mA}$, e posteriormente retorna para próximo de zero. O comportamento é semelhante para sucessivas injeções. Após sucessivas aplicações de potencial elétrico e injeções de sulfato de cobre a microestrutura foi sempre desmontada e o microcanal analisado por microscopia óptica e continuamente observa-se formação de cobre metálico na superfície do filme, como mostra a Figura 3.42. Observa-se, de modo semelhante ao descrito anteriormente, a formação de clusters em regiões específicas da estrutura, principalmente porque a queda de potencial se dá entre o núcleo e a saída de fluído. Avaliando-se a área recoberta da estrutura e/ou a corrente consumida é possível estimar o consumo do íon de cobre da solução, isto é, o total que pode ser retido pelo conjunto, da ordem de $10 \mathrm{nmol}$ por pulso, ou seja, no máximo $11 \%$ de recuperação. A retenção também ocorre em soluções diluídas e corresponde a um alto valor se considerarmos que o fluxo de água foi mantido durante a aplicação de tensão, o que facilita a remoção do sal. Após o quinto pulso, as pequenas dimensões do canal começam a ser preenchidas pelos clusters de cobre, o que diminui a vazão, além disso, a corrente quase cessa, mesmo com a aplicação de tensões superiores a 4 Volts.

\footnotetext{
${ }^{1}$ valor estimado por simulação.
} 
Tabela 3.4. Valor mínimo de potencial elétrico e máximo corrente para diferentes volumes de $\mathrm{CuSO}_{4}$ e o mínimo tempo necessário para ocorrer tal condição.

\begin{tabular}{|c|c|c|c|c|}
\hline $\mathbf{N}^{\mathbf{0}}$. do pulso & $\begin{array}{c}\text { Vol. de CuSO } \\
\text { injetado }(\mu L)\end{array}$ & $\begin{array}{c}\text { Tempo } \\
\text { (segundos) }\end{array}$ & $\begin{array}{c}\text { Potencial elétrico } \\
\text { mínimo (Volts) }\end{array}$ & $\begin{array}{c}\text { Corrente máxima } \\
(\mathbf{m A})\end{array}$ \\
\hline 1 & 50 & -- & -- & 0,25 \\
\hline 2 & 50 & -- & -- & 0,25 \\
\hline 3 & 100 & -- & -- & 0,25 \\
\hline 4 & 100 & 40 & -- & -- \\
\hline 5 & 20 & 40 & 4,4 & 0,08 \\
\hline 6 & 20 & 38 & 4,65 & 0,06 \\
\hline 7 & 10 & 60 & 4,61 & 0,02 \\
\hline
\end{tabular}

--- = muito rápido, difícil estimar corretamente os dados.

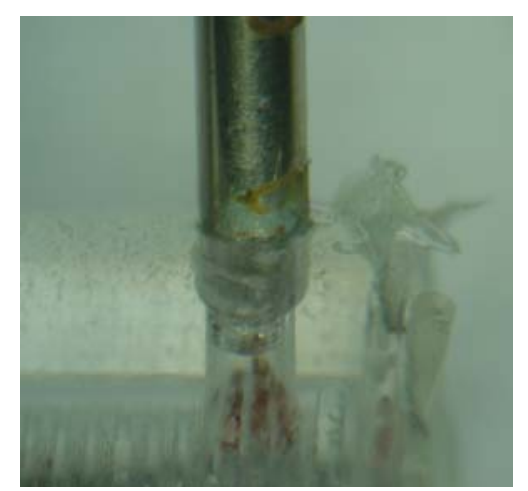

Figura 3.42. Formação de cobre metálico dentro do filme (120X).

O problema da formação de clusters que obstruem a coluna pode ser minimizado com aplicação do potencial elétrico igualmente distribuído ao longo do canal, como pode ser visto na Figura 3.43. A Tabela 3.5 apresenta para duas medidas diferentes o tempo necessário para o valor máximo de corrente ser obtido e a respectiva corrente. Isto significa que a remoção do íon foi quantitativa, mesmo se houver compostos orgânicos presentes, por exemplo, por contaminação intencional do fluxo de água com 2-Propanol. Além disso, o tempo necessário para obter a corrente máxima é similar nas duas medidas, indicando que o sistema pode ser utilizado em mais de um experimento. As pequenas diferenças nos valores máximos de corrente podem ser 
relacionadas à deposição de cobre durante o experimento. Por fim, o comportamento pode ser obtido nas estruturas com filme à base de TEOS exposto ou não ao vapor de HMDS.

De modo geral, não há interesse na remoção de íons e sim em sua detecção ou separação de uma amostra mais complexa. Portanto, o uso desta estrutura justificar-se-ia apenas pela proteção da área de deposição pelo filme fino, o que pode ser conseguido com uma estrutura mais simples abordada a seguir.

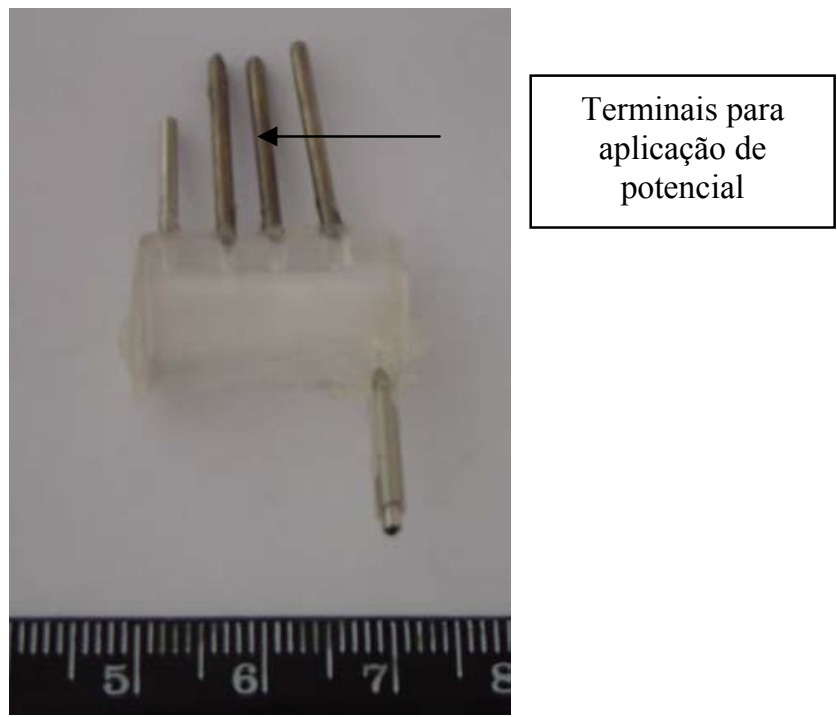

Figura 3.43. Coluna com aplicação de potencial elétrico distribuído ao longo do canal.

Tabela 3.5. Valor máximo de corrente obtido para a solução aquosa de $\mathrm{CuSO}_{4}$ e o mínimo tempo para obter tal resposta.

\begin{tabular}{|c|c|c|c|}
\hline Teste & $\begin{array}{c}\text { Vol. CuSO } \\
(\boldsymbol{\mu L})\end{array}$ & Tempo (aq) & $\begin{array}{c}\text { Corrente máxima } \\
(\mathbf{m A})\end{array}$ \\
\hline $\mathbf{1}$ & 10 & 510 & 11,5 \\
\hline $\mathbf{2}$ & 20 & 660 & 6,6 \\
\hline
\end{tabular}

\subsubsection{Com canal planar}

A possibilidade de deposição em fluxo contínuo (roll-to-roll) do filme de TEOS sobre celulose apresenta inúmeras vantagens, pois a celulose é um substrato ambientalmente correto e de baixo custo, além disso, tanto eletrodos como canais podem ser obtidos por processo de 
adesão, isto é, sem deposição em fase gasosa. Deste modo uma estrutura simples foi proposta, como esquematizada na Figura 3.44a. Os materiais utilizados, além da celulose com filme a base de TEOS depositado em sua superfície, são: acrílico, fita adesiva, metálica e acrílica, e PVC de 2 mm de espessura. O uso de acrílico deve-se apenas a seu baixo custo. A fita acrílica (3M, Scotch YR-9767) provê adesão entre as camadas, permitindo pressão interna nos canais de até 3 atm [9]. Para a montagem do arranjo, a celulose é imobilizada sobre acrílico, que funciona apenas como suporte mecânico. A fita metálica é então aderida ao filme, formando dois contatos elétricos. A fita acrílica é usada para aderir o PVC, cortado mecanicamente para formar o canal de $10 \mathrm{~mm}$ de comprimento e $1 \mathrm{~mm}$ de largura, e nova placa de acrílico, com um orifício definido mecanicamente, sela o conjunto. Nos testes, prendedores do tipo clips foram usados para facilitar a conexão à garra e suporte universal; portanto o conjunto fica suspenso facilitando a manipulação e evitando vazamentos (Figura 3.44 b e c). O procedimento de teste é adicionar uma gota $(5 \mu \mathrm{L})$ de solução no centro do canal e aplicar tensão entre os eletrodos, que no presente caso foi de $4 \mathrm{~V}$, suficiente para reduzir os íons da solução.

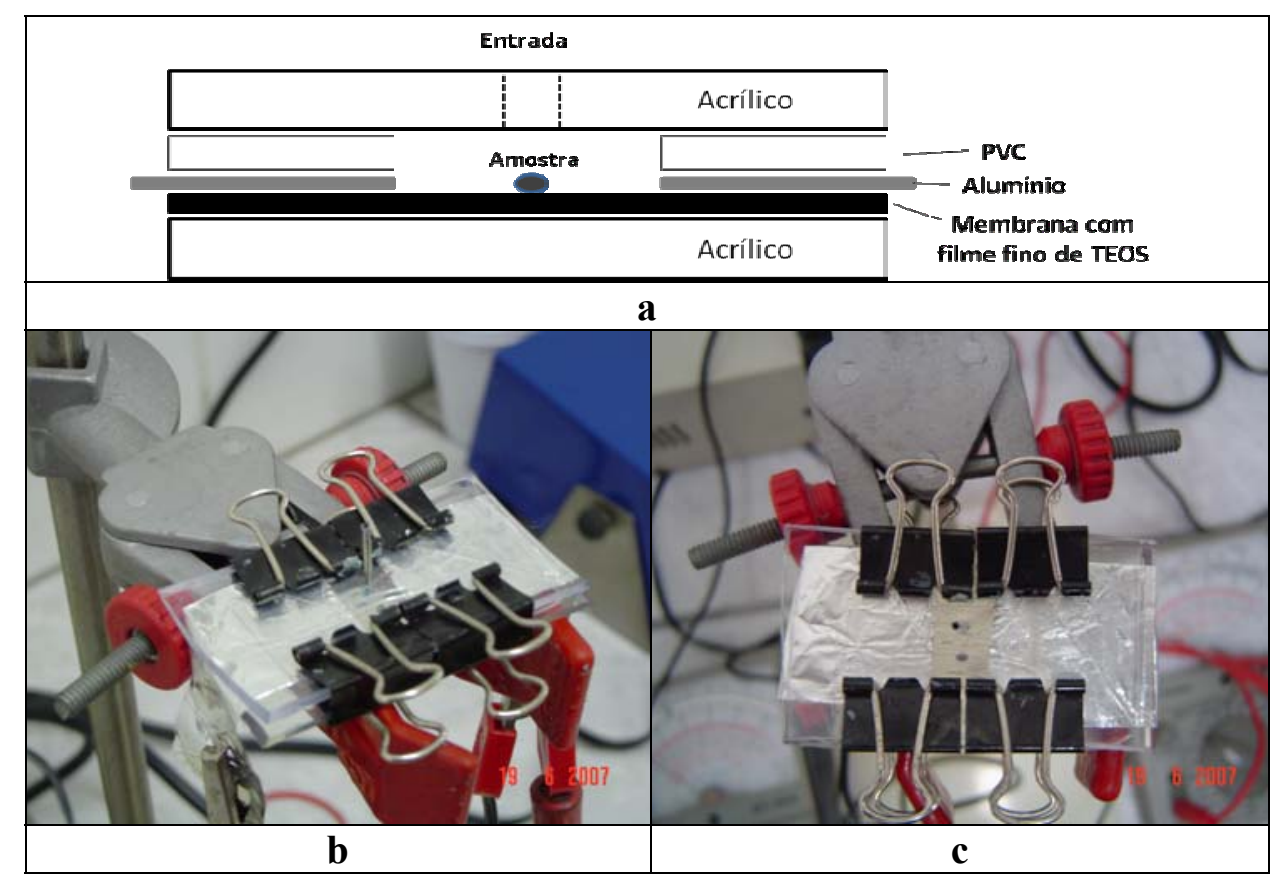

Figura 3.44. Esquema e fotos do arranjo utilizado para testes do filme para separação de íons em fase líquida. 
Se a solução aquosa saturada de $\mathrm{CuSO}_{4}$ é adicionada sem aplicação de tensão, para a celulose com ou sem tratamento, percebe-se variação na fita de alumínio no mesmo período de tempo e simultaneamente nos dois contatos, que se oxidam. Por outro lado, com a aplicação de tensão, o uso de celulose modificada pelo filme favorece a migração do íon de cobre, que ocorre cerca de $10 \%$ mais rápido se comparado à celulose sem tratamento. Como simultaneamente ocorre também a difusão, para celulose sem tratamento observa-se corrosão nos dois eletrodos enquanto para celulose modificada obtém-se apenas em um dos eletrodos, como apresentado na Figura 3.45.

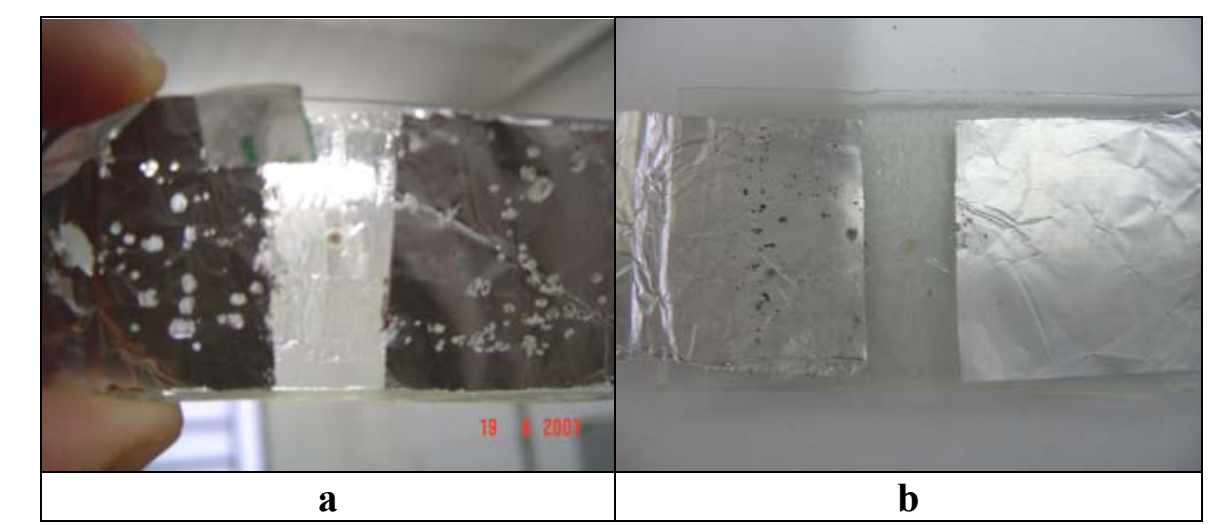

Figura 3.45. Corrosão do alumínio usado como contato (a) na celulose e na (b) celulose tratada com deposição do filme à base de TEOS.

Além disso, a medida de potencial elétrico neste arranjo não mostra variação significativa ao longo do tempo para a membrana de celulose sem filme. Por outro lado, a injeção de amostra com a celulose modificada pode levar a grandes variações de potencial elétrico, provavelmente devido à permeação do íon por caminhos preferenciais e a respectiva reação de óxido-redução, que varia o potencial elétrico medido. $\mathrm{O}$ uso de outros íons, como os testados anteriormente, não apresenta variação de comportamento, ou seja, não se trata de eletroforese ou técnica semelhante. Um possível uso desse arranjo é para separação de íons em amostras complexas, como as ambientais, para análise de água, ou mesmo biológicas, onde o contra-íon pode corresponder a uma molécula de grande massa molecular. Assim, com este artifício é possível separar os íons previamente à detecção. 


\subsubsection{Membranas (substrato flexível)}

Uma cavidade selada também pode ser produzida com os processos utilizados para a fabricação do canal planar. Contudo, neste caso é interessante avaliar a passagem dos íons no corpo da celulose e a aplicação de tensão, bem como a deposição do filme fino, deve ocorrer dos dois lados da membrana. A Figura 3.46 esquematiza a construção da cavidade. $O$ diâmetro da cavidade é de 1" (uma polegada), isto é, igual ao do tubo em "U" usado previamente. Para medidas de condutividade um tubo em "U" foi adaptado, para permitir obter o volume de solução necessária. Verificou-se o comportamento da corrente na membrana usando-se solução aquosa saturada de cobre II. A Figura 3.47 mostra o resultado da corrente e condutividade pela aplicação de potencial elétrico em função do tempo. Nos gráficos indicam-se também a região onde o potencial elétrico é aplicado e seu respectivo valor em relação à região com água destilada.

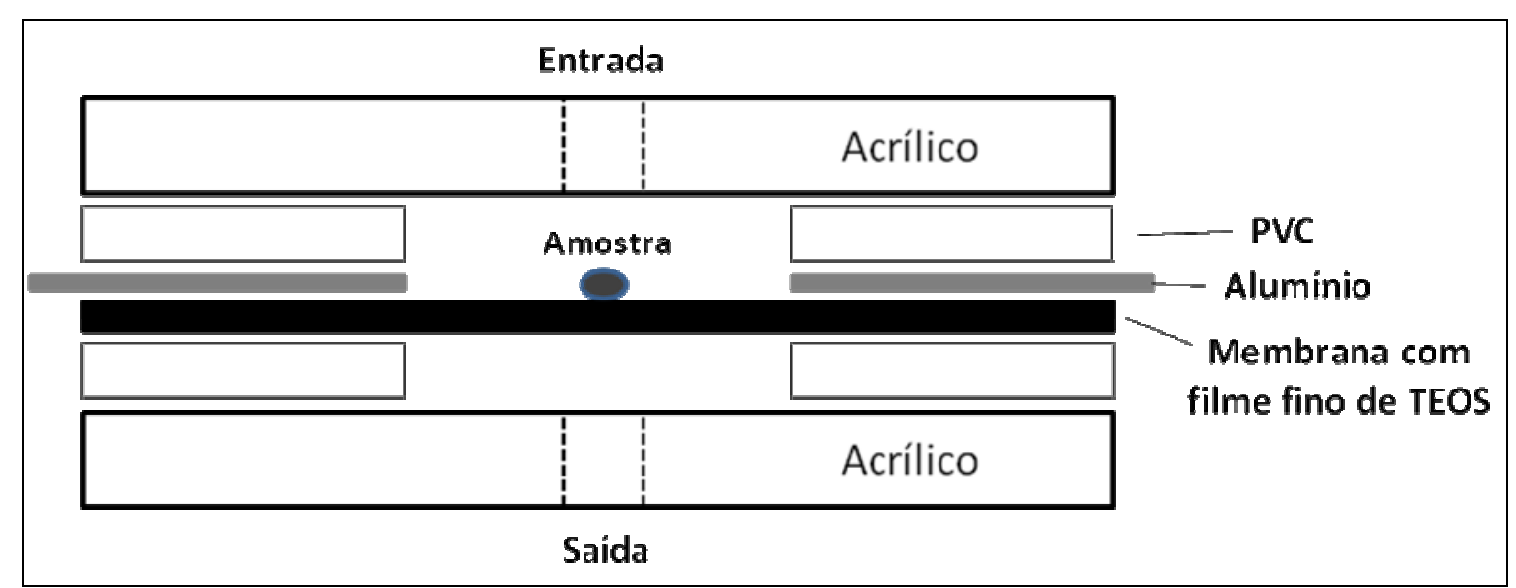

Figura 3.46. Esquema da construção de uma cavidade selada utilizando celulose modificada pela deposição de filme a base de TEOS.

Para a celulose a corrente é alta já no início do processo, ou seja, não há difículdade de passagem de íons. Provavelmente, como o potencial elétrico aplicado favorece a permeação de cobre, a repulsão que se segue diminui a corrente total medida. Mesmo sem potencial elétrico aplicado a condutividade aumenta porque a celulose não oferece barreira à passagem de sais.

Inicialmente, para TEOS, a corrente é pequena devido à necessidade de hidrólise do filme, após a hidrólise a corrente muda rapidamente. Contudo, provavelmente, como o filme ao longo do tempo impregna-se com os íons, a condutividade oscila, ou seja, não apresenta o comportamento ascendente observado para celulose. Portanto, esse dispositivo simples pode ser 
facilmente adaptado para recolher amostras onde o contra-íon é molécula de grande peso molecular para posterior análise.

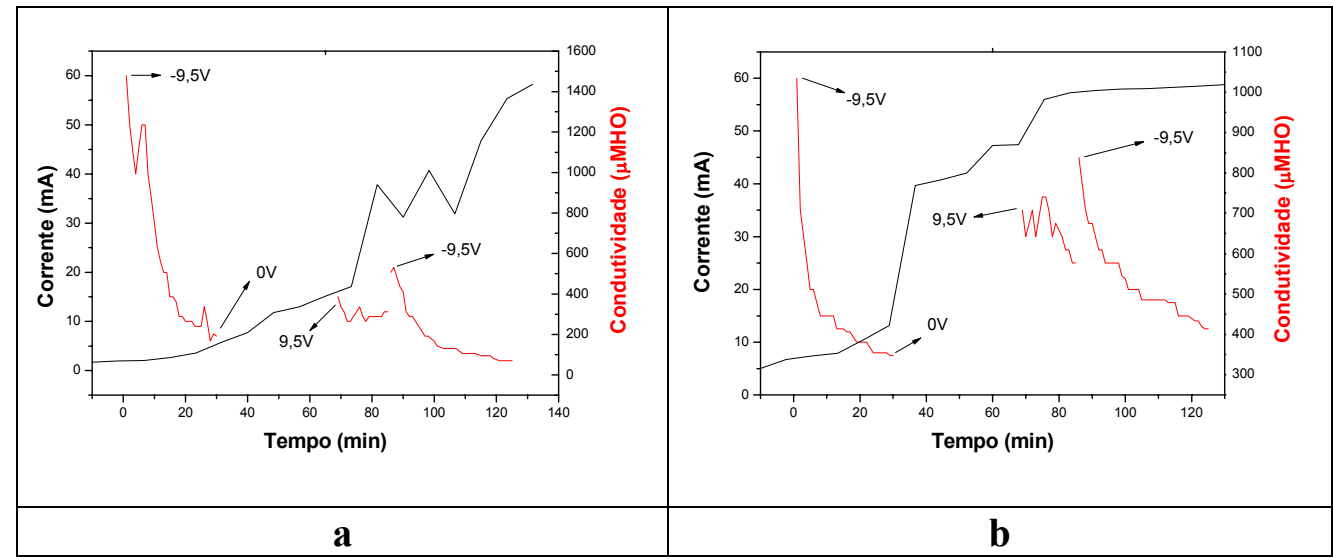

Figura 3.47. Resultado da corrente e condutividade pela aplicação de potencial elétrico em função do tempo para (a) celulose (b) celulose modificada.

\subsubsection{Modificação pelo recobrimento de eletrodos}

O filme à base de TEOS demonstrou que pode ser uma boa opção para proteção de eletrodos quando o contra-íon é uma molécula de grande massa molecular; contudo, em sistemas mais complexos, como em análises ambientais, é comum a existência de macro moléculas de origem orgânica e altíssimo peso molecular. Nesse caso, a proteção dos nanocanais do filme apesar de suficiente não será adequada, pois estes poderão ser obstruídos mesmo antes da análise ocorrer. Deste modo é necessário providenciar camadas anteriores de proteção.

Um material com boa capacidade de adsorção é o amido modificado [11], onde a modificação é obtida pela deposição por plasma de um filme a base de HMDS. As partículas têm 5 ou $50 \mu \mathrm{m}$ de diâmetro e, devido ao filme protetor, são hidrofóbicas mas permitem a adsorção e permeação de compostos orgânicos, polares e apolares. Portanto, esse produto possui um substrato altamente adsorvente protegido por um filme hidrofóbico.

Para avaliar o uso destas partículas modificadas para aumento da área de adsorção utilizou-se o conceito de traçadores, que já foi aplicado no desenvolvimento de estruturas várias vezes [6]. Neste caso é necessário verificar o comportamento físico-químico da partícula para adsorção de compostos orgânicos e iônicos, e para tanto utilizaram-se corantes e pigmentos, 
respectivamente. A área de teste é planar, sua fabricação foi por processo semelhante ao de fabricação e aplicação de uma tinta, isto é, por processo de silk screen manual. Contudo, a aplicação do produto não pode usar água como veículo de transporte e/ou homogeneização, devido às propriedades do filme fino depositado. Assim, os testes utilizaram para fabricação da tinta, aplicação e caracterização dos resultados os seguintes materiais:

- Álcool etílico 46,2 \%, álcool absoluto 99,3\%, álcool butílico, álcool gel (65\%) e água como solventes;

- Pigmento e corante para tintas flexográficas e rotográficas na cor ciano (azul);

- Promotor de aderência para tinta flexográficas;

- Amido (5 e 50 um de diâmetro) revestido com filme de Hexametildissilazana (utilizado como resina);

- Substrato: papel (sulfite 75 g e cartão);

- Hand Proof com anilox de 56 linhas/cm (simulador de impressão).

Utilizando amido tratado por deposição por plasma de HMDS, pigmento ou corante e variando-se o solvente (álcool etílico, álcool butílico ou álcool gel) foram feitos testes de formulação de uma tinta utilizando o solvente como carregador do pigmento ou corante através do filme fino até o amido. A tinta foi fabricada pela mistura de pigmento, amido, resina, solvente (álcool) e, eventualmente, promotor de aderência, nesta ordem, e homogeneizada por 5 minutos. Os produtos foram pesados, exceção ao solvente, que foi medido por volume, para aplicação da tinta inicialmente usou-se o equipamento Hand Proof, aplicando diferentes forças e diferentes volumes de tinta.

Verificou-se que:

1) O uso do álcool-gel permite que a tinta tenha uma melhor ancoragem, o que facilita a aderência. Também ocorre uma maior intensidade de coloração, causada pela evaporação do álcool. Isto é um indicativo de adsorção do pigmento na superfície do amido. Portanto, o excesso de pigmento/corante na tinta causa a saturação desta, e o valor necessário para ocorrer a saturação é pequeno, uma vez que o pigmento é mantido na superfície. Assim, as principais características obtidas foram: melhor aderência, boa uniformidade de cobertura, sem riscos e com maior intensidade de coloração. 
2) O álcool gel, devido ao grande tamanho das moléculas (polímero + álcool), permite uma melhor dispersão do amido e dá à tinta uma ancoragem melhor, este fato está diretamente relacionado com a viscosidade da tinta, homogeneidade de cobertura e coloração da tinta sobre o substrato. Para uma boa homogeneidade de cobertura necessita-se de uma boa dispersão do amido e do pigmento/corante no solvente. Assim, a dispersão do amido (uma partícula de grande tamanho) é mais homogênea no álcool gel e torna-se um fator limitante na produção da tinta.

3) A aplicação da tinta com bastão de vidro provou que a tinta não adere sobre ela mesma.

4) Testes de aderência da tinta sobre papel e celulose mostraram-se eficientes se um promotor de aderência é adicionado à tinta.

Os resultados obtidos mostram que há facilidade de compostos orgânicos permearem para o interior da partícula de amido, o mesmo ocorrendo com pigmentos. Por outro lado, a existência de solvente no exterior favorece a remoção destes compostos, especialmente os menores, como os íons. Portanto, é possível ter uma proteção com aderência que permita remover macromoléculas e proteger eletrodos para não ocorrer obstrução simplesmente adicionando essa tinta como última camada nos dispositivos das Figuras 3.43 e 3.44. Ademais, essa tinta é completamente biocompatível e biodegradável, o que torna todo o dispositivo ambientalmente mais correto. A deposição do filme de TEOS, nesse caso, deveria utilizar um filme com menor concentração de carbono, como os obtidos por deposição com eletrodos internos, para garantir um menor número de interferentes na medida.

\subsection{Conclusão}

O presente capítulo demonstrou que filmes finos a base de TEOS podem ser úteis no desenvolvimento de uma série de dispositivos, que permitem a separação de compostos, como colunas cromatográficas, sistemas para retenção e para pré-concentração, no pré-tratamento de amostras, tanto para compostos orgânicos como inorgânicos e a Tabela 3.6 resume as descobertas aqui enunciadas. 
Tabela 3.6. Resumo das possibilidades de uso do filme produzido pela deposição por plasma de TEOS em dispositivos miniaturizados.

\begin{tabular}{|c|c|c|c|}
\hline \multirow[t]{2}{*}{ Dispositivo } & \multicolumn{2}{|r|}{ Utilidade } & \multirow[t]{2}{*}{$\begin{array}{c}\text { Modo de } \\
\text { operação/limitações }\end{array}$} \\
\hline & Gás & Líquido & \\
\hline $\begin{array}{l}\text { 1. Microcanal } \\
\text { tridimensional/ filme } \\
\text { recém depositado }\end{array}$ & Retenção & Retenção & $\begin{array}{l}\text { Retenção de } \\
\text { compostos polares e } \\
\text { reação com a água }\end{array}$ \\
\hline $\begin{array}{l}\text { 2. Microcanal } \\
\text { tridimensional } \\
\text { empacotada/ filme } \\
\text { recém depositado ou } \\
\text { condicionado }\end{array}$ & Retenção & Retenção & $\begin{array}{l}\text { Pré-coluna } \\
\text { cromatográfica. } \\
\text { Longo tempo de } \\
\text { retenção, água retida } \\
\text { hidrolisa o filme, } \\
\text { depende de } \\
\text { aquecimento }\end{array}$ \\
\hline $\begin{array}{c}\text { 3. Microcanal } \\
\text { tridimensional/ filme } \\
\text { condicionado } \\
\text { (hidrólise) }\end{array}$ & Pré-concentração & Retenção & $\begin{array}{l}\text { Aquecimento auxilia } \\
\text { na remoção da água }\end{array}$ \\
\hline $\begin{array}{l}\text { 4. Microcanal } \\
\text { tridimensional/ filme } \\
\text { condicionado } \\
\text { (hidrólise) e } \\
\text { submetido a vapor } \\
\text { de HMDS }\end{array}$ & Separação & Retenção & $\begin{array}{c}\text { Separação/Retenção } \\
\text { de compostos } \\
\text { orgânicos }\end{array}$ \\
\hline $\begin{array}{l}\text { 5. Microcanal } \\
\text { tridimensional/ filme } \\
\text { condicionado } \\
\text { (hidrólise) e } \\
\text { aplicação de tensão }\end{array}$ & -- & Retenção & $\begin{array}{l}\text { Pré-coluna } \\
\text { cromatográfica. } \\
\text { Remoção de grande } \\
\text { quantidade de íons. }\end{array}$ \\
\hline $\begin{array}{l}\text { 6. Canal planar, } \\
\text { filme recém } \\
\text { depositado e } \\
\text { aplicação de tensão }\end{array}$ & -- & Separação & $\begin{array}{l}\text { Coluna } \\
\text { eletrocromatográfica }\end{array}$ \\
\hline 7. Membrana & -- & Retenção ou Pré-concentração & $\begin{array}{l}\text { Pré-tratamento de } \\
\text { amostras }\end{array}$ \\
\hline $\begin{array}{l}\text { 8. Construção de } \\
\text { camadas sobre } \\
\text { eletrodos: filme } \\
\text { recém depositado } \\
\text { /partículas de amido } \\
\text { recobertas por filme } \\
\text { à base de HMDS }\end{array}$ & -- & Retenção & $\begin{array}{l}\text { Pré-tratamento de } \\
\text { amostras }\end{array}$ \\
\hline
\end{tabular}




\section{REFERÊNCIAS}

[1] Carvalho, R. A. M.; Obtenção de filme poroso, útil na determinação de umidade e proteção contra radiação ultravioleta. Dissertação (Mestrado). Escola Politécnica, Universidade de São Paulo, São Paulo, 2004.

[2] Lima, R. R. et al. Production and deposition of adsorbent films by plasma polymerization on low cost micromachined non-planar microchannels for preconcentration of organic compound in air. Sensors and Actuators B-Chemical. 108. 1-2. 435-444p. 2005.

[3] Silva, L. M., et al. Low cost microstucture for preconcentration of polar and non-polar organic compounds. Materials Forum. Portugal. 2006.

[4] Ciola, R.; Fundamentos da cromatografia a líquido de alto desempenho. Ed. Edgard Blücher Ltda. São Paulo. 179p. 2003.

[5] Carvalho, R. A. M. et al. Use Of Thin Films Obtained By Plasma Polymerization For Grain Protection And Germination Enhancement. Química Nova. 28. 6. 1006-1009p. 2005.

[6] Santos, L. C. et al. Miniaturized Structures For Removal Or Selection Of Particles From Liquid Flow. 11th International Meeting on Chemical Sensors (IMCS 11). Brescia. Italy. 16-19p. 2006.

[7] Hernandez, L. F.; Uso de filme fino adsorvente para o desenvolvimento de sistemas de retenção de compostos orgânicos. Dissertação (Mestrado). Escola Politécnica, Universidade de São Paulo, São Paulo, 2006.

[8] Carvalho, A. T. et al. Improvement on organic compound adsorption and/or detection by using metallic thin films deposited onto highly-rough silicon substrates. Chemical Sensors. 20. B. 2P104. 572-573p. 2004.

[9] Nascimento, A. P.; Fabricação de sistemas para retenção de compostos orgânicos presentes em fase gasosa ou líquida. Tese (Doutorado). Escola Politécnica, Universidade de São Paulo, São Paulo, 2005.

[10] LICHTENBERG, J.; ROOJI, N. F.; VERPOORTE, E.; Sample pretreatment on microfabricated devices. Talanta. 56. 233p. 2002.

[11] Carvalho, A. T. et al. Nanostructured copper thin film used for catalysis. Sensors and Actuators B-Chemical. 130 (1). 141-149p. 2008.

[12] Lima, R. R. et al. Single step process for particles surface modification or thin film composite production. $11^{\text {th }}$ International Meeting on Chemical Sensors. 2008. 


\section{CONCLUSÕES E TRABALHOS FUTUROS}

Este trabalho teve como objetivo avaliar o uso de filmes obtidos pela polimerização por plasma de TEOS para fabricação de estruturas miniaturizadas, especialmente aquelas úteis para a área de análises.

Os estudos processados permitiram identificar pequenos dispositivos, de baixo custo e fabricação simples, que podem ser facilmente implantados na área de análises. Assim, a obtenção de uma pré-coluna e instalação em um cromatógrafo miniaturizado requer poucas etapas devido às similaridades entre a estrutura testada aqui e uma pré-coluna comercial. Essa nova pré-coluna também apresentaria grandes vantagens se fosse adicionada imediatamente antes de detectores não específicos, tais como os usados no nariz eletrônico. Pela diminuição de compostos presentes na mistura, as dificuldades de análise dos resultados igualmente decresce, pela maior facilidade de criação de padrões.

A pré-concentração é possível em algumas condições em fase gasosa, se compostos orgânicos apolares forem eluídos com 2-propanol.

A utilização de tais dispositivos na fase líquida, entretanto, apresenta muitas desvantagens se microcanais forem utilizados; por outro lado, o uso de membranas permite a utilização de câmara com eletrodos externos, devido à necessidade de grande concentração de radicais carbônicos no filme, uma vantagem para a aplicação da tecnologia roll-to-roll.

Até mesmo a produção de clusters metálicos em pequenas dimensões pode representar uma grande vantagem na produção de células de combustível, pelo isolamento e imobilidade conferidos a tais clusters pelo filme fino.

Por fim, a produção de uma dispersão, com características similares às de tinta de impressão, corresponde a uma oportunidade de obtenção, por um processo bem simples de silk screen, de camadas de um material bastante adsorvente para macromoléculas e ambientalmente correto. Assim, ao descarte de qualquer dispositivo, no que concerne a este material, não se impõe nenhuma restrição.

Portanto, a construção para teste em campo dos dispositivos aqui esboçados pode ser um trabalho futuro com alto grau tecnológico. 
Até o momento essa tese gerou ou contribuiu com as seguintes publicações:

CARVALHO, Rodrigo Amorim Motta; SILVA, Lilian Marques; LIMA, Roberto da Rocha; HERNANDEZ, Leonardo Frois; SILVA, Maria Lúcia Pereira da. Cellulose Surface Modified for Sample Pretreatment. In: $12^{\text {TH }}$ INTERNATIONAL MEETING ON CHEMICAL SENSORS, 2008, Comlubus. Proceedings of $12^{\text {th }}$ International Meeting on Chemical Sensors. 2008.

CARVALHO, Rodrigo Amorim Motta; CARVALHO, Alexsander Tressino de; HERNANDEZ, Leonardo Frois; DEMARQUETTE, Nicole Raymond; SILVA, Maria Lúcia Pereira da. Miniaturized chromatographic columns made by plasma polymerization of TEOS. In: XI INTERNATIONAL MEETING ON CHEMICAL SENSORS, 2006, Brescia. Proceedings of the Eleventh International Meeting on Chemical Sensors, 2006.

CARVALHO, Rodrigo Amorim Motta. Microcolunas Modificadas pela Polimerização por Plasma de TEOS para Retenção de Compostos Orgânicos e Inorgânicos. In: II ENCONTRO DE INICIAÇÃO CIENTíFICA, 2006, II Encontro de Iniciação Científica UNISANT'ANNA, 2006.

CARVALHO, Rodrigo Amorim Motta; HERNANDEZ, Leonardo Frois; LIMA, Roberto da Rocha; DEMARQUETTE, Nicole Raymond; SILVA, Maria Lúcia Pereira da. Retenção de Compostos lônicos em Microcanais pelo uso de Polimerização por Plasma de Tetraetilortossilicato. In: $8^{\circ}$ CONGRESSO BRASILEIRO DE POLÍMEROS, 2006, Águas de Lindóia. $8^{\circ}$ Congresso Brasileiro de Polímeros. São Carlos: Associação Brasileira de Polímeros, 2006.

CARVALHO, Rodrigo Amorim Motta; SILVA, Ana Neilde Rodrigues da; SILVA, Maria Lúcia Pereira da., Produção e caracterização de filmes finos nanoporosos e protetores obtidos por polimerização por plasma de TEOS. Revista Brasileira de Aplicações de Vácuo, São José dos Campos, v. 25, n. 3, p.141-148, 2006.

CARVALHO, Rodrigo Amorim Motta; CARVALHO, Alexsander Tressino de; SILVA, Maria Lúcia Pereira da; DEMARQUETTE, Nicole Raymond. Production of Selective Membranes Using Plasma Deposited Nanochanneled thin Films. Materials Research, São Carlos, v. 9, n. 4, 2006.

CARVALHO, Rodrigo Amorim Motta; SANTOS, Leandro Colevati dos; SILVA, Ana Neilde Rodrigues da; SILVA, Maria Lúcia Pereira da. MEMBRANA SELETIVA PARA ÍONS EM SOLUÇÃO AQUOSA OBTIDA A PARTIR DA POLIMERIZAÇÃO POR PLASMA DE TEOS. In: XVI CONGRESSO BRASILEIRO DE APLICAÇÕES DE VÁCUO NA INDÚSTRIA E NA CIÊNCIA, 2005, Londrina. Anais do XVI CBraVIC. São José dos Campos: Sociedade Brasileira de Vácuo, 2005.

CARVALHO, Rodrigo Amorim Motta; HERNANDEZ, Leonardo Frois; MORAIS, Douglas; SILVA, Maria Lúcia Pereira da; DEMARQUETTE, Nicole Raymond. POLIMERIZAÇÃO POR PLASMA DE ACETALDEÍDO: OBTENÇÃO DE FILME FINO. In: XVI CONGRESSO BRASILEIRO DE APLICAÇÕES DE VÁCUO NA INDÚSTRIA E NA CIÊNCIA, 2005, Londrina. Anais do XVI CBraVIC. São José dos Campos: Sociedade Brasileira de Vácuo, 2005.

CARVALHO, Rodrigo Amorim Motta; LIMA, Roberto da Rocha; NASCIMENTO FILHO, Antonio Pereira Do; SILVA, Maria Lúcia Pereira da; DEMARQUETTE, Nicole Raymond. Plasma polymerized TEOS films for nanochannels formation and sensor development. Sensors And Actuators B-Chemical, Japão, v. 108, p. 955-963, 2005.

CARVALHO, Rodrigo Amorim Motta; CARVALHO, Alexsander Tressino de; SILVA, Maria Lúcia Pereira da; DEMARQUETTE, Nicole Raymond; ASSIS, Odílio B G. Use of Thin Films Obtained by Plasma Polymerization for Grain Protection and Germination Enhancement. Química Nova, São Paulo, v. 28, n. 6, p. 1006-1009, 2005.

HERNANDEZ, Leonardo Frois; SILVA, Lilian Marques; CARVALHO, Rodrigo Amorim Motta; SIMÕES,

Eliphas Wagner; SILVA, Maria Lúcia Pereira da. A Simple Device for Initial Separation of Organic Compounds. In: 12TH INTERNATIONAL MEETING ON CHEMICAL SENSORS, 2008, Columbus. Proceedings of 12th International Meeting on Chemical Sensors. 2008.

LIMA, Roberto da Rocha; CARVALHO, Rodrigo Amorim Motta; CARVALHO, Alexsander Tressino de; SIMÕES, Eliphas Wagner; SILVA, Maria Lúcia Pereira da. Adsorbent New Materials and Composites Produced in a Single Step. In: $12^{\text {TH }}$ INTERNATIONAL MEETING ON CHEMICAL SENSORS, 2008, Columbus. Proceedings of $12^{\text {th }}$ International Meeting on Chemical Sensors. 2008.

LIMA, Roberto da Rocha; CARVALHO, Rodrigo Amorim Motta; SILVA, Lilian Marques; SILVA, Maria Lúcia Pereira da. Composite of Plasma Deposited Thin Films and Particles Obtained in a Single Step. In: VII ENCONTRO DA SBPMAT 2008, 2008, Guarujá. Abstracts VII Encontro da SBPMat 2008. 2008.

LIMA, Roberto da Rocha; CARVALHO, Alexsander Tressino de; CARVALHO, Rodrigo Amorim Motta; HERNANDEZ, Leonardo Frois; SILVA, Maria Lúcia Pereira da. Corrosion Resistant and Adsorbent Plasma Polymerized Thin Film. In: $12^{\mathrm{TH}}$ INTERNATIONAL MEETING ON CHEMICAL SENSORS, Columbus. Proceedings of $12^{\text {th }}$ International Meeting on Chemical Sensors. 2008.

LIMA, Roberto da Rocha; CARVALHO, Rodrigo Amorim Motta; SILVA, Lilian Marques; SIMÕES, Eliphas Wagner; SILVA, Maria Lúcia Pereira da. Single Step Process for Particles Surface Modification or Thin Film Composite Production. In: $12^{\text {TH }}$ INTERNATIONAL MEETING ON CHEMICAL SENSORS, 2008, Columbus. Proceedings of $12^{\text {th }}$ International Meeting on Chemical Sensors. 2008.

BOTTEON, Mayara Marques; MARTINS, Rafael de Oliveira; PERSEGHINI, Rafael; HERNANDEZ, Leonardo Frois; CARVALHO, Rodrigo Amorim Motta; SILVA, Maria Lúcia Pereira da. Metodologia para Ensino de Membranas Seletivas: PVC e Celulose como Exemplos. Boletim técnico da Faculdade de Tecnologia de São Paulo, São Paulo, v. 22, p. 48-52, 2007. 
MARTINS, Rafael de Oliveira; PERSEGHINI, Rafael; HERNANDEZ, Leonardo Frois; CARVALHO, Rodrigo Amorim Motta; SILVA, Maria Lúcia Pereira da. Dispositivo Educacional para Testes de Permeação em Membrana. Boletim técnico da Faculdade de Tecnologia de São Paulo, São Paulo, v. 23, p. 90-90, 2007.

MARTINS, Rafael de Oliveira; PERSEGHINI, Rafael; CARVALHO, Rodrigo Amorim Motta; SILVA, Maria Lúcia Pereira da. Microcromatografia por Exclusão de Tamanho em Dispositivo Miniaturizado. Boletim técnico da Faculdade de Tecnologia de São Paulo, São Paulo, v. 23, p. 84-84, 2007.

SANTOS, Leandro Colevati dos; BERALDO, Fábio Peppe; HERNANDEZ, Leonardo Frois; CARVALHO, Rodrigo Amorim Motta; SILVA, Maria Lúcia Pereira da. Desenvolvimento de testes semi-automatizados de miniestruturas. Revista Brasileira de Aplicações de Vácuo, São José dos Campos, v. 25, n. 2, p. 75-81, 2006.

CARVALHO, Alexsander Tressino de; CARVALHO, Rodrigo Amorim Motta; SILVA, Maria Lúcia Pereira da; DEMARQUETTE, Nicole Raymond. Hydrophobic plasma polymerized hexamethyldisilazane thin films: characterization and uses. Materials Research, São Carlos, v. 9, n. 1, p. 9-13, 2006

MARTINS, Rafael de Oliveira; PERSEGHINI, Rafael; CARVALHO, Rodrigo Amorim Motta; SILVA, Maria Lúcia Pereira da. Fabricação de sistema miniaturizado para retenção de compostos orgânicos. In: $8^{\circ}$ SIMPÓSIO DE INICIAÇÃO CIENTÍFICA E TECNOLÓGICA DA FATEC-SP, 2006, São Paulo. Boletim Técnico do $8^{\circ}$ Simpósio de Iniciação Científica e Tecnológica da FATEC-SP. 2006.

MARTINS, Rafael de Oliveira; PERSEGHINI, Rafael; CARVALHO, Rodrigo Amorim Motta; SILVA, Maria Lúcia Pereira da. Microcolunas cromatográficas para análise de compostos orgânicos. In: $8^{\circ}$ SIMPÓSIO DE INICIAÇÃO CIENTíFICA E TECNOLÓGICA DA FATEC-SP, 2006, São Paulo. Boletim Técnico do $8^{\circ}$ Simpósio de Iniciação Científica e Tecnológica da FATEC-SP, 2006

MARTINS, Rafael de Oliveira; PERSEGHINI, Rafael; CARVALHO, Rodrigo Amorim Motta; SILVA, Maria Lúcia Pereira da. Fabricação de Sistemas Miniaturizado para Retenção de Compostos Orgânicos. Boletim técnico da Faculdade de Tecnologia de São Paulo, São Paulo, v. 21, p. 17-17, 2006.

MARTINS, Rafael de Oliveira; PERSEGHINI, Rafael; CARVALHO, Rodrigo Amorim Motta; SILVA, Maria Lúcia Pereira da. Microcolunas Cromatográficas para Análise de Compostos Orgânicos. Boletim técnico da Faculdade de Tecnologia de São Paulo, São Paulo, v. 21, p. 86-86, 2006.

HERNANDEZ, Leonardo Frois; NASCIMENTO FILHO, Antonio Pereira Do; CARVALHO, Rodrigo Amorim Motta; SILVA, Maria Lúcia Pereira da; DEMARQUETTE, Nicole Raymond. COMPARAÇÃO DAS PROPRIEDADES DE FILMES ORGÂNICOS OBTIDOS PELA POLIMERIZACCÃO POR PLASMA. In: XVI CONGRESSO BRASILEIRO DE APLICACCÕES DE VÁCUO NA INDÚSTRIA E NA CIÊNCIA, 2005, Londrina. Anais do XVI CBraVIC. São José do Campos: Sociedade Brasileira de Vácuo, 2005

MARQUES, Christiana Dib; GOMES, Camila C; DIAS, Robson; NORBERTO JUNIOR; CARVALHO, Rodrigo Amorim Motta. DESENVOLVIMENTO DE TINTA PARA ROTOGRAVURA COM RESINA BIODEGRADÁVEL. In: $7^{\circ}$ SIMPÓSIO DE INICIACÃO CIENTíFICA E TECNOLÓGICA DA FATEC SÃO PAULO, 2005, São Paulo. Boletim Técnico. São Paulo: Faculdade de Tecnologia de São Paulo, 2005

LIMA, Roberto da Rocha; CARVALHO, Rodrigo Amorim Motta; NASCIMENTO FILHO, Antonio Pereira Do; SILVA, Maria Lúcia Pereira da; DEMARQUETTE, Nicole Raymond. Production and deposition of adsorbent films by plasma polymerization on low cost micromachined non-planar microchannels for preconcentration of organic compound in air. Sensors And Actuators BChemical, v. 108, p. 435-444, 2005. 


\section{Apêndice 1 - Fundamentos teóricos da cromatografia [1-6]}

Este trabalho utiliza conceitos de cromatografia, que serão descritos a seguir.

A técnica de cromatografia tem sido extensivamente estudada nas últimas décadas e excelentes revisões, como a de Souza [1], podem ser encontradas, além de vários livros e/ou [2-6] trabalhos, que descrevem seus fundamentos teóricos.

A cromatografia pode ser definida como um método físico-químico de separação dos componentes de uma mistura, realizada através da distribuição destes componentes entre duas fases que estão em contato íntimo, uma das quais é estacionária, e a outra move-se através da primeira. Durante a passagem da fase móvel sobre a fase estacionária, os componentes da mistura são distribuídos entre estas duas fases, de tal forma que cada um dos componentes é seletivamente retido pela fase estacionária, resultando em migrações diferenciais destes componentes.

A evolução da cromatografia só começou na década de 30, e a partir daí tem ocupado um lugar de destaque entre os métodos modernos de análise, devido a sua facilidade em efetuar a separação, identificação e quantificação das espécies químicas.

\section{Tipos de Cromatografia}

\section{a. Cromatografia planar}

$\mathrm{Na}$ cromatografia em papel (CP) utiliza-se um papel constituído por fibras de algodão purificadas contendo cerca de $90 \%$ de celulose servindo apenas para suporte da fase estacionária. Ao longo da estrutura existem grupos $-\mathrm{OH}$ que estabelecem pontes de hidrogênio entre as cadeias, sendo esta estrutura compostas por zonas cristalinas e compactas e por aproximadamente 40 \% de zonas amorfas com maior tendência para adsorção da água. Este tipo de cromotografia é uma técnica de partição líquido-líquido baseada na diferença de solubilidade das substâncias em questão entre duas fases imiscíveis.

$\mathrm{Na}$ cromatografia em camada delgada (CCD), a separação se dá pela diferença de afinidade dos componentes de uma mistura pela fase estacionária, sendo uma técnica de adsorção 
líquido-sólido. Teoricamente, possui características iguais à $\mathrm{CP}$, sendo que a fase estacionária, neste caso, é constituída principalmente por sílica gel ou alumina. O parâmetro mais importante a ser considerado nessa técnica é o fator de retenção que é a razão entre a distância percorrida pela substância da amostra em questão e a distância percorrida pela fase móvel.

\section{b. Eletrocromatografia}

A eletroforese capilar (EC) é uma técnica de separação baseada nas diferenças de mobilidade dos analitos quando submetidos à ação de um campo elétrico. Essa técnica utiliza um capilar com uma solução de eletrólito ou um núcleo metálico onde se aplica uma diferença de potencial nas extremidades do capilar com uma fonte de alta tensão através de eletrodos de platina.

Dentre as dificuldades encontradas para separação é o fato desta ser feita por diferença de mobilidade iônica e, quando se utiliza analitos com valores de condutância similares, conseqüentemente as mobilidades iônicas serão próximas tornando inviável a separação. $\mathrm{O}$ uso de agentes complexantes faz com que haja uma modificação da mobilidade decorrente da formação de um complexo metálico de tamanho e carga diferentes. $\mathrm{O}$ agente complexante pode ser adicionado antes ou posterior a injeção, neste caso sendo chamada de aditivo.

A eletrocromatografia capilar (ECC) é uma junção da EC e da CLAE onde a vazão da fase móvel é controlada por um fluxo eletroosmótico (FEO) e separação utiliza-se fases moveis e estacionárias como vistas em CLAE. O FEO é o fluxo da solução em um tubo com parede eletrocarregadas sob ação de campo elétrico alto, isso faz com que o fluxo independa da pressão. A ECC apresenta eficiência de separação muito maior do que na CLAE que possui fluxo laminar, e do que na EC por não separar somente analitos ionizados, mas também soluções neutras pela sua fase estacionária.

A eletrocromatografia capilar é uma técnica da separação em que o fluxo da fase móvel é dirigido através de uma coluna cromatográfica por uma pressão aplicada enquanto o soluto é melhor conduzido por um campo elétrico. Conseqüentemente é uma técnica que combina o potencial de separação e da seletividade da cromatografia líquida com alta performance e da eficiência elevada da eletrocromatografia capilar.

O uso de um fluxo eletroosmótico na cromatografia foi sugerido já em 1939 por Strain, que usou uma combinação de métodos eletroforéticos e cromatográficos de adsorção para a 
separação de várias tinturas orgânicas nas colunas de adsorção de Tswett. Entretanto, esta sugestão não se tornou viável até 1974 quando Pretorius e colegas de trabalho aplicaram este conceito para o uso de um fluxo eletroosmótico na cromatografia líquida. No começo da década de 80 , os desenvolvimentos técnicos na fabricação dos capilares criaram técnicas de eletroseparação para o uso prático do laboratório. Apesar das perspectivas interessantes do CEC, há várias questões fundamentais ainda sem completa solução, em especial o comportamento de fases estacionárias e móveis além de solutos sob alta tensão. Obviamente, um conhecimento de tal comportamento é importante para a predição e/ou otimização das separações, para o desenvolvimento do método e também para a transferência de protocolos da separação das técnicas relacionadas, e bem estabelecidas, tais como o CLAE, ao ECC. Além disso, poucas aplicações foram mostradas para justificar a propagação do ECC como uma técnica de análise rotineira.

\section{c. Cromatografia em coluna}

$\mathrm{Na}$ cromatografia líquida (CL) utiliza-se um liquido de baixa viscosidade como fase móvel, que percorrerá a fase estacionária onde a amostra será adsorvida ou particionada. Dependendo da fase estacionária, se esta for sólida, a separação é por adsorção e se for líquida por partição. Para a análise, utilizam-se primeiramente as amostras com eluentes apolares seguindo até o mais polar [6].

$\mathrm{Na}$ cromatografia gasosa $(\mathrm{CG})$, a fase móvel é um gás, sendo seu processo semelhante ao da CL. Esta técnica é bastante utilizada por apresentar resoluções em escala de nano a picograma $\left(10^{-9}-10^{-12} \mathrm{~g}\right)$. Os gases utilizados como fase móvel devem ter alta pureza e serem inertes em relação à fase estacionária. Como gases mais usados temos o hidrogênio, nitrogênio e hélio [3].

\section{Classificação dos Métodos Cromatográficos}

A cromatografia pode ser classificada seguindo vários critérios, sendo os mais comuns: a técnica empregada, os diferentes tipos de fases utilizadas, o procedimento de introdução e desenvolvimento da amostra, e o mecanismo de separação envolvido. 


\section{a) Segundo a técnica empregada e aos diferentes tipos de fases utilizadas}

A técnica empregada é definida pela forma física do sistema de cromatografia: a fase estacionária pode ser colocada em um tubo cilíndrico ou disposta sobre uma superfície planar. Baseando-se neste critério, a cromatografia pode ser subdividida em cromatografia em coluna e cromatografia planar. No presente trabalho, as duas hipóteses foram testadas, a primeira através dos microcanais tridimensionais e a segunda nos testes de permeação de íons no filme a base de TEOS.

Considerando o estado físico da fase móvel, a cromatografia pode ser dividida em: cromatografia gasosa, quando a fase móvel é um gás; cromatografia líquida, quando a fase móvel é um líquido; e cromatografia supercrítica, quando a fase móvel é um vapor pressurizado em temperatura acima de sua temperatura crítica. Neste trabalho apenas a cromatografia gasosa e líquida foram testadas.

Ainda o estado físico da fase estacionária pode ser líquido ou sólido. Neste trabalho a fase estacionária, o filme fino obtido por plasma, encontra-se no estado sólido.

\section{Classificação pelo modo de separação}

Por este critério, separações cromatográficas se devem à adsorção, partição, troca iônica, exclusão ou misturas desses mecanismos, como exemplificado a seguir.

b) Segundo o procedimento de introdução e desenvolvimento da amostra.

Eluição: A eluição é a técnica mais usada em cromatografia. Esta técnica envolve a passagem da fase móvel (que em cromatografia gasosa é chamada de gás de arraste) continuamente através da coluna cromatográfica. Uma pequena quantidade de amostra (gasosa ou líquida) é introduzida em uma única aplicação na corrente da fase móvel que arrasta a amostra ao longo da coluna. A fase móvel é inerte ou tem uma menor afinidade com a fase estacionária do que os componentes da amostra. Cada constituinte da amostra, de acordo com suas propriedades físicas e químicas, migra através da coluna com uma taxa diferente e mais lentamente do que a fase móvel, saindo da coluna em tempos diferentes e, se o sistema for bem projetado, completamente separados entre 
si. O gráfico do valor de uma propriedade física da mistura (por exemplo, condutividade térmica) em função do tempo é usado para caracterizar tal mistura e é chamado de cromatograma. Deste cromatograma, diversos valores podem ser retirados e alguns conceitos fundamentais são descritos a seguir:

- tempo de retenção de uma substância - é o tempo decorrido desde o instante em que a amostra foi introduzida até o instante de máximo do pico;

- volume de retenção - volume de fase móvel necessário para eluir a substância, do momento da introdução da amostra até o máximo do pico.

Tempo e volume de retenção são características da substância analisada naquela coluna, se todos os parâmetros de processo - tais como temperatura - são mantidos fixos. O tempo de retenção pode ser usado para identificação da substância. A área sob o pico, dependendo do sistema de detecção usado, é proporcional à massa ou à concentração da substância e pode ser usada para determinação da proporção desta na mistura sob análise.

A temperatura é um parâmetro de extrema importância, logo a cromatografia pode ser isotérmica, quando a temperatura é mantida constante, ou com temperatura programada, se a temperatura da coluna é aumentada durante a análise. A variação da temperatura é importante em cromatografia gasosa, pois melhora a separação e diminui o tempo de análise, especialmente quando a amostra é composta de substâncias com uma grande diferença em seus pontos de ebulição. O uso dos microcanais tridimensionais e injeção de uma quantidade fixa de amostra já foram tentados anteriormente por Silva [7].

Análise frontal: Nesta a amostra é introduzida continuamente no fluxo da fase móvel que passa através da coluna cromatográfica. Inicialmente, o componente da amostra que possui menor afinidade com a fase estacionária passa ao longo da coluna enquanto os demais componentes se acumulam na fase estacionária até que a capacidade desta seja excedida. Portanto, o sistema pode ser usado com um retentor para tais componentes, especialmente se for miniaturizado, já que para microTAS o pré-tratamento da uma matriz complexa é uma das etapas mais importantes. Silva [7] também usou a idéia de admissão contínua em microcanais, para testes de cinética da estrutura. Admissão semelhante já foi usada com o filme a base de TEOS [8] para análise de suas principais propriedades de adsorção. 
Análise por deslocamento: a amostra é primeiramente introduzida na coluna cromatográfica e adere na fase estacionária, após o que a fase móvel contendo uma substância a qual possui uma maior afinidade com a fase estacionária do que os componentes da amostra é passada pela coluna. Esse tipo de injeção pode ser útil na pré-concentração, especialmente usando estruturas miniaturizadas. Este conceito foi usado neste trabalho e denominado como injeção seqüencial.

\section{c) Segundo ao mecanismo de separação envolvido}

A cromatografia pode também ser classificada de acordo com o mecanismo de separação, que de ser um por processo físico de sorpção - adsorção ou partição - baseado em forças de Van der Waals ou mesmo eletrostáticas ou de dipolo, permanente ou induzido.

Quando a fase estacionária é um sólido a adsorção do soluto ocorre na interface entre o sólido e a fase móvel. Quando a fase estacionária é um líquido, o processo ocorre por partição, ou seja, a mostra percorre o líquido em diferentes profundidades. No presente caso, muito embora o filme a base de TEOS seja um sólido e a interação deva ocorrer na superfície, seus nanocanais provavelmente permitem um comportamento similar ao obtido com um líquido, em um processo mais adequadamente descrito com cromatografia por exclusão de tamanho.

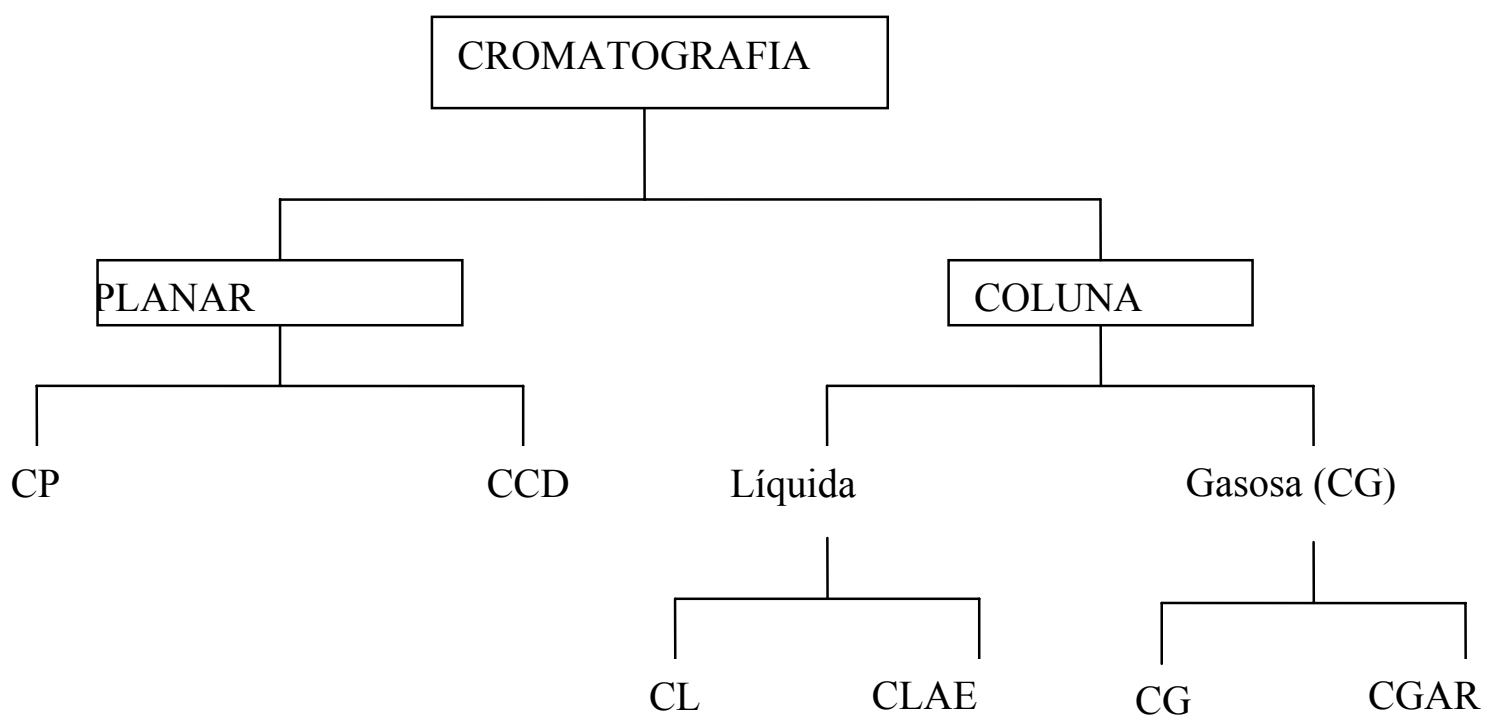




\section{Análise do cromatograma}

A cromatografia permite que uma série de informações seja obtida através da análise do cromatograma. A Figura 1.1 mostra um cromatograma típico.

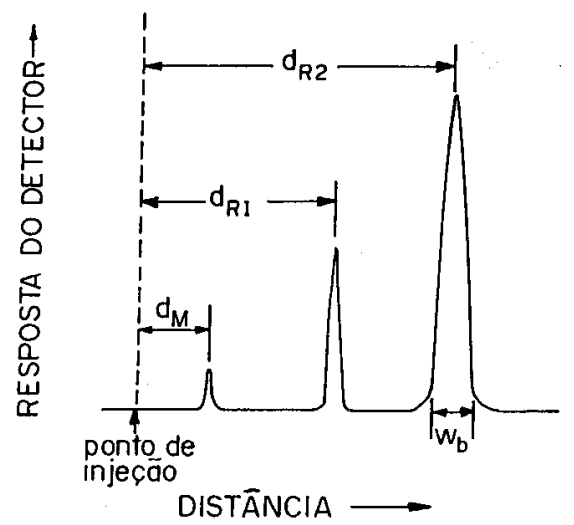

Figura 1.1. Cromatograma típico, onde a distância (eixo x) normalmente é uma medida de tempo.

Nestes cromatogramas, a linha base representa a passagem somente da fase móvel através do detetor e os picos a eluição dos componentes da mistura. Para esse cromatograma temse:

- tempo de retenção $\left(d_{R}\right.$ na Figura 1.1): tempo gasto desde o instante da injeção da amostra no sistema cromatográfico até o máximo do pico traçado);

- tempo de retenção "do solvente" ( $\mathrm{d}_{\mathrm{M}}$ na Figura 1.1): tempo gasto desde a injeção até a eluição de um componente que não interage com a fase estacionária, normalmente a fase móvel, ou seja, "o solvente".

Como parte do tempo de retenção depende do tempo necessário para a fase móvel percorrer a coluna, o tempo de retenção corrigido $\left(t_{R}^{\prime}\right.$, calculado de acordo com o cromatograma de Figura 1.1) é mais adequado para descrever o tempo de retenção do composto na fase estacionária e é calculado pela diferença $\left(\mathrm{t}^{\prime} \mathrm{r}=\mathrm{d}_{\mathrm{r}}-\mathrm{d}_{\mathrm{m}}\right)$. $\mathrm{O}$ volume da fase móvel necessário para eluir um componente pode ser calculado a partir do cromatograma, mas o conceito não foi utilizado neste trabalho. Estas medidas de tempo e volume são usadas não só para a identificação 
das substâncias como também para calcular a retenção e a eficiência nas separações cromatográficas.

Do mesmo modo, considerando a Figura 1.1 e as medições processadas, têm-se outros conceitos, descritos a seguir. A retenção de um componente, também definida por fator de capacidade, $K$, é determinada pela razão dos tempos de retenção do composto e do solvente, ou seja:

$$
K=\frac{t_{R}^{\prime}}{t_{M}}
$$

Até o presente momento não se utilizou o fator de capacidade, mas este pode vir a ser útil para definir uma estrutura como retentora ou não.

O fator de separação, $\alpha$, é calculado pela razão dos tempos de retenção corrigidos de dois picos adjacentes:

$$
\alpha=\frac{t_{R 2}^{\prime}}{t_{R 1}^{\prime}}
$$

A eficiência de um cromatógrafo pode ser avaliada em um cromatograma através da determinação do número de pratos teóricos. Um prato teórico eqüivale a uma etapa de equilíbrio entre as duas fases, portanto quanto maior o número, mais eficiente é a coluna e melhor a separação. O número de pratos teóricos, $n$, é um número adimensional calculado a partir do cromatograma, como segue:

$$
n=\frac{16 t_{R}^{2}}{w_{b}^{2}}=5,545\left(\frac{t_{R}}{w_{h}}\right)^{2}
$$

onde $w_{b}$ é a largura do pico e $w_{h}$ é a largura do pico na sua meia altura.

O número de pratos efetivos, $N$, corresponde ao uso do tempo de retenção corrigido, portanto:

$$
N=\frac{16 t_{R}^{\prime 2}}{w_{b}{ }^{2}}=5,545\left(\frac{t_{R}^{\prime}}{w_{h}}\right)^{2}
$$

no presente caso não é relevante seu uso porque o solvente percorre a coluna rapidamente. 
O número de pratos é afetado por vários fatores, tais como tamanho da amostra, comprimento e diâmetro interno da coluna, etc.

Vários outros conceitos foram adequadamente descritos para a cromatografia, tais como resolução, além da equação proposta por Van Deemter para descrever teoricamente a cromatografia gasosa em termos dos parâmetros da coluna.

\section{Coluna cromatográfica}

A coluna cromatográfica pode ser empacotada ou capilar, mas geralmente são mantidas no formato espiral para poder ocupar um menor espaço. No primeiro caso trata-se de um tubo largo, de cobre, aço inox, alumínio, teflon, etc., que é preenchido por partículas de pequenas dimensões. Estas partículas são previamente modificadas pela deposição da fase estacionária sobre sua superfície. As colunas capilares são normalmente de quartzo, muito longas (comprimentos de 10 a $100 \mathrm{~m}$ ), estreitas (diâmetros internos de 0,15 a $0,75 \mathrm{~mm}$ ) e recobertas por um filme fino, poroso ou não, que funciona como fase estacionária. Nas colunas capilares há um aumento significativo no número de pratos teóricos, pois a pressão é muito menor que em colunas empacotadas, portanto, o comprimento da coluna pode ser muito maior. A Tabela A.1, obtida de Souza [1] resume estas características.

Tabela A.1. Comparação entre colunas empacotadas analíticas e colunas capilares.

\begin{tabular}{lll}
\hline \hline & \multicolumn{2}{l}{ Coluna } \\
\cline { 2 - 3 } Parâmetro & Empacotada & Capilar \\
\hline & $1-4$ & $0,15-0,75$ \\
Diâmetro interno (mm) & $1-3$ & $10-100$ \\
Comprimento (m) & 2400 & 3000 \\
Pratos teóricos por metro (mínimo) & 5 & $0,5-2$ \\
Espessura do filme (um) & $80-100$ & - \\
Granulometria das partículas & $20-60$ & $1-5$ \\
Vazão média da fase móvel (ml/min) & $0,2-20$ & $0,001-0,5$ \\
Volume da amostra (ul) & & \\
&
\end{tabular}




\section{Temperatura}

Durante uma análise, as temperaturas do sistema de injeção, coluna e detector necessitam ser controladas para garantir reprodutibilidade. Contudo, como será observado no capítulo 4, há certas vantagens em aquecer o filme à base de TEOS quando este é usado como fase estacionária. O controle de temperatura da coluna deve ser rigoroso e reprodutível para que não haja alterações nos tempos de retenção durante as análises, além disso, a temperatura não pode causar modificação nas propriedades da fase estacionária usada. Quanto ao detector, a temperatura deve ser suficientemente alta, para que não haja condensação da amostra da coluna.

\section{REFERÊNCIA}

[1] Souza, Silvana Gasparotto de, Obtenção de micro-estrutura para pré-concentração de poluentes, Tese de Doutorado, EPUSP, 2003.

[2] C. H. Collins, "Introdução a métodos cromatográficos", Editora da Unicamp, 1995.

[3] Ciola, R., "Fundamentos da cromatografia a líquido de alto desempenho", Ed. Edgard Blücher Ltda., São Paulo, 179 p., 2003.

[4] A. Braithwaite, "Chromatographic methods", John Wiley \& Sons, 1996.

[5] R. L. Grob, "Modern practice of gas chromatography", John Wiley \& Sons, 1995.

[6] R. Ciola, "Introdução à cromatografia em fase líquida", EDUSP, 1998.

[7] Silva, L. M., et al. Low cost microstucture for preconcentration of polar and non-polar organic compounds, Materials Forum, Portugal, janeiro, 2006.

[8] Carvalho, Rodrigo Amorim Motta, Obtenção de filme poroso, útil na determinação de umidade e proteção contra radiação ultravioleta, Dissertação de mestrado, EPUSP, 2004. 